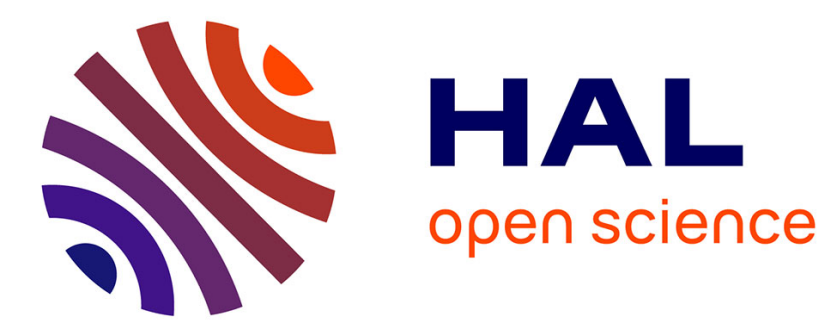

\title{
Potential Growth and Natural Yield Curve in Japan
} Gilles Dufrénot, Meryem Rhouzlane, Etienne Vaccaro-Grange

\section{To cite this version:}

Gilles Dufrénot, Meryem Rhouzlane, Etienne Vaccaro-Grange. Potential Growth and Natural Yield Curve in Japan. 2019. halshs-02091035

\section{HAL Id: halshs-02091035 https://shs.hal.science/halshs-02091035}

Preprint submitted on 5 Apr 2019

HAL is a multi-disciplinary open access archive for the deposit and dissemination of scientific research documents, whether they are published or not. The documents may come from teaching and research institutions in France or abroad, or from public or private research centers.
L'archive ouverte pluridisciplinaire HAL, est destinée au dépôt et à la diffusion de documents scientifiques de niveau recherche, publiés ou non, émanant des établissements d'enseignement et de recherche français ou étrangers, des laboratoires publics ou privés. 


\title{
amse
}

école d'économie d'aix-marseille

aix-marseille school of economics

\section{Working Papers / Documents de travail}

\section{Potential Growth and Natural Yield Curve in Japan}

\author{
Gilles Dufrénot \\ Meryem Rhouzlane \\ Etienne Vaccaro-Grange
}




\title{
Potential growth and natural yield curve in Japan*
}

\author{
Gilles Dufrénot, ${ }^{\dagger 1,2}$ Meryem Rhouzlane ${ }^{\ddagger 1}$ \& Etienne Vaccaro-Grange $\$ 1$ \\ ${ }^{1}$ Aix-Marseille Univ., CNRS, EHESS, Centrale Marseille, AMSE, Marseille, France \\ ${ }^{2}$ CEPII
}

April 2019

\begin{abstract}
We estimate the yield curve gap in Japan and examine whether it has contributed to the sustained low growth and low inflation rates observed since the beginning 2000s. We use a semi-structural empirical model that generalizes Laubach and Williams' approach, considering the entire range of maturities of the interest rates and dealing with the issue of mixed frequency sampling. We consider global factors exerting downward pressures on inflation and examine how the neutral yield curve has affected the snowball effect in the dynamics of the Japanese public debt ratio.
\end{abstract}

JEL classification: C32; E43; E52.

Keywords: Yield curve; Potential growth; State-space model; Japan.

\section{Introduction}

This paper examines the following issue. Does Japan's persistently low potential growth rates and weak inflation rates emanate from the the Bank of Japan's inadequate intervention to increase medium-term growth and to combat deflation? Should we blame monetary policy for not allowing the economy to fully return its full employment/full capacity levels? Why Japan's economy was sent into several lost decades and did not succeed in rebounding to inflation and potential growth of the late 1980s is still an enigma. While there are certainly diverse reasons for such a situation (for instance the lack of rapid structural reforms), some economists blame the conduct of monetary policy in a specific context very similar to what happened in other industrialized countries in the wake of the 2008 financial crisis: the burst of unsustainable financial bubbles that has contributed to deflationary pressures and has implied steep declines in cyclical and medium-term output. What has been termed as "lost decades" to describe the Japanese experience of slow growth/deflationary spiral is now referred to as "secular stagnation" in the United States, Europe and other industrialized countries (see, Summers (2015), Teulings and Baldwin (2014)).

Both in Japan from the 1990s onward and in the industrialized countries after the 2008 financial crisis, central banks reacted by drastically lowering their policy rates and then resorted to unconventional monetary policies to maintain market rates at levels close to zero or even negative. It is surprising that inflation rates and potential growth rates seem not to respond to these expansionary monetary policies in spite of their effects on the long-term yields. Two types of explanations can be mentioned here.

The first is that the situations of lost decades in Japan, and of today secular stagnation in the developed countries, are due to structural factors that have nothing to with unsuccessful monetary

\footnotetext{
*This work was supported by French National Research Agency Grant ANR-17-EURE-0020.

$\dagger$ Email : gilles.dufrenot@univ-amu.fr

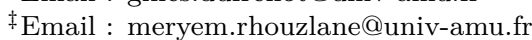

$\S$ Email : etienne.vaccaro-grange@univ-amu.fr
} 
policies. Some authors highlight slowing population growth and the slowdown in productivity gains (Gordon (2016), Cette et al. (2016) Bergeaud et al. (2016)). Others suggest that aggregate demand is structurally weak stemming from a "saving glut", rising income inequalities, excess global net saving, or a downward shift in investment (Delong and H. (2012), Eggertsson et al. (2016), Glaeser (2014), Stiglitz (2016)).

A second interpretation for the the low potential growths and deflation regimes, is the inability of fiscal and monetary policies to provide the right response to reverse the dynamics that generated the so-called lost decades in Japan and secular stagnation in the United States and Europe. The standard analysis is that, to counter the great recessions caused by the financial crises of high magnitude like those experienced by Japan during the 1990s and by the United States and Europe in 2008, central bankers sought to bring long-term interest rates down as much as possible. These rates were assumed to be those influencing the agents' decisions in the goods and credit markets. To do this, they first targeted very low short-term rates (through both unconventional and conventional monetary policies) and then turned to targeting the monetary base (through unconventional monetary policies like quantitative easing). The financial markets forces were supposed to activate the transmission channels from the policy rates and monetary base to long-term rates (forward guidance, portfolio rebalancing effects, etc).

This view has recently been challenged by the Japanese monetary authorities who turned in September 2016 to a new unconventional monetary policy with the control of the entire yield curve. As explained by Amemiya (2012), executive director of the Bank of Japan, the yield curve control policy is an old idea though not implemented by the Japanese monetary authorities so far. In an open letter to President Roosevelt in 1933, Keynes advocated this policy at the time of the Great Depression. During the second world war, to curb the cost of the financing of expenses for war, the fiscal and monetary authorities adopted a framework that set caps on both the short-term and long-term government bond yields. The control of long-term rates continued until the beginning of the 1950s. In another country, the United Kingdom, a similar Government bond price support was adopted after the end of the war. Another historical illustration of central bankers' desire to act simultaneously on short and long rates is known as Operation Twist. It was first introduced by the US Federal Reserve in 1961 to prevent capital outflows and defend the dollar, while stimulating the economy. Massive sales of short-term securities and, conversely, large purchases of securities with longer maturities led to a rise in short-term rates and a fall in long-term rates. As explained by Masayoshi Amemiya, this raised a controversy among the academics because there was no solid empirical evidence about its efficiency and the idea was progressively abandoned. In 2011 and 2012, the Federal Reserve has adopted a program based on Operation Twist by buying long-term treasuries and simultaneously selling short-term bonds.

A policy of yield curve control aims at changing the shaping of interest rates at different maturities, because mortgage rates and corporate borrowing costs are influenced by interest rates at different "intermediate" maturities (and not necessarily only at the short end or long end of the yield curve). Such a policy is, however, not the one usually favored by central bankers because it is thought that its effects on the economy are very weak to boost growth and bring down the unemployment rate. This paper argues against this view and proposes a new evidence about the conditions under which a policy of yield curve control can be or cannot be fully efficient to curb deflation and increase potential growth, taking Japan as an illustration.

A policy of yield curve control is adequate when, in the financial markets, the private sector borrows at different maturities. This is indeed the case in Japan where consumers and firms predominantly borrows in the short-to-intermediate part of the yield curve and not only at long-term maturities. Besides, targeting exclusively the long-term interest rate can result in a flattening of the yield curve that affects the financial sector's long-term profitability with a disincentive effect on loans to the private sector. Finally, when there is no room for a further decline of the long-term rate because they are near zero and the central bank faces limits in purchases of government bond yields, the monetary authorities may attempt to change the interest rates at other maturities to overcome this difficulty. 
To know which part of the yield curve is effective in stimulating medium-term growth and rising inflation, we must compare the real yield curve with its equilibrium path corresponding to the "neutral" yield curve. When the yield curve is equalized to its equilibrium path (neutral yield curve) and there are no changes in the other policy instruments (for instance fiscal and exchange rate policies), aggregate investment equals aggregate saving. In this case the output gap is zero and the real yield curve is neither expansionary nor contractionnary. Theoretically, one would require that the observed real yield curve lies below the neutral yield curve for monetary policy to be expansionary. However, given that a flatten curve at the longer end of the yield curve over long time periods can have detrimental effects on the economy, the monetary authorities can seek to make this portion of the curve steeper. In this case, an expansionary monetary policy could be reflected by a negative yield curve gap over the short-to intermediate portion of the curve, with actual long-term rates above the neutral long-term rates. This means that, not only the long-term and the slope of the yield curve are important, but also the curvature.

This paper builds on the rapidly growing literature on the estimation on natural interest rates initiated since the seminal paper by Laubach and Williams (2003). However, rather than focusing on the natural short-term rate, we extend the estimation to the entire range of the yield curve ${ }^{1}$ We focus on the Japanese case since the beginning 1990s. To our knowledge very few papers have addressed this issue. Two exceptions are Brzoza-Brzezina and Kotłowski (2014) and Imakubo et al. (2017). The first paper is an application to the United States, while the second applies to Japan. In contrast to these papers, we propose a model that is general enough to encompass many of the stylized facts of an economy experiencing a prolonged period of recession and low level of inflation. We make several new contributions in the modelling of the neutral yield curve components.

Firstly, we generalize to the entire yield curve the assumption made by Holston et al. (2017) that the natural rate is time-varying.

Secondly, changes in the yield curve gap are not only correlated with changes in monetary policy actions, but also with other macroeconomic fundamentals. Indeed, some papers suggest that term spread changes are caused by intertemporal consumption or investment smoothing (see Hu (1993)). For instance, the term structure in Japan could be explained by consumers' and firms' expectations of prolonged recession, thereby implying an increase in current saving that rises future income (by substituting future for present income). To capture the influence of intertemporal smoothing we choose changes in the current account (measured as share of GDP) as reflecting the dynamics of aggregate net saving in a country. Other papers find that the following macro-financial fundamentals also contain valuable information that account for the impact of the term structure on future output: the exchange rate (Bernard and Gerlach (1998)), inflation rates (Rouwenhorst and Plosser (1994)) and asset prices (Smets (1997)). We account for these factors by considering the following variables as determinants of the yield curve gap: changes in the real effective exchange rate, lagged inflation rates, changes in financial prices measured as a weighted average of the stock market price, the real estate prices and credit to the private sector as share of GDP. In addition to macroeconomic fundamentals, changes in the yield curve can also come from economic policy changes. We consider fiscal and monetary policies. Fiscal policy is measured by changes in the ratio of primary deficit in total GDP. For monetary policy, we choose changes in the Bank of Japan's money base and the policy rate.

Thirdly, in addition to proposing a new model of the yield curve gap, another contribution of the paper concerns the modelling of inflation. Recent works on Phillips curves find that the trade-off between inflation and the unemployment gap has become weak in a context where price expectations are anchored on low inflation rates and prevent any resumption of inflation (see Blanchard et al. (2015), Blanchard (2016)). Unemployment is not necessarily a good predictor of the inflation rate (Dotsey et al. (2017)). Instead of the traditional supply curve used in many models, we take stock of the results of the recent empirical literature suggesting the following structural drivers of

\footnotetext{
${ }^{1}$ In what follows we shall interchangeably use the expression "neutral" yield curve or "natural" yield curve.
} 
the downward trend in prices observed in Japan (and more generally in the industrialized countries): changes in the share of wages, world inflation, technical progress, capacity utilization rate.

Fourthly, we address the issue of frequency mismatch which is rarely considered in the estimation of the natural interest rates. Indeed, the real yield curve gap series is sampled at a monthly frequency, while GDP, inflation rate, potential growth and the macroeconomic variables that explain the yield curve gap are recorded at a quarterly frequency. To combine monthly and quarterly data, our output gap equation is estimated as a state-space MIDAS regression (Mixed Data Sampling) and the yield curve gap is modelled as a function of several macroeconomic variables using a state-space VAR-MIDAS regression.

Taking a close look at the case of Japan, the paper proposes a semi-structural state-space model that provide a joint estimation of the natural (or neutral) yield curve, declining potential growth and weak inflation performance since the beginning nineties. It helps us to judge whether monetary policy has been sufficiently accommodative under different monetary policy regimes.

The remainder of the paper is organized as follows. In Section 2, we present a brief historical overview of monetary policy in Japan since 1990s. In Section 3, we propose an estimation of the real yield curve in Japan using a dynamic Nelson-Siegel decomposition to obtain three components: the level, the slope and the curvature. This allows us to have a general picture of the term structure of the interest rates across different monetary policy regimes. Section 4 contains our state-space model and joint estimation of the natural yield curve and potential growth. Section 5 explains the results. Finally, the last section concludes.

\section{A brief history of monetary policy in Japan}

Since the late 1990s, five monetary easing programs have been implemented in Japan : the zero interest rate policy (ZIRP), the quantitative easing policy, the comprehensive monetary easing policy (QE), the quantitative and qualitative monetary easing (QQE) policy and quantitative and qualitative monetary easing (QQE) with yield curve control. In each program, the Bank of Japan (BOJ) chose different targets as shown in Table 1. The decrease in yields throughout the different regimes can be observed in Figure 1

Table 1: Monetary policy regimes in Japan

\begin{tabular}{|c|l|l|}
\hline Period & \multicolumn{1}{|c|}{ Monetary policy } & \multicolumn{1}{|c|}{ Target } \\
\hline \hline $1999 / 02-2000 / 06$ & $\begin{array}{l}\text { Zero Interest Rate Policy } \\
\text { (ZIRP) }\end{array}$ & O/N call rate \\
\hline $2001 / 03-2006 / 02$ & Quantitative Easing (QE) & $\begin{array}{l}\text { current account } \\
\text { balances of BOJ }\end{array}$ \\
\hline $2010 / 10-2013 / 03$ & $\begin{array}{l}\text { Comprehensive Monetary } \\
\text { Easing (CME) }\end{array}$ & O/N call rate \\
\hline $2013 / 04-2016 / 09$ & $\begin{array}{l}\text { Quantitative and Qualita- } \\
\text { tive Easing (QQE) }\end{array}$ & monetary base \\
\hline $2016 / 09-$ onward & $\begin{array}{l}\text { QQE with yield curve con- } \\
\text { trol }\end{array}$ & $\begin{array}{l}\text { short-term and } \\
\text { long-term rates }\end{array}$ \\
\hline
\end{tabular}




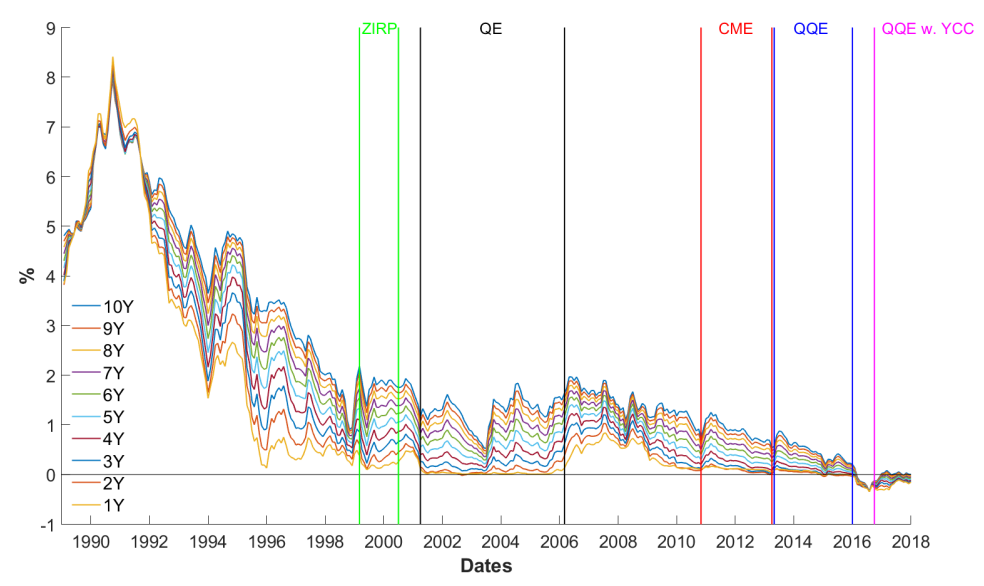

Figure 1: Nominal government bond yields under different monetary policy regimes in Japan

In the 1980s, Japan experienced an economic miracle. However, the appreciation of the domestic currency, coupled with higher inflationary pressures and uprising financial asset prices,led the BOJ to adopt a restrictive monetary policy. This resulted into a financial bubble burst. The central bank then turned to easing its policy by cutting its policy rate. Unfortunately, because this decision was taken lately, the economy sank into depression. This paved the way to the so-called lost decade which was characterized by low potential growth, low interest rates, low inflation and several bad bank loans.

In this context, the BOJ implemented a Against this situation, Japan implemented the ZIRP in February 1999. This policy consisted in making the overnight call rate move at very low levels through the provision of higher amounts of liquidity to the monetary and financial markets. In the mean time, forward guidance intended to lower down the long-term interest rates.

The decline on the nominal interest rates was followed in March 2001 by a QE policy. The economy rebounded during the 2000s until the rise of the 2008 financial crisis. From that moment, monetary authorities introduced several unconventional monetary easing measures known as Comprehensive Monetary Easing (CME) (that included the purchase of both sovereign bonds and risky assets from the private sector like corporate bonds, real estate investment trusts (REITs)). In addition, the central bank engaged into a forward guidance policy and set an inflation target of $2 \%$ to anchor inflation expectations.

These measures were not enough to boost the real activity and to raise inflation. The BOJ accordingly moved to a new policy called Quantitative and Qualitative easing (QQE) in April 2013. The central bank pursued a large-scale 10-year JGBs purchases in order to decrease long-term interest rates, and continued to purchase of risk assets in an effort to reduce the risk premia. In addition, the monetary authorities announced negative interest rates in January 2016 to remove the ZLB.

In spite of the positive effects on the real activity, inflation expectations remained low (below the $2 \%$ target). This led to a new policy know as QQE with yield curve control in September 2016, and to target the level of prices - rather than inflation. Under QQE the operating target is interest rates that determine the amount of JGBs purchases in a flexible manner. No central bank has ever made such commitment. More precisely, this new policy consists of 2 major components Kuroda (2016) :

1. Yield curve control : the BOJ targets the short-term policy rates at $-0.1 \%$ and sets a level of 10 -year japanese government bond yields as an operating target (close to 0\%). It purchases JGBs at a price it designates in order to cap long-term interest rates (close to 0\%) and thus to control the entire yield curve smoothly. 
2. Inflation-overshooting commitment : the bank commits itself to maintain an increase in the monetary base until the price stability target of $2 \%$ is reached and stays above the target in a stable manner. The aim is to increase inflation expectations and to overcome the secular stagnation.

Today, inflation is certainly not negative but still far away from the price stability target of $2 \%$. This is due to low inflation expectations because of the so-called deflationary mindset that has been anchored among people during the lost decades. Moreover, they're seeking, in the near future, to steepen the yield curve depending on economic conditions to improve bank margins, since a flat yield curve may have a negative effect on economic activity.

\section{Estimation of the Japanese yield curve}

\subsection{The empirical framework : the Nelson-Siegel model}

The first step consists in estimating three components of the yield curve that will then be considered as observed variables in our state-space model of the next section: the level, the slope and the curvature of the yield curve. Such a decomposition is now quite standard in the literature. Among the several methods available to obtain this decomposition, we choose the Nelson-Siegel approach.

Denote the level factor $L_{t}$, the slope factor $S_{t}$ and the curvature factor $C_{t}$. They are useful to characterize the short-end, the long-end and the intermediate part of the term-structure. It has been shown in the empirical literature that they replicate most of the variations of the shape of the yield curves (see, among others, Diebold and Li (2006), Diebold and Rudebusch (2013)), Joslin et al. (2014)).

The Dynamic Nelson-Siegel representation of an $n$-period zero-coupon bond yield is:

$$
y_{t}^{(n)}=L_{t}+S_{t} \frac{1-e^{-n / \lambda}}{n / \lambda}+C_{t}\left(\frac{1-e^{-n / \lambda}}{n / \lambda}-e^{-n / \lambda}\right)+\epsilon_{t}^{(n)},
$$

where $\epsilon_{t}^{(n)} \sim \mathcal{N}\left(0, \sigma^{2}\right), t \in \llbracket 1, T \rrbracket, n \in \mathbb{N}$ with $n$ the maturity of the bond and $\lambda \in \mathbb{R}$ a scale parameter that determines where the "bow center" (i.e the maximal curvature interest rate) is located.

More specifically, we define the following measurement equation:

$$
Y_{t}=\Lambda X_{t}+\varepsilon_{t}
$$

where $Y_{t}=\left(y_{t}^{\left(n_{1}\right)}, y_{t}^{\left(n_{2}\right)}, \ldots, y_{t}^{\left(n_{N}\right)}\right)^{\prime}$ with $N$ the number of yields observed, $X_{t}=\left(L_{t}, S_{t}, C_{t}\right)^{\prime}$, $\varepsilon_{t} \sim \mathcal{M} \mathcal{V N}\left(0, \Sigma_{\varepsilon}\right)$ with $\varepsilon_{t}=\left(\epsilon_{t}^{\left(n_{1}\right)}, \epsilon_{t}^{\left(n_{2}\right)}, \ldots, \epsilon_{t}^{\left(n_{N}\right)}\right)^{\prime}$ is the vector of observation errors and $\Lambda \in \mathcal{M}_{N \times 3}(\mathbb{R})$ is the matrix of loadings filled with Equation (1), (see details in Appendix A).

The State equation is described by a first-order auto-regressive process:

$$
X_{t}=\mu+\Theta X_{t-1}+\zeta_{t},
$$

where $\mu=\left(\mu_{L}, \mu_{S}, \mu_{C}\right)^{\prime}$ is the vector of intercept, $\zeta_{t} \sim \mathcal{M V N} \mathcal{N}\left(0, \Sigma_{\zeta}\right)$ with $\zeta_{t}=\left(\xi_{t}^{L}, \xi_{t}^{S}, \xi_{t}^{C}\right)^{\prime}$ and $\Theta \in \mathcal{M}_{N \times 3}(\mathbb{R})$ an unrestricted feedback matrix.

As is common practice (see Diebold and Li (2006) and Imakubo et al. (2017), we assume that the deviations of the observed yields at various maturities from the model-implied yield curve are uncorrelated (i.e variance-covariance matrix $\Sigma_{\varepsilon} \in \mathcal{M}_{N \times N}(\mathbb{R})$ from Equation (2) is diagonal) and that $\xi_{t}^{L}, \xi_{t}^{S}$ and $\xi_{t}^{C}$ can be correlated (i.e $\Sigma_{\zeta} \in \mathcal{M}_{3 \times 3}(\mathbb{R})$ from Equation (3) is left unrestricted).

Data are monthly average of nominal Japanese government bond yields of maturity $1,2,3,4$, $5,6,7,8,9$ and 10 years from January 1989 to December 2017. In this framework, we estimate $L_{t}$, $S_{t}$ and $C_{t}$ using a Bayesian estimation of the parameters through the Kalman filter using priors 
from Imakubo et al. (2017), as detailed in Appendix A.

\section{2 $\quad$ Fitting the yield curves}

Our Nelson-Siegel model provides a very good fitting of the term structure. Figure2 2 presents the fitted and observed median Japanese government bond yield curves over the period 1989:M01—2017:M12. Figure 10 in Appendix E shows the loading components and we also report there the estimated parameters of the models. We also graph the government bond yield surface (Figure 3) and the loading factors under different monetary policy regimes (Figure 4).

In Figure 4 the negative slope suggests a typical ascending yield curve with the maturities, except between 1989 and 1991. This period is indeed known as one of restrictive monetary policy. The BOJ started hiking its policy rate in May 1989 until the early 1991 (it reached 8\%) to tackle inflation. The induced deteriorating growth conditions then led the central bank to react by adopting a series of rate cuts after July 1991. After 1991, the level shows a steady fall after 1991. Over the whole period, the average nominal interest rate is $1.46 \%$ at the longest maturity and $0.44 \%$ at the shortest maturity. However, as shown in Table 3.2 the gap between the short and long-term rates has been narrowing rapidly since the beginning 1990s, which reflects a flattening yield curve (this is confirmed by Figures 11 to 16 in Appendix E, which show the yield curves over the successive monetary policy regimes).

The estimated factor $\lambda$ corresponds to a maximum of the curvature at 4 years (see Figure 10p. The curvature displays higher variations than the other latent factors, which is usual in the literature. We observe a strongly positive correlation with the slope. Lower negative values of the slope (flatter ascending curves) are associated to lower negative values of the curvature (less pronounced concavities).

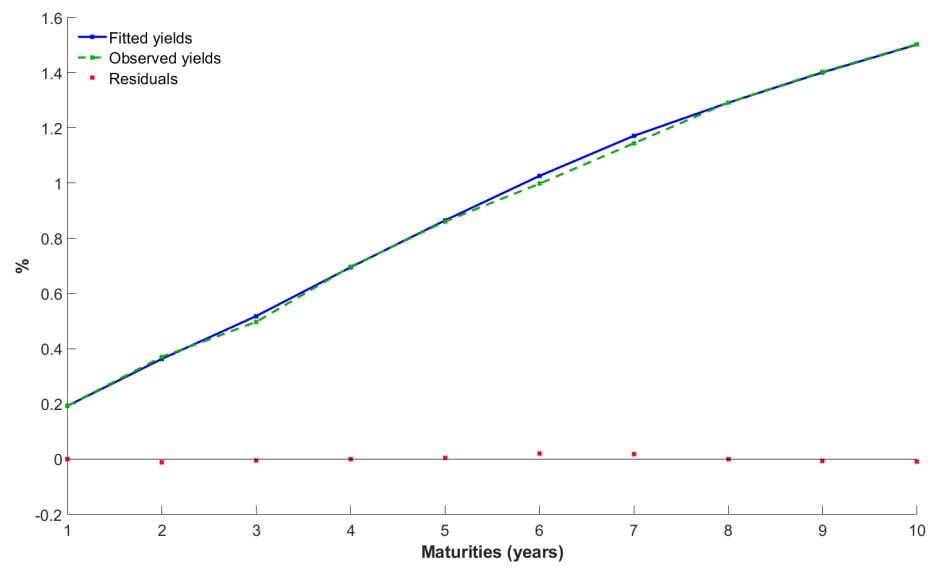

Figure 2: Median government bond yield curve over 1989:M01-2017:M12 


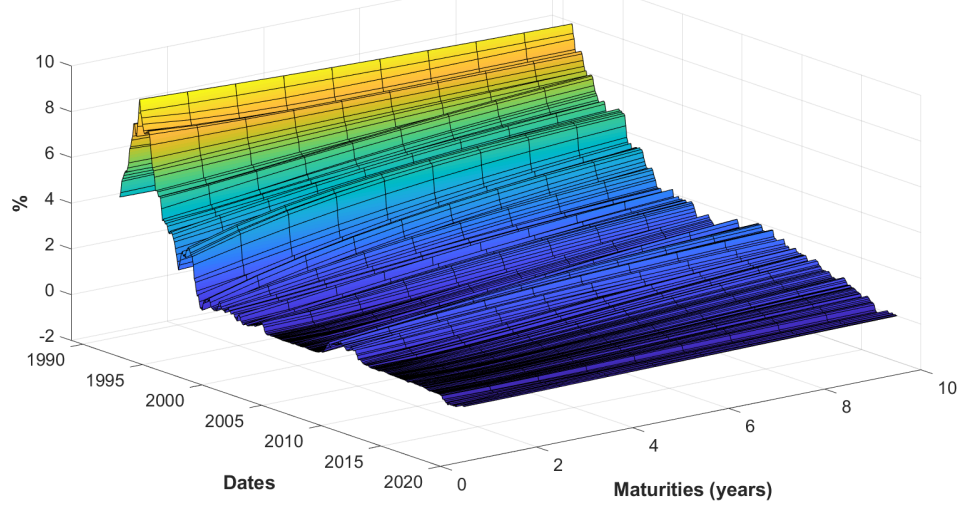

Figure 3: Government bond yield surface over 1989:M01-2017:M12

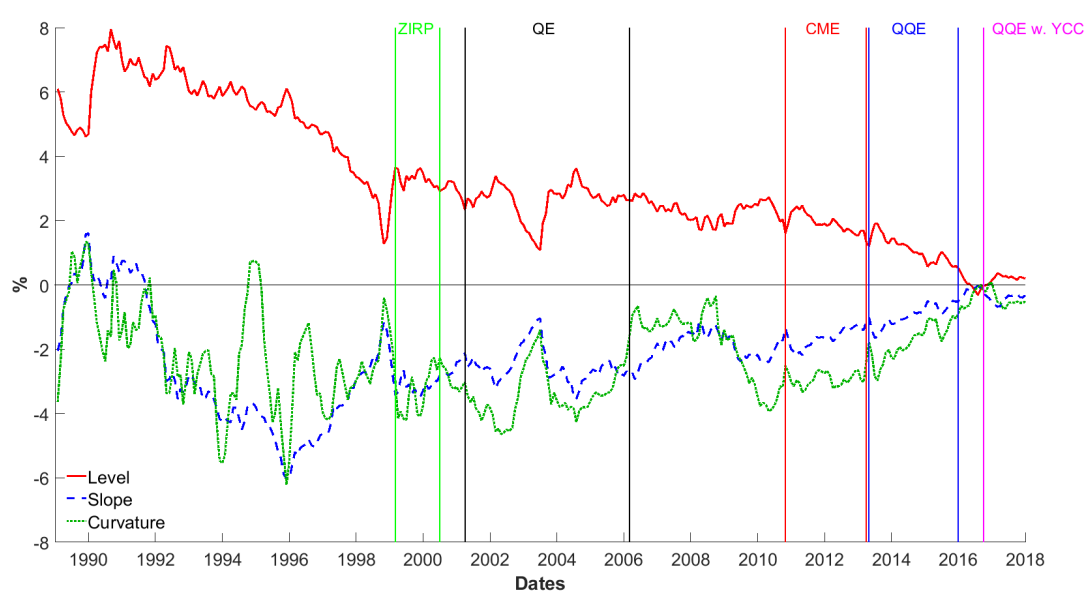

Figure 4: Nelson-Siegel factors under different monetary policy regimes in Japan

\begin{tabular}{|c|c|c|}
\hline Years & Short and long maturities & Difference \\
\hline Until 1999 & {$[2,5 \% ; 4,4 \%]$} & $1.90 \%$ \\
\hline 1999-2000 : ZIRP & {$[0,2 \% ; 1,8 \%]$} & $1.60 \%$ \\
\hline $2001-2006: \mathrm{QE}$ & {$[0 \% ; 1,3 \%]$} & $1.30 \%$ \\
\hline $2010-2013: \mathrm{CME}$ & {$[0,1 \% ; 0,82 \%]$} & $0.72 \%$ \\
\hline 2013-2016: QQE & {$[0,05 \% ; 0,45 \%]$} & $0.40 \%$ \\
\hline Since 2016: YCC & {$[-0,2 \% ; 0,01 \%]$} & $0.21 \%$ \\
\hline
\end{tabular}

Table 2: Intervals of the interest rates for short and long maturities

\section{A model for estimating the neutral yield curve}

\subsection{The general model}

Our approach to estimating the neutral yield curve draws on an empirical literature where timevarying neutral interest rates are obtained by the estimate of a saving-investment equilibrium semi-structural model, in line with Wicksell (1898)'s view of a natural interest rate. In this literature, the neutral rates are estimated as the results of an aggregate demand and supply equilibrium. 
Based on the original paper by Laubach and Williams (2003), the bulk of the models estimated in the literature include an aggregate demand curve in which the output gap is related to the interest rate gap, a Phillips curve in which inflation depends on the output-gap and an equation relating the neutral rate (usually the unobserved target of monetary policy short-term rate) to potential growth and some unobserved determinants that are supposed to capture shifts in preferences, demographic factors, changes in productivity, global saving. Potential growth is defined as the first-difference of potential GDP and is assumed to follow a random walk or mean-reverting autoregressive process.

Here, we extend the baseline framework. The unobserved variables (state variables) are written with a $*$.

\subsubsection{Aggregate demand}

The IS curve - written in terms of log-deviations of real GDP from potential - relates the output gap to the real yield curve gap (to capture the stance of monetary policy) and changes in the government's overall fiscal balance ratio to assess the stance of fiscal policy as follows:

$$
y_{t}-y_{t}^{\star}=\phi_{1}\left(y_{t-1}-y_{t-1}^{\star}\right)+\mu\left[\int_{n} \phi_{n}\left(r_{t-1}^{(n)}-r_{t-1}^{\star(n)}\right) d n-\pi_{t-1}\right]+\eta_{o b} \Delta o b_{t-1}+u_{t}^{\Delta y},
$$

where $r_{t}^{n}$ and $r_{t}^{n \star}$ are, respectively, the actual nominal interest rate of maturity $n$ at time $t$ and the natural rate of interest of maturity $n$ at time $t . y_{t}$ is actual real GDP, $y_{t}^{\star}$ is potential GDP, and $u_{t}^{\Delta y} \sim \mathcal{N}\left(0, \sigma_{\Delta y}^{2}\right) . \mu$ is a parameter that describes the sensitivity of the output gap to the real yield curve gap. For purpose of simplicity, we retain one lag to capture the influence of the yield curve. $o b_{t}$ is the ratio of the overall fiscal to GDP. $\Delta o b_{t}>0$ indicates a contractionary fiscal stance, while $\Delta o b_{t}<0$ means an expansionary fiscal stance. Therefore, in contrast to the common wisdom, we assume that a deficit or a surplus is not per se an indication of whether fiscal policy is becoming lax or tight. What matters is whether fiscal authorities are reducing or increasing their fiscal balance ${ }^{2}$ We assume $\mu<0:$ an expansionary monetary policy (for instance when the actual yield curve is below the neutral yield curve) increases the real GDP. However, we do not impose the constraint $\eta_{o b}<0$ : fiscal policy may have Ricardian effects.

Our motivation for considering a demand-based approach of the policy-mix is the following. Since the sharp deceleration of the Japanese growth in the mid-1990s and the accompanying marked decline in potential growth and inflation, the successive governments have searched to restore them through a policy-mix focused on the demand side of the economy. On the monetary policy side, as we already observed in the preceding section, the policy rate was lowered and a quantitative easing policy was introduced. On the fiscal policy side, higher deficits have been geared with a view to boosting aggregate demand in a context whereby the governments enjoyed exceptionally low interest rates on public debt. The combination of loose monetary and fiscal policies culminated in the so-called "Abenomics" in 2013.

Since the neutral rate, potential growth and the medium-term fiscal deficits jointly determine the dynamics of public debt in the medium term, we also consider an equation for the dynamics of the public debt ratio. Changes in the public debt ratio $\Delta b_{t}$ (nominal debt over nominal GDP) depend upon the so-called snowball effect and on the primary balance ratio $p b_{t}$ (primary balance as share of GDP. The snowball effect is captured by the difference between the "average" natural rate computed over the different maturities and potential growth $g_{t}^{3}$

\footnotetext{
${ }^{2}$ In contrast to what is observed in the other OECD countries, the automatic stabilizers are very weak in Japan. We therefore interpret the changes affecting the overall balance as stemming from the governments' counter-cyclical policies.

${ }^{3}$ Since these variables refers to medium term values of growth and interest rate, the primary deficit should be the structural deficit. However, the accumulation of deficits over time is a source of hysteresis in the dynamics of the overall balance, thereby implying that the cyclical balance has an impact on the public debt ratio in the medium-term.
} 


$$
\begin{aligned}
\Delta b_{t} & =\left(\int_{n} \phi_{n} r_{t}^{\star} d n-g_{t}\right) b_{t-1}-p b_{t}, \\
\Leftrightarrow \Delta b_{t} & =\left(L_{t}^{\star}+\mu_{S}^{\prime} S_{t}^{\star}+\mu_{C}^{\prime} C_{t}^{\star}-g_{t}\right) b_{t-1}-p b_{t} .
\end{aligned}
$$

where $\mu_{S}^{\prime}$ and $\mu_{C}^{\prime}$ are defined below.

Using the Nelson-Siegel decomposition, $r_{t}^{(n)}$ and $r_{t}^{\star(n)}$ can be rewritten in terms of their three latent factors :

$$
\begin{aligned}
& r_{t}^{(n)}=L_{t}+S_{t} \frac{1-e^{-n / \lambda}}{n / \lambda}+C_{t}\left(\frac{1-e^{-n / \lambda}}{n / \lambda}-e^{-n / \lambda}\right), \\
& r_{t}^{\star(n)}=L_{t}^{\star}+S_{t}^{\star} \frac{1-e^{-n / \lambda}}{n / \lambda}+C_{t}^{\star}\left(\frac{1-e^{-n / \lambda}}{n / \lambda}-e^{-n / \lambda}\right) .
\end{aligned}
$$

where we assumed that the two curves have the same scale parameter $\lambda$.

Subtracting (6) to (7), we obtain :

$$
r_{t}^{(n)}-r_{t}^{\star(n)}=\left(L_{t}-L_{t}^{\star}\right)+\left(S_{t}-S_{t}^{\star}\right)\left(\frac{1-e^{-n / \lambda}}{n / \lambda}\right)+\left(C_{t}-C_{t}^{\star}\right)\left(\frac{1-e^{-n / \lambda}}{n / \lambda}-e^{-n / \lambda}\right),
$$

and putting (8) into [4], we obtain :

$$
\begin{array}{r}
y_{t}-y_{t}^{\star}=\phi_{1}\left(y_{t-1}-y_{t-1}^{\star}\right)+\mu_{L}\left(L_{t-1}-L_{t-1}^{\star}\right)+\mu_{S}\left(S_{t-1}-S_{t-1}^{\star}\right)+\mu_{C}\left(C_{t-1}-C_{t-1}^{\star}\right)-\mu \pi_{t-1}+ \\
\eta_{o b} \Delta o b_{t-1}+u_{t}^{\Delta y} .
\end{array}
$$

$\phi_{n}($.$) in Equation (4) is a weighting function of the interest rate gaps of different maturities. For$ purpose of simplicity we assume that this function is described by a Uniform law. The Uniform weighting amounts to assigning the same weight to the different interest rates so that no particular maturity has more or less influence on the output gap than another. It can be shown that, under such a distribution, the coefficients $\mu_{L}, \mu_{S}$ and $\mu_{C}$ can be rewritten as follows (see Imakubo et al. (2017)):

$$
\left\{\begin{array}{l}
\mu_{L}=\mu, \\
\mu_{S}=\frac{\mu}{T_{n}} \int_{n} \frac{1-e^{-n / \lambda}}{n / \lambda} d n=\mu \times \mu_{S}^{\prime}, \\
\mu_{C}=\frac{\mu}{T_{n}} \int_{n}\left(\frac{1-e^{-n / \lambda}}{n / \lambda}-e^{-n / \lambda}\right) d n=\mu \times \mu_{C}^{\prime} .
\end{array}\right.
$$

Replacing in the IS curve yields :

$$
\begin{array}{r}
y_{t}-y_{t}^{\star}=\phi_{1}\left(y_{t-1}-y_{t-1}^{\star}\right)+\mu\left[\left(L_{t-1}-L_{t-1}^{\star}\right)+\mu_{S}^{\prime}\left(S_{t-1}-S_{t-1}^{\star}\right)+\mu_{C}^{\prime}\left(C_{t-1}-C_{t-1}^{\star}\right)-\pi_{t-1}\right]+ \\
\eta_{o b} \Delta o b_{t-1}+u_{t}^{\Delta y} .
\end{array}
$$

Since the value of $\lambda$ and $n$ are known, $\mu, \mu_{S}^{\prime}$ and $\mu_{C}^{\prime}$ are parameters to be estimated.

Potential output $y^{\star}$ is represented as the result of a unit root process with a time-varying drift. Potential growth $g_{t}$ is assumed to follow an AR(1) process with a drift (with possibly unit root if $\left.\phi_{g_{1}}=1\right)$ :

$$
y_{t}^{\star}=y_{t-1}^{\star}+g_{t-1}+w_{t}^{y^{\star}},
$$


where $w_{t}^{y^{\star}} \sim \mathcal{N}\left(0, \sigma_{y^{\star}}^{2}\right)$ and

$$
g_{t}=\phi_{g_{0}}+\phi_{g_{1}} g_{t-1}+w_{t}^{g} \text {, }
$$

where $w_{t}^{g^{\star}} \sim \mathcal{N}\left(0, \sigma_{g}^{2}\right)$.

The yield curve gap is endogenous and determined according to the following system:

$$
\left(\begin{array}{c}
L_{t}-L_{t}^{\star} \\
S_{t}-S_{t}^{\star} \\
C_{t}-C_{t}^{\star}
\end{array}\right)=\left(\begin{array}{ccc}
\phi_{L} & 0 & 0 \\
0 & \phi_{S} & 0 \\
0 & 0 & \phi_{C}
\end{array}\right)\left(\begin{array}{c}
L_{t-1}-L_{t-1}^{\star} \\
S_{t-1}-S_{t-1}^{\star} \\
C_{t-1}-C_{t-1}^{\star}
\end{array}\right)+\left(\begin{array}{ccc}
\alpha_{1} & \ldots & \alpha_{6} \\
\gamma_{1} & \ldots & \gamma_{6} \\
\kappa_{1} & \ldots & \kappa_{6}
\end{array}\right)\left(\begin{array}{c}
\text { Polic }_{t-1} \\
\text { BOJbase }_{t-1} \\
\Delta \text { ob }_{t-1} \\
\text { Financial }_{t-1} \\
\text { REER }_{t-1} \\
\text { Inflation }_{t-1}
\end{array}\right)+
$$

with $\left(\begin{array}{l}u_{t}^{\Delta L} \\ u_{t}^{\Delta S} \\ u_{t}^{\Delta C}\end{array}\right) \sim \mathcal{M} \mathcal{V N}\left(0, \Omega_{2}\right), \quad \Omega_{2}=\left(\begin{array}{lll}l & 0 & 0 \\ 0 & s & 0 \\ 0 & 0 & c\end{array}\right)$

The equation for the latent factors is:

$$
\left(\begin{array}{c}
L_{t}^{\star} \\
S_{t}^{\star} \\
C_{t}^{\star}
\end{array}\right)=\left(\begin{array}{ccc}
\beta & 0 & 0 \\
0 & \delta & 0 \\
0 & 0 & \eta
\end{array}\right)\left(\begin{array}{c}
L_{t-1}^{\star} \\
S_{t-1}^{\star} \\
C_{t-1}^{\star}
\end{array}\right)+\left(\begin{array}{c}
c^{L} \\
c^{S} \\
c^{C}
\end{array}\right) g_{t-1}+\left(\begin{array}{c}
w_{t}^{L^{\star}} \\
w_{t}^{S^{\star}} \\
w_{t}^{C^{\star}}
\end{array}\right)
$$

and $\left(\begin{array}{l}w_{t}^{L^{\star}} \\ w_{t}^{S^{\star}} \\ w_{t}^{C^{\star}}\end{array}\right) \sim \mathcal{M} \mathcal{V N}\left(0, \Omega_{1}\right), \quad \Omega_{1}=\left(\begin{array}{ccc}l^{\star} & 0 & 0 \\ 0 & s^{\star} & 0 \\ 0 & 0 & c^{\star}\end{array}\right)$

The definitions of the variables that enter as control variables in the right-hand side of the yield curve gap Equation (12) are the following. Policy : changes in the BOJ's policy rate, BOJbase: changes in the BOJ's base money (M3), $\Delta o b_{t}$ : changes in the overall fiscal balance, Financial: changes in the current financial environment, $R E E R$ : changes in the real effective exchange rate and Inflation: inflation rate. Our financial cycle index is a weighted average of credit to nonfinancial corporations, stock prices and real estate prices, smoothed with a Christiano-Fitzgerald filter.

This equation can be motivated with regards to the vast theoretical and empirical literature on the macroeconomic determinants of the yield curve. Not only their shocks, but also the variables themselves, affect the components of the yield curve. For instance, inflation drives the level of the real yield curve by changing long-run inflation expectations. The literature also emphasizes the role of macroeconomic management in the determination of the risk premium (fiscal and monetary policies, trade and exchange rate policies). Whether or not the monetary policy programs implemented by the industrialized countries (asset purchase programs, zero interest rate, qualitative easing) have been able to affect the global yield curve is still a matter of debate in the literature (see Diez de los Rios and Maral (2017)). Considering changes in the BOJ's money base and policy rates will help us examine this issue in the case of Japan 4 In addition, the inclusion

\footnotetext{
${ }^{4}$ For recent papers about the influence of macroeconomic fundamentals on the term structure of interest rate, the reader can refer to Bikbov and Chernov (2010), Evans and Marshall (2007), Rudebusch and Wu (2008), Chen and Tu (2018).
} 
of a proxy for financial conditions is justified by our will to better capture business cycle dynamics as well as other aspects of monetary transmission not contained in our first two policy variables.

The equation of the latent factors generalizes the commonly used equation in models à la LaubachWilliams in which the natural policy rate has a time-varying dynamics according to the time-path of potential growth. We assume a similar relationship.

\subsubsection{Aggregate supply}

Aggregate supply is described by an equation in which inflation is explained by lagged inflation, by lagged output and by some variables that reflect some key determinants of the decline in historical inflation found in the literature:

$$
\begin{aligned}
\pi_{t}=d_{\pi} \pi_{t-1}+\eta_{1}\left(\operatorname{cap}_{t-1}-\operatorname{cap}_{t-1}^{\star}\right)+\eta_{2} \pi_{t-1}^{\text {wages }}+\eta_{3} \pi_{t-1}^{U S, P P I}+\eta_{4} T O T_{t-1}^{\text {emerg }} \\
+\eta_{5} \pi_{t}^{\text {energy }}+u_{t}^{\pi},
\end{aligned}
$$

where $\eta_{1}$ is assumed to be positive and $u_{t}^{\pi} \sim \mathcal{N}\left(0, \sigma_{\pi}^{2}\right)$.

This formulation broadly reflects the main findings of the empirical literature on Phillips curves.

Firstly, wage inflation is taken as a proxy of the role of unionization in the bargaining process in the workers-employers relations. The bargaining power of employees has decreased over time due to factors such as technology, tighter credit constraints, diminishing saving. These provided more leverage to firms to hold down wages and in turn has implied that employers have been able to afford lower margins to keep competitiveness in markets.

Secondly, a consensus seems to emerge in the literature about a weakening of the relationship between inflation and unemployment gap, thereby implying that the latter is not necessarily a good predictor of the former. One implication is that demand-pull inflation is better described by an equation relating price changes to an indicator of tension in the market of goods and services (here the capacity utilization gap).

Thirdly, there are some empirical evidence that domestic inflation rates in open economies are determined by global factors (for instance, international prices -captured here by the producer price

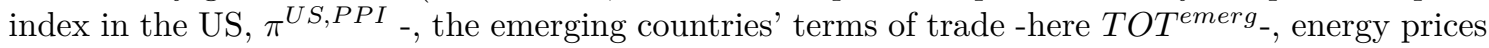
-here $\pi^{\text {energy }}-\sqrt{5}$

The formalization of capacity utilization gap is standard. It depends on the output gap and has an autoregressive component. The variable cap refers to capacity utilization and $c a p^{\star}$ to the long-term capacity utilization which can be thought of as a NAICU (non-accelerating inflation rate capacity utilization):

$$
\operatorname{cap}_{t}-\operatorname{cap}_{t}^{\star}=\theta_{0}+\theta_{1}\left(\operatorname{cap}_{t-1}-\operatorname{cap}_{t-1}^{\star}\right)+\theta_{2}\left(y_{t-1}-y_{t-1}^{\star}\right)+u_{t}^{\Delta c a p}
$$

where $\theta_{2}$ is assumed to be positive, and :

$$
\operatorname{cap}_{t}^{\star}=\chi_{0}+\chi_{1} \operatorname{cap}_{t-1}^{\star}+w_{t}^{c a p^{\star}},
$$

where $u_{t}^{\Delta c a p} \sim \mathcal{N}\left(0, \sigma_{\Delta c a p}^{2}\right)$ and $w_{t}^{c a p^{\star}} \sim \mathcal{N}\left(0, \sigma_{c a p^{\star}}^{2}\right)$.

\subsection{Matching the frequencies}

In the aggregate demand Equation (9), output gap measured at a low frequency (quarter) is explained by yield curve series sampled at higher frequency (monthly). To deal with this mixed data sampling, we employ the methodology of MIDAS (mixed-data sampling) models originally suggested by Ghysels et al. (2007). The original equation is now written as follows:

\footnotetext{
${ }^{5}$ Nowadays, there is an abundant literature about supply driven and demand-pull inflation to which the interested reader can refer. See, among many others, Auer et al. (2017), Leduc and Wilso (2017), Blanchard (2018).
} 


$$
\begin{gathered}
y_{t}-y_{t}^{\star}=\phi_{1}\left(y_{t-1}-y_{t-1}^{\star}\right)+\mu_{L} \sum_{j=1}^{j_{\max }} b_{L}\left(j, \theta_{1}^{L}, \theta_{2}^{L}\right)\left(L_{t-\frac{j}{m}}-L_{t-\frac{j}{m}}^{\star}\right)+\mu_{S} \sum_{j=1}^{j_{\max }} b_{S}\left(j, \theta_{1}^{S}, \theta_{2}^{S}\right)\left(S_{t-\frac{j}{m}}-S_{t-\frac{j}{m}}^{\star}\right)+ \\
\mu_{C} \sum_{j=1}^{j_{\max }} b_{C}\left(j, \theta_{1}^{C}, \theta_{2}^{C}\right)\left(C_{t-\frac{j}{m}}-C_{t-\frac{j}{m}}^{\star}\right)-\mu \pi_{t-1}+\eta_{o b} \Delta o b_{t-1}+u_{t}^{\Delta y}, \quad \text { (17) }
\end{gathered}
$$

with $\left\{\begin{aligned} b_{L}\left(j, \theta_{1}^{L}, \theta_{2}^{L}\right) & =\frac{e^{\theta_{1}^{L} j+\theta_{2}^{L} j^{2}}}{\sum_{j \operatorname{lax}}^{j_{\text {max }}} e_{1}^{\theta_{1} j+\theta_{2}^{L} j^{2}}}, \\ b_{S}\left(j, \theta_{1}^{S}, \theta_{2}^{S}\right) & =\frac{e^{\theta_{1}^{S} j+\theta_{2}^{S} j^{2}}}{\sum_{j=1}^{j_{m a x}} e_{1}^{\theta_{1}^{S} j+\theta_{2}^{S} j^{2}}}, \\ b_{C}\left(j, \theta_{1}^{C}, \theta_{2}^{C}\right) & =\frac{e_{1}^{\theta^{C} j+\theta_{2}^{C} j^{2}}}{\sum_{j=1}^{j_{\max }} e^{\theta_{1}^{C} j+\theta_{2}^{C} j^{2}}}\end{aligned}\right.$

$\theta=\left[\theta_{1}^{L}, \theta_{2}^{L} ; \theta_{1}^{S}, \theta_{2}^{S} ; \theta_{1}^{C}, \theta_{2}^{C}\right]$ is a set of parameters to estimate, with $\theta_{1}^{L, S, C}$ and $\theta_{2}^{L, S, C}$ unconstrained. We fix the lag $j_{\max }$ to 6 , which amounts to assuming that the influence of the yield curve gap on the output gap lasts a maximum of 6 months. The notation $\left(\frac{j}{m}\right)$ refers to a month defined as a fraction of a quarter $(1 / 3)$. We examine how the output gap of a given quarter $t$ is explained by the yield curve gap of the last month within the current quarter, the preceding month, the month before,,.., and $\left(\frac{j_{\max }}{m}\right)$ months backward. The Almon lag distribution captures different shapes of the weighting of the months.

Now, in the yield curve gap equation we also have variables sampled at mixed frequencies. This time the endogenous variable has a higher frequency (the yield curve gap measured at a monthly frequency) than the quarterly macroeconomic variables. The issue of exploiting the information contained in low frequency data to forecast high frequency data has been addressed in several papers, among which Ghysels (2016), Mariano and Murasawa (2010), Schorfheide and Song (2015). Here, we use the MIDAS-VAR representation which is simple. For purpose of clarity in the exposition, we consider each of the components of the yield curve gap separately. For purpose of parsimony, we reduce the dimension of the vector of the macroeconomic fundamentals. Instead of gathering all the variables simultaneously, we consider them one by one.

Under our assumption of one single quarterly lag, the MIDAS-VAR representation of the level, slope and curvature gaps are as follows:

$$
\begin{gathered}
\left(\begin{array}{c}
L_{t, 1}-L_{t, 1}^{\star} \\
L_{t, 2}-L_{t, 2}^{\star} \\
L_{t, 3}-L_{t, 3}^{\star} \\
\text { Macrot }^{\star}
\end{array}\right)=\left(\begin{array}{cccc}
\alpha_{11}^{L} & \alpha_{12}^{L} & \alpha_{13}^{L} & \alpha_{1} \\
\alpha_{21}^{L} & \alpha_{22}^{L} & \alpha_{23}^{L} & \alpha_{2} \\
\alpha_{31}^{L} & \alpha_{32}^{L} & \alpha_{33}^{L} & \alpha_{3} \\
\alpha_{L 1} & \alpha_{L 2} & \alpha_{L 3} & \alpha_{M}
\end{array}\right)\left(\begin{array}{c}
L_{t-1,1}-L_{t-1,1}^{\star} \\
L_{t-1,2}-L_{t-1,2}^{\star} \\
L_{t-1,3}-L_{t-1,3}^{\star} \\
\text { Macro } t-1
\end{array}\right)+\left(\begin{array}{c}
u_{t, 1}^{\Delta L} \\
u_{t, 2}^{\Delta L} \\
u_{t, 3}^{\Delta L} \\
u_{t}^{\text {Macro }}
\end{array}\right) \\
\left(\begin{array}{c}
S_{t, 1}-S_{t, 1}^{\star} \\
S_{t, 2}-S_{t, 2}^{\star} \\
S_{t, 3}-S_{t, 3}^{\star} \\
\text { Macrot }
\end{array}\right)=\left(\begin{array}{cccc}
\gamma_{11}^{S} & \gamma_{12}^{S} & \gamma_{13}^{S} & \gamma_{1} \\
\gamma_{21}^{S} & \gamma_{22}^{S} & \gamma_{23}^{S} & \gamma_{2} \\
\gamma_{31}^{S} & \gamma_{32}^{S} & \gamma_{33}^{S} & \gamma_{3} \\
\gamma_{S 1} & \gamma_{S 2} & \gamma_{S 3} & \gamma_{M}
\end{array}\right)\left(\begin{array}{c}
S_{t-1,1}-S_{t-1,1}^{\star} \\
S_{t-1,2}-S_{t-1,2}^{\star} \\
S_{t-1,3}-S_{t-1,3}^{\star} \\
\text { Macro } t-1
\end{array}\right)+\left(\begin{array}{c}
u_{t, 1}^{\Delta S} \\
u_{t, 2}^{\Delta S} \\
u_{t, 3}^{\Delta S} \\
u_{t}^{\text {Macro }}
\end{array}\right) \\
\left(\begin{array}{c}
C_{t, 1}-C_{t, 1}^{\star} \\
C_{t, 2}-C_{t, 2}^{\star} \\
C_{t, 3}-C_{t, 3}^{\star} \\
\text { Macro }_{t}^{\star}
\end{array}\right)=\left(\begin{array}{llll}
\kappa_{11}^{C} & \kappa_{12}^{C} & \kappa_{13}^{C} & \kappa_{1} \\
\kappa_{21}^{C} & \kappa_{22}^{C} & \kappa_{23}^{C} & \kappa_{2} \\
\kappa_{31}^{C} & \kappa_{32}^{C} & \kappa_{33}^{C} & \kappa_{3} \\
\kappa_{C 1} & \kappa_{C 2} & \kappa_{C 3} & \kappa_{M}
\end{array}\right)\left(\begin{array}{c}
C_{t-1,1}-C_{t-1,1}^{\star} \\
C_{t-1,2}-C_{t-1,2}^{\star} \\
C_{t-1,3}-C_{t-1,3}^{\star} \\
\text { Macro } o_{t-1}
\end{array}\right)+\left(\begin{array}{c}
u_{t, 1}^{\Delta C} \\
u_{t, 2}^{\Delta C} \\
u_{t, 3}^{\Delta C} \\
u_{t}^{\text {Macro }}
\end{array}\right)
\end{gathered}
$$

Macro is a macroeconomic variable that influences the latent factors (Policy, BOJbase, $\Delta o b_{t}$, Financial, $R E E R$ or Inflation). When we write $X_{t, j}$ the time index refers to the quarter while the couple $(t, j)$ indicates the month $j$ within the quarter $t, j=1$ being the most recent month of 
the quarter and $j=3$ the oldest. The last vector contains the residual terms. This representation has several advantages. First, it allows considering bi-causality in the relationship between the level gap and the macroeconomic fundamentals. Secondly, it does not impose any restriction on the aggregation of high frequency to low frequency.

Similarly, one defines the dynamics of the neutral latent factors by a MIDAS-VAR:

$$
\begin{aligned}
& \left(\begin{array}{c}
L_{t, 1}^{\star} \\
L_{t, 2}^{\star} \\
L_{t, 3}^{\star} \\
g_{t}^{\star}
\end{array}\right)=\left(\begin{array}{llll}
\beta_{11}^{L^{\star}} & \beta_{12}^{L^{\star}} & \beta_{13}^{L^{\star}} & \beta_{1} \\
\beta_{21}^{L^{\star}} & \beta_{22}^{L^{\star}} & \beta_{23}^{L^{\star}} & \beta_{2} \\
\beta_{31}^{L^{\star}} & \beta_{32}^{L^{\star}} & \beta_{33}^{L^{\star}} & \beta_{3} \\
\beta_{L 1^{\star}} & \beta_{L 2^{\star}} & \beta_{L 3^{\star}} & \beta_{g}
\end{array}\right)\left(\begin{array}{c}
L_{t-1,1}^{\star} \\
L_{t-1,2}^{\star} \\
L_{t-1,3}^{\star} \\
g_{t-1}
\end{array}\right)+\left(\begin{array}{c}
w_{t, 1}^{L^{*}} \\
w_{t, 2}^{L^{*}} \\
w_{t, 3}^{L^{*}} \\
w_{t}^{g^{*}}
\end{array}\right) \\
& \left(\begin{array}{c}
S_{t, 1}^{\star} \\
S_{t, 2}^{\star} \\
S_{t, 3}^{\star} \\
g_{t}^{\star}
\end{array}\right)=\left(\begin{array}{llll}
\delta_{11}^{S^{\star}} & \delta_{12}^{S^{\star}} & \delta_{13}^{S^{\star}} & \delta_{1} \\
\delta_{21}^{S^{\star}} & \delta_{22}^{S^{\star}} & \delta_{23}^{S^{\star}} & \delta_{2} \\
\delta_{31}^{S^{\star}} & \delta_{32}^{S^{\star}} & \delta_{33}^{S^{\star}} & \delta_{3} \\
\delta_{S 1^{\star}} & \delta_{S 2^{\star}} & \delta_{S 3^{\star}} & \delta_{g}
\end{array}\right)\left(\begin{array}{c}
S_{t-1,1}^{\star} \\
S_{t-1,2}^{\star} \\
S_{t-1,3}^{\star} \\
g_{t-1}
\end{array}\right)+\left(\begin{array}{c}
w_{t, 1}^{S^{*}} \\
w_{t, 2}^{S^{*}} \\
w_{t, 3}^{S^{*}} \\
w_{t}^{g^{*}}
\end{array}\right) \\
& \left(\begin{array}{c}
C_{t, 1}^{\star} \\
C_{t, 2}^{\star} \\
C_{t, 3}^{\star} \\
g_{t}^{\star}
\end{array}\right)=\left(\begin{array}{cccc}
\eta_{11}^{C^{\star}} & \eta_{12}^{C^{\star}} & \eta_{13}^{C^{\star}} & \eta_{1} \\
\eta_{21}^{C^{\star}} & \eta_{22}^{C^{\star}} & \eta_{23}^{C^{\star}} & \eta_{2} \\
\eta_{31}^{C^{\star}} & \eta_{32}^{C^{\star}} & \eta_{33}^{C^{\star}} & \eta_{3} \\
\eta_{C 1^{\star}} & \eta_{C 2^{\star}} & \eta_{C 3^{\star}} & \eta_{g}
\end{array}\right)\left(\begin{array}{c}
C_{t-1,1}^{\star} \\
C_{t-1,2}^{\star} \\
C_{t-1,3}^{\star} \\
g_{t-1}
\end{array}\right)+\left(\begin{array}{c}
w_{t, 1}^{C^{*}} \\
w_{t, 2}^{C^{*}} \\
w_{t, 3}^{C^{*}} \\
w_{t}^{g^{*}}
\end{array}\right)
\end{aligned}
$$

\subsection{Estimation}

\subsubsection{Restrictions}

The estimation of our model has the inconvenient of the proliferation of coefficients that need to be estimated. Therefore, some of them must be restricted.

A first issue to deal with is the under-identification of some parameters. Potential GDP $g_{t}$ is determined in four equations : it is defined in Equation 10 as an endogenous variable and also appears as an endogenous variable in the MIDAS-VAR system. The equation of $g_{t}$ is identified under the following restrictions implying that the components of the natural yield curve do not impact directly potential growth:

$$
\left\{\begin{array}{l}
\beta_{g}=\delta_{g}=\eta_{g}=\phi_{g_{1}} \\
\beta_{L 1^{\star}}=\beta_{L 2^{\star}}=\beta_{L 3^{\star}}=0 \\
\delta_{S 1^{\star}}=\delta_{S 2^{\star}}=\delta_{S 3^{\star}}=0 \\
\eta_{C 1^{\star}}=\eta_{C 2^{\star}}=\eta_{C 3^{\star}}=0
\end{array}\right.
$$

Some equality restrictions are also imposed on some coefficients in such a way that the autocorrelation dynamics in the latent and gap components of the yield curve is considered at low frequency sampling (but not at the monthly frequency):

$$
\left\{\begin{array}{l}
\beta_{i j}^{L^{\star}}=\beta, \quad(i, j)=\{1,2,3\} \\
\delta_{i j}^{S^{\star}}=\delta, \quad(i, j)=\{1,2,3\} \\
\eta_{i j}^{C^{\star}}=\eta, \quad(i, j)=\{1,2,3\} \\
\alpha_{i j}^{L}=\phi_{L}, \quad(i, j)=\{1,2,3\} \\
\gamma_{i j}^{S}=\phi_{S}, \quad(i, j)=\{1,2,3\} \\
\kappa_{i j}^{C}=\phi_{C}, \quad(i, j)=\{1,2,3\}
\end{array}\right.
$$


Then, we assume that a quarterly macro variable loads equally on each month of the monthly yield curve factors:

$$
\left\{\begin{array}{l}
\alpha_{L 1}=\alpha_{L 2}=\alpha_{L 3}=\alpha_{L} \\
\gamma_{L 1}=\gamma_{L 2}=\gamma_{L 3}=\gamma_{S} \\
\kappa_{L 1}=\kappa_{L 2}=\kappa_{L 3}=\kappa_{C}
\end{array}\right.
$$

Reciprocally, we have:

$$
\left\{\begin{array}{l}
\alpha_{1}=\alpha_{2}=\alpha_{3}=\alpha \\
\gamma_{1}=\gamma_{2}=\gamma_{3}=\gamma \\
\kappa_{1}=\kappa_{2}=\kappa_{3}=\kappa
\end{array}\right.
$$

Finally, we need the following additional identifying restriction for the parameters of the equations in which the macroeconomic variables depend upon their lagged values in the latent factor gap systems:

$$
\alpha_{M}=\gamma_{M}=\kappa_{M}=\rho
$$

As we actually have 6 macro variables, we order them by exogeneity as in Equation (12). We therefore assume that $\rho$ is a higher triangular matrix to reduce the number of parameters to estimate.

\subsubsection{Two-step estimation}

How to estimate the model is not only an econometric issue, but also depends on our interpretation of the neutral yield curve. There are two opposite views in the literature about whether neutral rates should be interpreted using a short- or long-run perspective.

On the one hand, the long-run interpretation relies on the following assumption : the neutral rates are driven by structural factors determining trend GDP (total factor productivity growth, the growth rate of population, saving resulting from individual's preferences, etc). This approach is adopted in papers based on Laubach and Williams' methodology. Potential growth enters as a determinant of the natural rate and is considered as a proxy of trend growth.

On the other hand, a short-term interpretation relies on the assumption that most of the changes in the actual real rates come from changes in the interest rate gaps rather than in the neutral rates. The reference to a neutral rate is useful because it serves as an indicator of the stance of monetary policy and provides the central bankers with a benchmark. In this case, the neutral rate does not depends upon any indicator reflecting trend growth and the interest rate gap is correlated with the business cycle.

Choosing between these two alternative approaches is usually an empirical issue and the literature is still inconclusive 6 . Here, we adopt a short-term perspective for two reasons. Firstly, the aim of the paper is to see whether the growth and inflation performances in Japan were related or not to the stance of monetary policy. Secondly, we consider a maximum maturity horizon of 10 years which corresponds to a typical duration of the business cycle (Juglar cycles). Under these assumptions, we set $c^{L}, c^{S}, c^{C}=0$ (potential growth does not drive the neutral yield curve) in the equation of the latent components of the yield curve and their dynamics is described by autoregressive processes.

The model is estimated using a two-step approach.

\section{Step 1. Estimation of the yield curve gap using the restricted MIDAS-VAR model}

\footnotetext{
${ }^{6}$ For an overview of the empirical literature, the reader can refer to Garnier and Wilhelmsen (2009).
} 
This step consists in estimating a state-space model in order to obtain time series of neutral level, slope and curvature at a monthly frequency. It corresponds to the system of equations (18) to (28).

The state equation is written in compact form as

$$
X_{t}=A X_{t-1}+W_{t}
$$

where $X_{t}$ is a matrix with dimension $9 \times 1, X_{t}^{\prime}=\left(X_{1 t}^{\prime}, X_{2 t}^{\prime}, X_{3 t}^{\prime}\right)$ with:

$$
\begin{aligned}
& X_{1 t}^{\prime}=\left(L_{t, 1}^{*}, L_{t, 2}^{*}, L_{t, 3}^{*}\right) \\
& X_{2 t}^{\prime}=\left(S_{t, 1}^{*}, S_{t, 2}^{*}, S_{t, 3}^{*},\right) \\
& X_{3 t}^{\prime}=\left(C_{t, 1}^{*}, C_{t, 2}^{*}, C_{t, 3}^{*}\right)
\end{aligned}
$$

$A \in \mathcal{M}_{9 \times 9}(\mathbb{R}), W_{t}^{\prime}=\left(w_{t, 1}^{L^{*}}, w_{t, 2}^{L^{*}}, w_{t, 3}^{L^{*}}, w_{t, 1}^{S^{*}}, w_{t, 2}^{S^{*}}, w_{t, 3}^{S^{*}}, w_{t, 1}^{C^{*}}, w_{t, 2}^{C^{*}}, w_{t, 3}^{C^{*}}\right)$ with $W_{t} \sim \mathcal{M V N}\left(0, \Omega_{1}\right)$ and $\Omega_{1}$ as a diagonal variance-covariance matrix. We are constrained to impose this latter restriction due to the high-dimensionality of the system.

The measurement equation is written as

$$
Y_{t}=E X_{t}+D X_{t-1}+B Y_{t-1}+U_{t}
$$

where $Y_{t}$ has dimension $10 \times 1, Y_{t}^{\prime}=\left(Y_{1 t}^{\prime}, Y_{2 t}^{\prime}, Y_{3 t}^{\prime}\right.$, Macro $\left._{t}\right)$, with:

$Y_{t, 1}^{\prime}=\left(L_{t, 1}, L_{t, 2}, L_{t, 3}\right)$

$Y_{t, 2}^{\prime}=\left(S_{t, 1}, S_{t, 2}, S_{t, 3}\right)$

$Y_{t, 3}=\left(C_{t, 1}, C_{t, 2}, C_{t, 3}\right)$

$E \in \mathcal{M}_{10 \times 9}(\mathbb{R}), D \in \mathcal{M}_{10 \times 9}(\mathbb{R}), B \in \mathcal{M}_{10 \times 10}(\mathbb{R}), U_{t}^{\prime}=\left(u_{t, 1}^{L}, u_{t, 2}^{L}, u_{t, 3}^{L}, u_{t, 1}^{S}, u_{t, 2}^{S}, u_{t, 3}^{S}, u_{t, 1}^{C}, u_{t, 2}^{C}, u_{t, 3}^{C}, u_{t}^{\text {Macro }}\right)$ with $U_{t} \sim \mathcal{M} \mathcal{V N}\left(0, \Omega_{2}\right)$ and $\Omega_{2}$ as a diagonal variance-covariance matrix. Matrices $A, E, D, B$ are filled with Equations $(18)$ to 28 . Details are presented in Appendix B

In this framework, we estimate $L_{t}^{\star}, S_{t}^{\star}$ and $C_{t}^{\star}$ using a Bayesian estimation of the parameters through the Kalman filter, as detailed in B

\section{Step 2. Plugging the estimated yield curve gap into the MIDAS model}

The first step provides us with estimations of $\left(L_{t, 1}-L_{t, 1}^{*}\right),\left(S_{t, 1}-S_{t, 1}^{*}\right)$ and $\left(C_{t, 1}-C_{t, 1}^{*}\right)$, that is the components of the yield curve gap at a monthly frequency. These are considered as observable variables, in a second step, to estimate the system that consists of Equations (10), (11), (14), 15, (16) and 17). The second step involves the estimation of a new state-space model. We use the same notations: $X$ for the state vector, $Y$ for the observed endogenous variables that define the measurement equation and $Z$ as a vector of exogenous variables.

The state equation is written in compact form as :

$$
X_{t}=\alpha+A X_{t-1}+W_{t}
$$

$X_{t}$ is a matrix with dimensions $3 \times 1: X_{t}^{\prime}=\left(y_{t}^{\star}, g_{t}, \operatorname{cap}_{t}^{\star}\right)$,

$\alpha$ is a $3 \times 1$ vector, $A \in \mathcal{M}_{3 \times 3}(\mathbb{R})$ and $W_{t}^{\prime}=\left(w_{t}^{y^{\star}}, w_{t}^{g}, w_{t}^{\text {cap }}{ }^{\star}\right)$ with $W_{t} \sim \mathcal{M V N}\left(0, \Omega_{3}\right)$ and $\Omega_{3}$ as a diagonal variance-covariance matrix. We are constrained to impose this latter restriction due to the high-dimensionality of the system.

The measurement equation is written as :

$$
Y_{t}=\beta+E X_{t}+D X_{t-1}+B Z_{t-1}+U_{t}
$$

$Y_{t}$ is a matrix with dimensions $3 \times 1: Y_{t}^{\prime}=\left(\pi_{t}\right.$, cap $\left._{t}, y_{t}\right)$, 
$Z_{t-1}$ is a $3 j_{\max }+8 \times 1$ vector of pre-determined variables:

$$
\begin{aligned}
& Z_{t-1}^{\prime}=\left(\pi_{t-1}, \pi_{t-1}^{\text {wages }}, \pi_{t-1}^{U S, P P I}, \operatorname{TOT}_{t-1}^{\text {emerg }}, \pi_{t}^{\text {energy }}, y_{t-1}, \operatorname{cap}_{t-1}, \Delta o b_{t-1}, \tilde{L}_{t-j / m}, \tilde{S}_{t-j / m}, \tilde{C}_{t-j / m}\right), \\
& \tilde{L}_{t-j / m}^{\prime}=\left(L_{t-1 / m}-L_{t-1 / m}^{\star}, \ldots, L_{t-j_{\max } / m}-L_{t-j_{\max } / m}^{\star}\right), \\
& \tilde{S}_{t-j / m}^{\prime}=\left(S_{t-1 / m}-S_{t-1 / m}^{\star}, \ldots, S_{t-j_{\max } / m}-S_{t-j_{\max } / m}^{\star}\right), \\
& \tilde{C}_{t-j / m}^{\prime}=\left(C_{t-1 / m}-C_{t-1 / m}^{\star}, \ldots, C_{t-j_{\max } / m}-C_{t-j_{\max } / m}^{\star}\right),
\end{aligned}
$$

$\beta$ has dimension $3 \times 1, E \in \mathcal{M}_{3 \times 3}(\mathbb{R}), D \in \mathcal{M}_{3 \times 3}(\mathbb{R}), B \in \mathcal{M}_{3 \times 3 j_{\max }+8}(\mathbb{R})$, where $j=$ $\left(1,2,3 \ldots, j_{\max }\right)$ and $U_{t}^{\prime}=\left(u_{t}^{\pi}, u_{t}^{c a p}, u_{t}^{y}\right)$ with $U_{t} \sim \mathcal{M} \mathcal{V N}\left(0, \Omega_{4}\right)$ and $\Omega_{4}$ as a diagonal variancecovariance matrix. Matrices $\alpha, \beta, A, E, D, B$ are filled with Equations (10), (11), (14), (15), (16) and (17). Details are presented in Appendix C

In this framework, we estimate $y_{t}^{\star}, g_{t}$ and $\operatorname{cap}_{t}^{\star}$ using a Bayesian estimation of the parameters through the Kalman filter, as detailed in C

\subsubsection{A challenging estimation}

It is well known that estimating the natural rate within semi-structural models is a challenging task. Problem usually encountered are a high estimation uncertainty and the so-called 'pile up' issue. As illustrated in Fiorentini et al. (2018), a high uncertainty in filtering the state variables (rather than the model's parameters) arises when the IS and Phillips curves are too flat. In that case, a high uncertainty in the filtered $z_{t}$ component of Laubach \& Williams type of models emerges, which leads to an imprecise estimate of the natural rate. An accurate estimate requires the slope of the IS and Phillips curve to be steep, much more than we usually observe in the data. Nevertheless, our model is not subject to the same source of uncertainty, as we estimate the natural yield curve and the trend components of the economy $\left(g_{t}, y_{t}^{\star}\right.$ and $\left.c a p_{t}^{\star}\right)$ in two distinct steps. Our natural yield curve therefore remains unaffected by the trend variables.

Second, the so-called 'pile up' issue, which consists in the variance of the residuals of some of the latent factors being biased towards zero (see Stock and Watson (1998)), can arise when the data are not informative enough in a model simultaneously estimated via maximum-likelihood. As illustrated by Brand and Mazelis (2018), the problem can be solved by turning to Bayesian with the use of relatively tight priors on the variance of the residuals, provided that one has any prior information 7 That is also what we do.

However, if the usual estimation issues arising in small-size semi-structural models à la Laubach and Williams are avoided, the high dimension of our state-space models leads to other serious challenges. First, the high number of parameters to be estimated in the context of the frequency mismatch adjustment may lead to large standard errors of the estimated parameters ${ }^{8}$ Indeed, as our sample size is only 115 for the MIDAS-VAR model and 113 for MIDAS model (with $j \max =6$ ), unrestricted models would contain too little degrees-of-freedom to provide accurate estimations. Thus, many economically reasonable restrictions are set to address this point, as described in Section 4.3.1. Still, the number of parameters that we need to estimate in Step 1 is 87 (and 28 in Step 2), which can be a challenge for a software's optimization algorithm if no relevant initial point is given. For this reason, we initialize the Kalman Filters with parameters and state variables values that we believe are very close to the true ones. To do so, we conduct OLS regressions on the HP-Filtered trends of the nominal yield curve, output, output growth and capacity utilization. We assume that the low-frequency component of these variables is a good approximation of their natural and potential level. In addition, we use these preliminary estimations as priors in the Bayesian estimation of the MIDAS-VAR and MIDAS parameters. On the other hand, the

\footnotetext{
${ }^{7}$ Which may not be the case for a undefined $z_{t}$ component.

${ }^{8}$ The standard errors being themselves imprecise as the high dimension of the Hessian matrix to be inverted also leads to imprecise results.
} 
Dynamic Nelson-Siegel model is initialized with preliminary estimations from OLS on the approximated Level, Slope and Curvature by linear combinations of selected yields (see Appendix A). Plus, we use Imakubo et al. (2017) estimated values as priors in our Bayesian estimation. Furthermore, the high dimension of our systems can lead to sizeable run-off errors when inverting the MSE matrix of the Measurement Equation in the Kalman Filter algorithm, especially because we impose a lot of restrictions to the feedback matrices, that may render the MSE matrix nearly rank deficient in some situations. Hence, we compute the Kalman gain without inversion of the MSE matrix, using a Modified Cholesky decomposition, as presented in Appendix A Additionally, the presence of lags in the State and Measurement Equations of our MIDAS-VAR and MIDAS models, due to the frequency mismatch adjustment, requires the Kalman Filter Algorithm to be amended as in Qian (2014).

Overall, the maximization of our penalized-likelihood is relatively time consuming in our models, especially for the MIDAS-VAR. We therefore transferred all Matlab codes into $\mathrm{C}++$ and run the optimization in a pool of 20 parallel workers 9

\section{Results}

Appendices E,F,G presents the detailed results of estimates. In the main text, we summarize our main findings.

\subsection{Determinants of the yield curve gap}

Figure 5 shows the natural yield curve surface throughout our sample period (1989:M04-2017-M12). We see a downward trend in the natural rates at all maturities. This finding suggests that former results obtained in the literature on the historical decline of the neutral short-term interest rates (see, for instance, Holston et al. (2017), and Fujiwara et al. (2016)) also apply to the longer end of the yield curve. Figure 6 shows the natural latent factors. There are some similarities between the neutral curves and the historical latent factors estimated in Section 3.

However, as shown in Table 3 they display some substantial gaps. On average, over the different sub-periods, the natural rates are below their estimated historical level for both the shortest and longest maturities. Appendix F shows some graphs on the gap of the different loading factors, as well as the differences between the natural and historical yield curves during the different monetary policy regimes. All graphs show that the yield curve has rarely been at its equilibrium path. The most symptomatic case is the QQE period. The economic conditions would have required a yield curve with negative rates at all maturities, but the historical rates remained positive. What factors have prevented the yield curve from reaching its neutral level?

In Table 4 we investigate the key determinants of the loading factors gaps (defined as the difference between the historical and natural level, slope, and curvature). We propose to call "push" factors those leading to a narrower gap and "pull" factors those increasing the gap. From the estimations, we see that cuts in the BOJ policy rate, higher public deficits and high inflation rates were push factors that should have led to narrower slope gap. On the opposite, exchange rate appreciation, higher financial prices and fiscal consolidation (positive changes in overall budget balance) were pull factors to the level gap. Moreover, the curvature gap increased with higher financial prices. The persistently opened gap in the yield curve can be explained by, either by a dominance of the pull factors, or because the strength of push factors have been moderate.

\footnotetext{
${ }^{9}$ We use Matlab Mex functions to do so.
} 


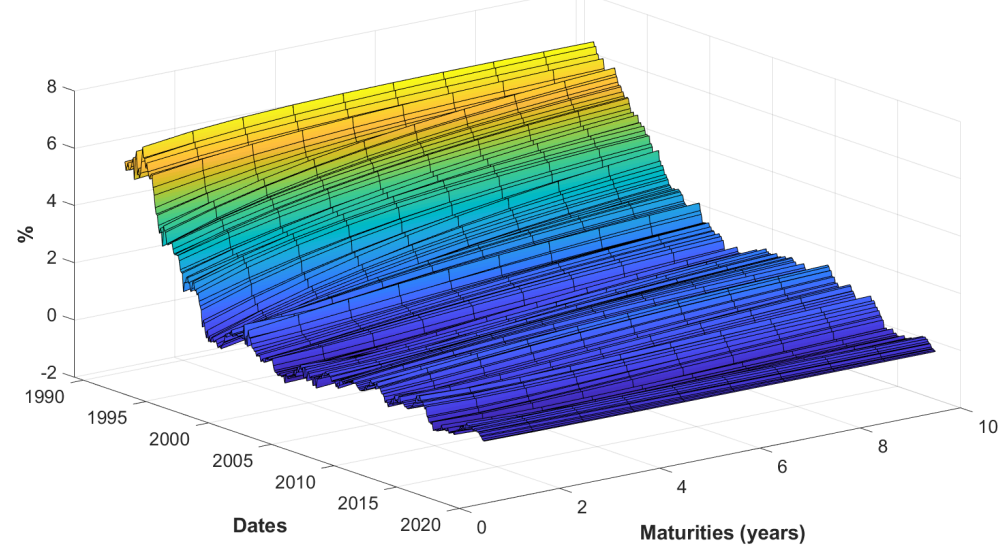

Figure 5: Natural yield surface across different monetary policy regimes in Japan.

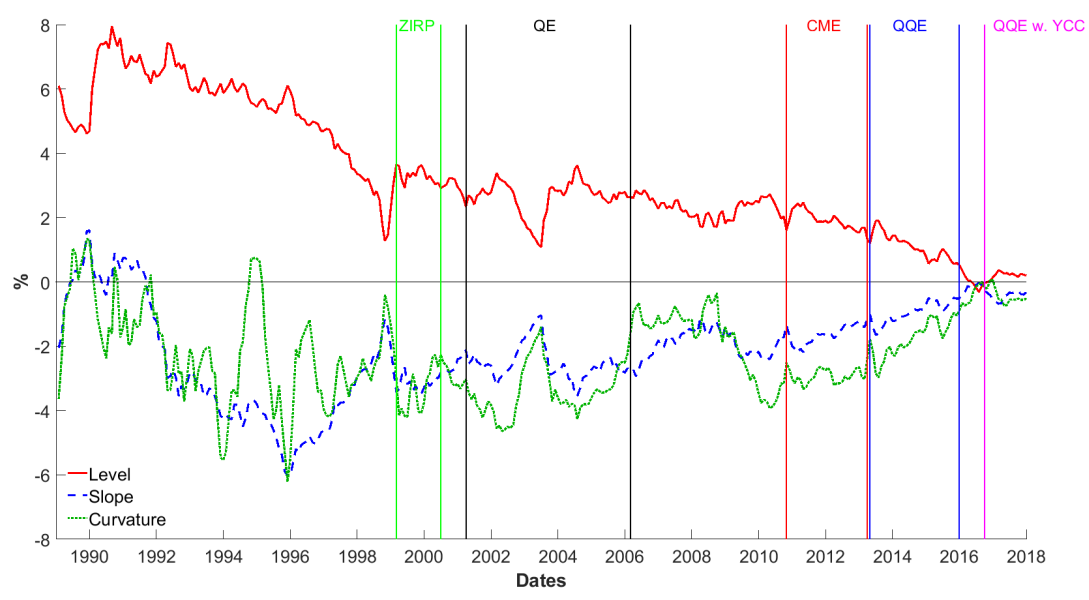

Figure 6: Natural factors under different monetary policy regimes in Japan

To explain the insufficient strength of push factors to close the slope gaps, here are several possible explanations. First, regarding the role of monetary policy, the BOJ has been too slow in cutting rates during the years of economic contraction that followed the financial bubble burst in the early 1990s. Even during the period of ZIRP, between 1998 and 2001, one had to wait until 2001 before the call rate fell to zero. During the first half of the years of the QE policy, the purchases of Japanese Governments Bonds (JGB) were not designed to cut the long-term rates, but they were done at the short-end of the yield curve. Until the "break" of the Abenomics policy, the loosing of monetary policy has been moderate. Some explanations to this moderation are investigated in the literature: fear of inflation, failure to recognize the severity of the zero-lower bound, noncooperation with fiscal policy (see, among others, Bernanke (2000), Kuttner (2014)).

Second, from the early 1990s until the Abenomics policy, the successive governments have avoided turning to expansionary fiscal policies. When fiscal stimuli were implemented, they were followed by restrictive policies. For instance, the fiscal expansion of the period 1998-2000 was followed by fiscal consolidation in 2001 (going back to the restrictive policies that had been implemented between 1996 and 1998). Similarly, fiscal deficits were widened in the aftermath of the Great Depression in 2008 and 2009 (under Taro Aso), but Naoto Kan and Yoshuhiro Noda turned to fiscal retrenchment between 2010 and 2012 by raising taxes. 
The regime of low inflation, in which Japan has been for three decades, also prevented the slope components from being adjusted to its natural level. The explanation is simply that the zero lower bound constraint creates an aggregate demand that is nonlinear (kinked). In case of a negative shock, the real interest rate would have to fall sharply in order to pull the economy out of the recession, which in turn would raise the interest rate. However, this mechanism does not operate if inflation does not increase enough.

Regarding the pull factors, our variable of financial prices is defined as the average of housing prices, equity prices and credit to the private sector. One would expect that, during financial booms, when prices peak up, investors have a more pronounced appetite for risk and invest in riskier assets at short-term maturities. This should reduce prices and induce an increase in the yields at longer maturities. However, the positive and statistically significant coefficient of the financial cycle variable in the level gap and curvature gap equations suggests an alternative explanation in the Japanese case. Against a backdrop of falling interest rates at all maturities, Japanese banks - which are among the biggest investors in the financial markets - have favored an increase in their profitability over risk-taking strategies. In search of further income growth, they expanded their loan activities in the Asian countries - as new asset classes. Such behaviors, by inducing a shift in the composition of their asset portfolios, tend to exert an upward pressure on the long-term yields of the other -classical- financial assets.

Turning to the real exchange rate, since the early 1990s Japan is stuck into a disinflation path (during the lost decades, the country even suffered from a deflationary spiral), thereby implying that the yen's real exchange rate has, on average, followed a depreciation trend. In addition to this nominal exchange rate effects, the productivity gains, though slowing down, have helped increasing competitiveness and have prevented a strong fall in potential growth. Since the latter is one of the drivers of the natural long-term rate, this could explain why we find a positive correlation between the coefficient of REER and the level gap.

\begin{tabular}{|c|c|c|}
\hline Years & Short and long maturities (neutral) & Short and long maturities (historical) \\
\hline Until 1999 & {$[1.90 \% ; 4 \%]$} & {$[2.5 \% ; 4.4 \%]$} \\
\hline $1999-2000:$ ZIRP & {$[0.05 \% ; 1.3 \%]$} & {$[0.2 \% ; 1.8 \%]$} \\
\hline $2001-2006: \mathrm{QE}$ & {$[-0.1 \% ; 0.7 \%]$} & {$[0 \% ; 1.3 \%]$} \\
\hline $2010-2013: \mathrm{CME}$ & {$[0.1 \% ; 0,6 \%]$} & {$[0.1 \% ; 0.82 \%]$} \\
\hline $2013-2016: \mathrm{QQE}$ & {$[-0.35 \% ;-0.2 \%]$} & {$[0.05 \% ; 0.45 \%]$} \\
\hline Since $2016: \mathrm{YCC}$ & {$[-0.07 \% ;-0.1 \%]$} & {$[-0.2 \% ; 0.01 \%]$} \\
\hline
\end{tabular}

Table 3: Intervals of the natural rates for short and long maturities 


\begin{tabular}{|c|c|c|}
\hline Level gap & Coefficients & P-values \\
\hline Policy rate & $\alpha_{11}=-0.021$ & $1.932 \mathrm{E}-01$ \\
BOJ base money & $\alpha_{12}=0.022$ & $4.895 \mathrm{E}-01$ \\
Change in overall budget balance & $\alpha_{13}=0.054^{* *}$ & $2.713 \mathrm{E}-02$ \\
Financial cycle & $\alpha_{14}=0.057^{* *}$ & $3.653 \mathrm{E}-05$ \\
REER & $\alpha_{15}=0.036^{* *}$ & $1.663 \mathrm{E}-02$ \\
inflation & $\alpha_{16}=0.018$ & $5.395 \mathrm{E}-01$ \\
\hline Slope gap & Coefficients & P-values \\
\hline Policy rate & $\gamma_{11}=0.185^{* * *}$ & $3.552 \mathrm{E}-05$ \\
BOJ base money & $\gamma_{12}=-0.020$ & $5.946 \mathrm{E}-01$ \\
Change in overall budget balance & $\gamma_{13}=-0.050^{*}$ & $4.718 \mathrm{E}-02$ \\
Financial cycle & $\gamma_{14}=0.021$ & $2.173 \mathrm{E}-01$ \\
REER & $\gamma_{15}=-0.047$ & $1.045 \mathrm{E}-01$ \\
Inflation & $\gamma_{16}=-0.047^{*}$ & $8.749 \mathrm{E}-02$ \\
\hline Curvature gap & Coefficients & P-values \\
\hline Policy rate & $\kappa_{11}=-0.038$ & $3.750 \mathrm{E}-01$ \\
BOJ base money & $\kappa_{12}=0.058$ & $3.137 \mathrm{E}-01$ \\
Change in overall budget balance & $\kappa_{13}=-0.050$ & $2.720 \mathrm{E}-01$ \\
Financial cycle & $\kappa_{14}=0.047^{*}$ & $7.796 \mathrm{E}-02$ \\
REER & $\kappa_{15}=-0.052$ & $2.510 \mathrm{E}-01$ \\
Inflation & $\kappa_{16}=0.015$ & $7.627 \mathrm{E}-01$ \\
\hline
\end{tabular}

Table 4: Key determinants of the yield curve gap natural factors

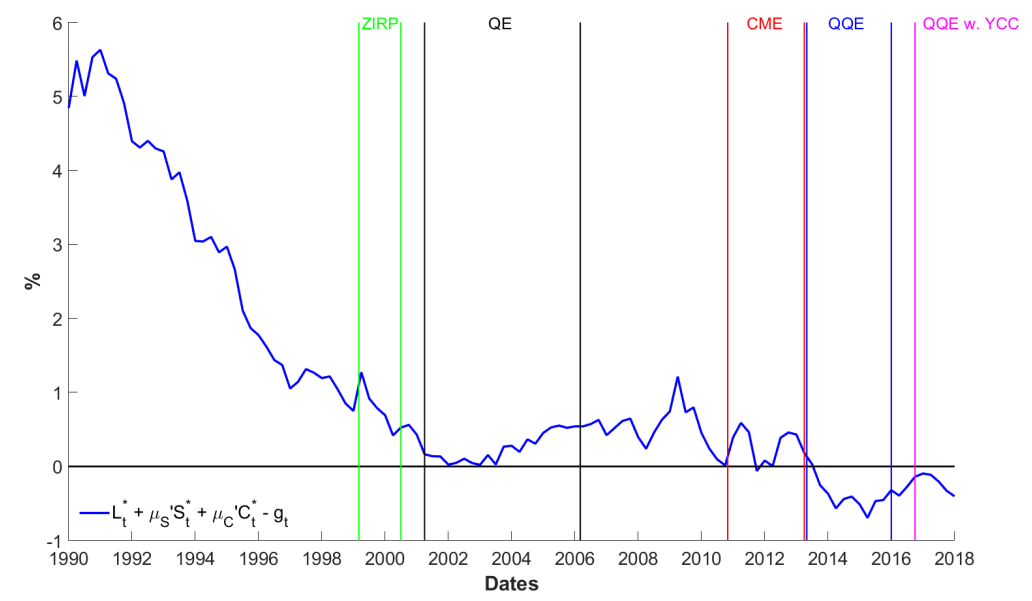

Figure 7: Snowball effect

\subsection{Influence of the yield curve gap on the macroeconomic variables}

Tables 5 and 6 present the estimates of aggregate demand and supply equations. To save place, we present a selection of graphs: potential growth and output and the interest rate-growth differential (Figures 7, 8 and 9).

The yield curve gap coefficient $\mu_{L}$ enters the aggregate demand equation with a negative and statistically significant sign. A $10 \%$ decrease in the nominal yield curve below the nominal natural curve implies a gain in production relative to its potential by $0.76 \%$. This positive effect works through long-run maturity interest rates (the coefficient of the level gap is positive and statistically significant). For medium-term maturities, the positive effect on output is, however, reversed (the coefficient $\mu_{C}$ is negative). This happens if the economy is on the portion of the aggregate demand curve where it is upward sloping, because of the lower bound on the interest rates. In this case, 
only higher inflation rates can trigger an increase in the output. As short-term maturities the interest rate is not statistically significant. We therefore see that the policy rate did not, directly, influenced the real activity.

The coefficient of changes in fiscal balance aims to capture the behavior of governments when they commit themselves to maintain the same orientation of their fiscal policy over several consecutive periods. According to our estimates, if fiscal balance is initially in surplus and the government decides to increase this surplus further by $10 \%$, this makes the GDP increase from above its potential level by $0.47 \%$. Symmetrically, an additional increase of deficit by $10 \%$ reduces the output by $0.47 \%$ below its potential. There are two alternative explanations to this finding. The first interpretation is that, over the whole period, fiscal policies have had non-Keynesian effects.

This issue was one of the main topics of fiscal policy debated in Japan during the 1990s and has regained popularity in recent years. The usual hypothesis is that consumption has remained stagnant due to Barro-Ricardo effects, because people had concerns over fiscal sustainability. In Figure 7. we compute the differences between the weighted average of the loading factors of the yield curve and the estimated potential growth. This difference captures the snowball effect in the debt dynamics. We see that it has been positive until 2013, thereby suggesting that public debt has been unsustainable since 1990. To avoid an explosion of future debt, fiscal policy has been restrictive over several periods.

An alternative view is that expansionary fiscal policies have had Keynesian effects, by increasing the output, but always below potential GDP. Figure 9 shows the level of GDP, the estimated potential GDP and, for comparison purpose, the trend computed from an HP filter. There are two interesting features. First, the trend GDP is always below the estimated potential GDP. Second, the historical GDP is very often below the potential. This is a typical characteristic of the Japanese economy over this period: the output-gap has remained negative from 1991 onwards, thereby reflecting that the economy has been operating under low capacity utilization.

Figure 8 shows the estimated potential growth. It has been regularly decreasing from a $0.5 \%$ low level from 1990 to 2006, where it becomes negative until 2013. Since then, we observe a rebound but potential growth reaches half of its 1990 level.

In aggregate supply equation (Table 6), cost-push inflation is caused by higher energy prices and decreases in terms of trade (caused for instance by rises in import prices). Demand-pull inflation stems from production over-capacities. The relationship between inflation and wage growth is negative. This suggests that the moderate wage growth added disinflationary pressures on the CPI, because aggregate consumption has remained weak.

\begin{tabular}{|c|c|c|c|}
\hline Independent variables & Coefficients & Z-ratio & P-values \\
\hline Real yield curve & $\mu=-0.076^{\star \star \star}$ & -3.66 & $2.50 \mathrm{E}-04$ \\
\hline Lagged output-gap $y_{t-1}-y_{t-1}^{\star}$ & $\phi_{1}=0.924^{\star \star \star}$ & 27.56 & $3.09 \mathrm{E}-167$ \\
\hline Change in fiscal balance & $\eta_{o b}=0.047^{\star \star \star}$ & 2.24 & $2.49 \mathrm{E}-02$ \\
\hline Level-gap L-L ${ }^{\star}$ & $\mu_{L}^{\prime}=-0.076^{\star \star \star}$ & -3.66 & $2.50 \mathrm{E}-04$ \\
\hline Slope-gap S-S & $\mu_{S}^{\prime}=-0.034$ & -1.047 & $2.95 \mathrm{E}-01$ \\
\hline Curvature-gap C-C & $\mu_{C}^{\prime}=-0.129^{\star}$ & -1.947 & $5.15 \mathrm{E}-02$ \\
\hline
\end{tabular}

Table 5: Coefficients for the Midas model-Aggregate demand (see equations (32) and (17)) 


\begin{tabular}{|c|c|c|c|}
\hline Independent variables & Coefficients & Z-ratio & P-values \\
\hline Lagged inflation $\pi_{t-1}$ & $\mathrm{~d}_{\pi}=-0,078$ & -0.94 & $3,47 \mathrm{E}-01$ \\
\hline Wage inflation $\pi_{t-1}^{\text {wages }}$ & $\eta_{2}=-0,344^{\star \star \star}$ & -5.64 & $1,72 \mathrm{E}-08$ \\
\hline US inflation $\pi_{t-1}^{U S, P P I}$ & $\eta_{3}=0,019$ & 0.65 & $5,15 \mathrm{E}-01$ \\
\hline Terms of trade $\mathrm{TOT}_{t-1}^{\text {emerg }}$ & $\eta_{4}=-0,028^{\star \star \star}$ & -2.26 & $2,37 \mathrm{E}-02$ \\
\hline Energy prices $\pi_{t}^{\text {energy }}$ & $\eta_{5}=0,123^{\star \star \star}$ & 6.75 & $1,53 \mathrm{E}-11$ \\
\hline Cap. Util. gap cap-cap ${ }_{t-}^{\star}$ & $\eta_{1}=0,210^{\star \star \star}$ & 4.56 & $5,09 \mathrm{E}-06$ \\
\hline
\end{tabular}

Table 6: Coefficients for the Midas model-Aggregate supply (see equations (32) and (14))

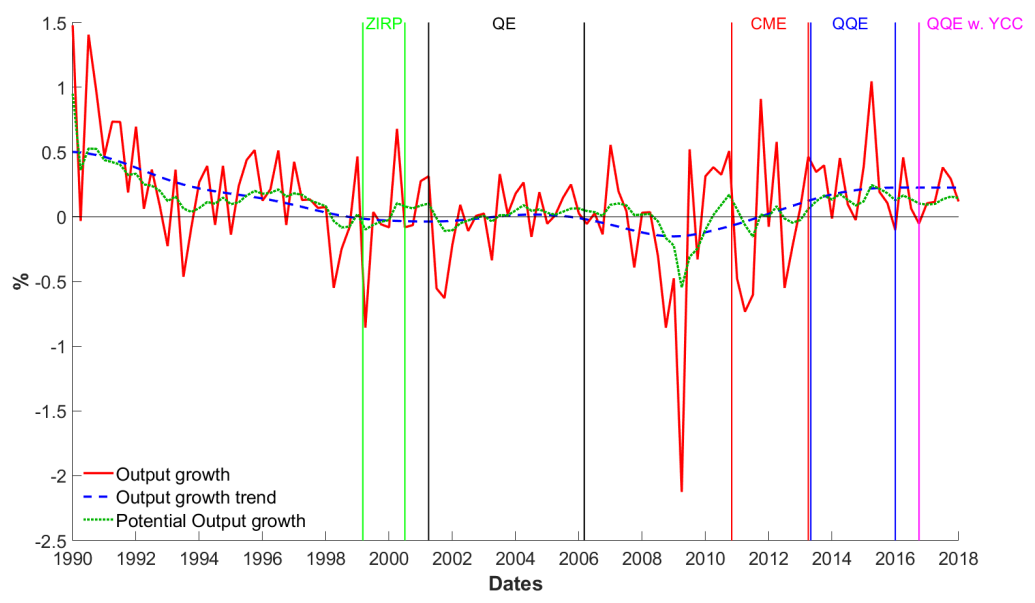

Figure 8: Potential growth

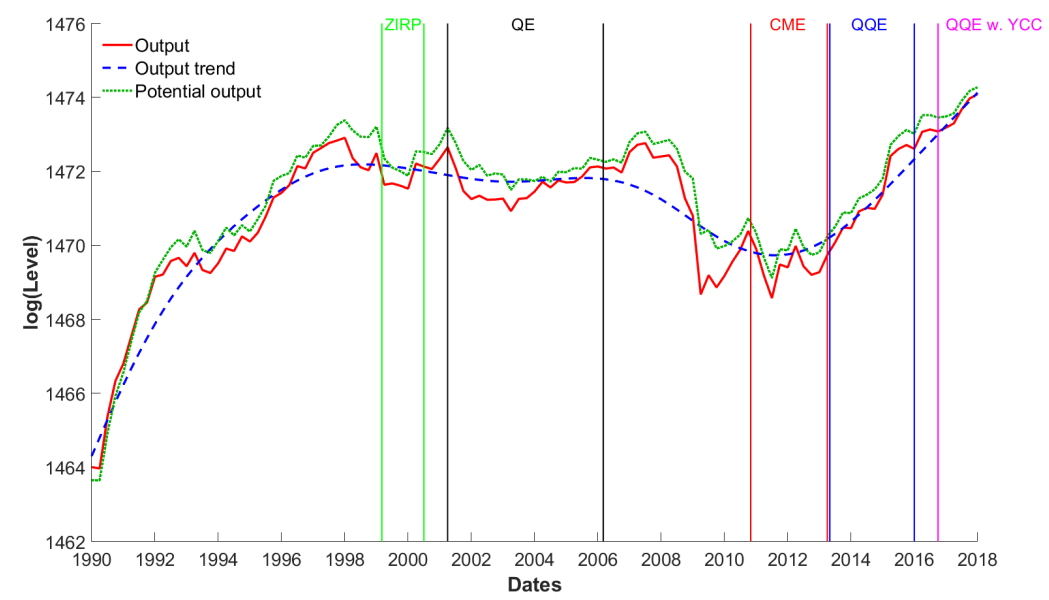

Figure 9: Potential Output

\section{Conclusion}

While most of the works in the literature have focused on the analysis of the causes of the drastic decline in the natural interest rates, this paper provides estimates of the natural yield curve. Considering the case of Japan, we observe a decline in the natural interest at all maturities. Potential growth is one of the driving factors explaining the evolution of the neutral rates. We document 
the existence of a persistent gap between the natural and observed interest rates at all maturities. The methodology proposed is new. We exploit the information in our data at different frequencies. First, we investigate the low frequency (quarterly) sources of the yield curve gap measured at high frequency (monthly). Second, we study how the monthly interest rate gaps influences macroeconomic variables at quarterly frequencies (inflation, output-gap, debt ratio). We proposed estimates based on Mixed-frequency Data sampling (MIDAS) and VAR-MIDAS models, which provides more precise results than those based on interpolation and aggregation of data. The neutral yield curve is considered as an unobserved variable and is estimated using a semi-structural model containing information in macroeconomic and financial data.

Taking the neutral yield curve as the benchmark level required for the economy to be at long-term equilibrium, we investigate the sources of discrepancy between the observed historical yields and the natural yields. We find that one needs to go beyond the traditional explanation based on the sole role of monetary policy and consider the additional influence of fiscal policy, of the financial cycle, of inflation and real exchange rates. We show that the difficulty to adjust the yield curve to its neutral level have had negative consequences on the Japanese economy: potential growth has remained at low levels and decreased over several decades, the debt ratio has been subject to snowball effects and the output-gaps have remained negative up until the recent Abenomics policies.

Our paper shed some lights on the results that one could expect, in the future, from the recent BOJ's yield curve control policy. The Central bank wants to steepen the slope by increasing the difference between short-term and long-term maturities. Our estimations lead us to conclude that the success in reaching some targeted slope - for instance the neutral slope - will depends upon the strength of both monetary and fiscal policies, which mean that both policies need to be oriented in the same direction. Some side effect may, however, be the unsustainable level of debt. Moreover, we find a positive correlation between the financial cycle and the level gaps, thereby implying that in the current context of booming financial prices and high levels of credit to the private sector, it makes sense raising the longest end of the yield curve to increase the financial sector's profitability.

The next step to this paper is to do a similar exercise for the other industrialized countries for purpose of comparison.

\section{References}

Amemiya, M. (2012). Chapter 7: Evaluation on nontraditional monetary policy. Japanese Economic Association, page 193-235.

Auer, R., Borio, C. E. V., and Filardo, A. J. (2017). The globalisation of inflation: The growing importance of global value chains. CEPR Discussion Paper No. DP11905.

Bai, J., Ghysels, E., and Wright, J. H. (2013). State space models and midas regressions. Econometric Reviews, 32(7):779-813.

Bergeaud, A., Cette, G., and Lecat, R. (2016). Productivity trends in advanced countries between 1890 and 2012. The Review of Income and Wealth, 62(3):420-444.

Bernanke, B. (2000). Japanese monetary policy: a case of self-induced paralysis? ASSA Meetings, Boston.

Bernard, H. and Gerlach, S. (1998). Does the term structure predict recessions? the international evidence. International Journal of Finance and Economics, 3(3):195-215.

Bikbov, R. and Chernov, M. (2010). No-arbitrage macroeconomic determinants of the yield curve. Journal of Econometrics, 159(1):166-182.

Blanchard, O. (2016). The phillips curve: Back to the '60s? American Economic Review, 106(5):3134. 
Blanchard, O. (2018). Should we reject the natural rate hypothesis? Journal of Economic Perspectives, 32(1):97-120.

Blanchard, O., Cerutti, E., and Summers, L. H. (2015). Inflation and activity - two explorations and their monetary policy implications. NBER Working Paper No. 21726.

Borio, C. and Filardo, A. (2017). The globalisation of inflation: the growing importance of global value chains. BIS Working Paper, (602).

Brand, C. and Mazelis, F. (2018). Taylor-rule consistent estimates of the natural rate of interest. ECB Draft Paper.

Brzoza-Brzezina, M. and Kotłowski, J. (2014). Measuring the natural yield curve. Applied Economics, 46(17):2052-2065.

Cette, G., Fernald, J., and Mojon, B. (2016). The pre-great recession slowdown in productivity. European Economic Review, 88:3-20.

Chen, C. Y.-H. and Tu, A. (2018). A factor-based approach to bond portfolio value-at-risk: the information role of macroeconomic and financial stress factors. Journal of Empirical Finance, $45: 243-268$.

Delong, B. J. and H., S. L. (2012). Fiscal policy in a depressed economy. Brookings Papers on Economic Activity, pages 233-297.

Diebold, F. X. and Li, C. (2006). Forecasting the term structure of government bond yields. Journal of econometrics, 130(2):337-364.

Diebold, F. X. and Rudebusch, G. D. (2013). Yield curve modeling and forecasting: the dynamic Nelson-Siegel approach. Princeton University Press.

Diebold, F. X., Rudebusch, G. D., and Aruoba, S. B. (2006). The macroeconomy and the yield curve: a dynamic latent factor approach. Journal of econometrics, 131:309-338.

Diez de los Rios, A. and Maral, S. (2017). Quantitative easing and long-term yields in small open economies. IMF Working Paper Working Paper No. 2012.

Dotsey, M., Fujita, S., and Stark, T. (2017). Do phillips curves conditionally help to forecast inflation? Federal Reserve Bank of Philadelphia Working Paper, 17-26.

Eggertsson, G. B., R., M. N., and Summers, L. H. (2016). Secular stagnation in the open economy. American Economic Review, 106(5):503-507.

Evans, C. L. and Marshall, D. A. (2007). Economic determinants of the nominal treasury yield curve. Journal of Monetary Economics, 54(7):1986-2003.

Fiorentini, G., Galesi, A., Perez-Quiros, G., and Sentana, E. (2018). The rise and fall of the natural interest rate. Banco de España, Draft Paper.

Fujiwara, S., Iwasaki, Y., Muto, I., Nishizaki, K., and Sudo, N. (2016). Developments in the natural rate of interest in japan. Bank of Japan Review, 2016(E-12).

Garnier, J. and Wilhelmsen, B.-R. (2009). The natural rate of interest and the output gap in the euro area: a joint estimation. Empirical Economics, 36(2):297-319.

Ghysels, E. (2016). Macroeconomics and the reality of mixed frequency data. Journal of Econometrics, 193(2):294-314.

Ghysels, E., Sinko, A., and Valkanov, R. (2007). Midas regressions: Further results and new directions. Econometric Reviews, 26(1):53-90.

Glaeser, E. L. (2014). Secular joblessness. Article in the book "Secular stagnation: Facts, causes, and cures", pages 69-80. 
Gordon, R. J. (2016). Secular stagnation: A supply-side view. American Economic Review, 106(5):54-59.

Grewal, M. S. and Andrews, A. P. (2008). Kalman Filtering, Theory and Practice Using Matlab. John Wiley Sons, Inc., third edition.

Hamilton, J. D. (1994). Time series analysis, volume 2. Princeton university press Princeton.

Holston, K., Laubach, T., and Williams, J. C. (2017). Measuring the natural rate of interest: International trends and determinants. Journal of International Economics, 108(1):S59-S75.

$\mathrm{Hu}$, Z. (1993). The yield curve and real activity. International Monetary Fund Staff Papers, 40(4):781-806.

Imakubo, K., Kojima, H., and Nakajima, J. (2017). The natural yield curve: its concept and measurement. Empirical Economics, pages 1-22.

Joslin, S., Priebsch, M., and Singleton, K. J. (2014). Risk premiums in dynamic term structure models with unspanned macro risks. The Journal of Finance, 69(3):1197-1233.

Kadiyala, K., Karlsson, L. S., et al. (1989). Forecasting with bayesian vector autoregressions. Technical report, Purdue University, Department of Economics.

Kuroda, H. (2016). " quantitative and qualitative monetary easing (qqe) with yield curve control": New monetary policy framework for overcoming low inflation. speech at Brookings Institution in Washington DC on October, 8.

Kuttner, K., N. (2014). Monetary policy during japan's great recession: from self-induced paralysis to rooseveltian resolve. Peterson Institute for International Economics Briefings, 14(4).

Laubach, T. and Williams, J. C. (2003). Measuring the natural rate of interest. Review of Economics and Statistics, 85(4):1063-1070.

Leduc, S. and Wilso, D. (2017). Has the wage phillips curve gone dormant? Federal Reserve Board of San Francisco, 2017-30.

Litterman, R. B. (1986). Forecasting with bayesian vector autoregressions - five years of experience. Journal of Business \& Economic Statistics, 4(1):25-38.

Lütkepohl, H. (2005). New introduction to multiple time series analysis. Springer Science \& Business Media.

Mariano, R. S. and Murasawa, Y. (2010). A coincident index, common factors, and monthly real gdp. Oxford Bulletin of Economics and Statistics, 72(1):27-46.

Nelson, C. R. and Siegel, A. F. (1987). Parsimonious modeling of yield curves. Journal of Business, 60(4):473-489.

Qian, H. (2014). A flexible state space model and its applications. Journal of Time Series Analysis, $35(2): 79-88$.

Rouwenhorst, G. K. and Plosser, C. I. (1994). International term structures and real economic growth. Journal of Monetary Economics, 33(1):133-155.

Rudebusch, G. D. and Wu, T. (2008). A macro-finance model of the term structure, monetary policy and the economy. The Economic Journal, 118:906-926.

Schorfheide, F. and Song, D. (2015). Real-time forecasting with a mixed-frequency var. Journal of Business 83 Economic Statistics, 33(3):366-380.

Smets, F. (1997). Financial asset prices and monetary policy: Theory and evidence. BIS Working Paper No. $4 \%$. 
Stiglitz, J. E. (2016). How to restore equitable and sustainable economic growth in the united states. American Economic Review, 106(5):43-47.

Stock, J. and Watson, M. (1998). Median unbiased estimation of coefficient variance in a timevarying parameter model. Journal of the American Statistical Association, 93:349-358.

Summers, L. H. (2015). Demand side secular stagnation. American Economic Review, 105(5):60-65.

Teulings, C. and Baldwin, R. (2014). Secular stagnation: Facts, causes, and cures. CEPR press. 


\section{Appendices}

\section{A Kalman Filter - Dynamic Nelson-Siegel model}

Here, we present the Bayesian estimation of the parameters in the Dynamic Nelson-Siegel model using the Kalman Filter. In particular, we consider the following state-space model:

State Equation:

$$
X_{t}=\mu+\Theta X_{t-1}+\zeta_{t} \text { with } \zeta_{t} \sim \mathcal{M V N \mathcal { N }}\left(0, \Sigma_{\zeta}\right)
$$

Measurement Equation:

$$
Y_{t}=\Lambda X_{t}+\varepsilon_{t} \text { with } \varepsilon_{t} \sim \mathcal{M} \mathcal{V N}\left(0, \Sigma_{\varepsilon}\right)
$$

where

$$
\begin{gathered}
\mu=\left(\begin{array}{l}
\mu_{L} \\
\mu_{S} \\
\mu_{C}
\end{array}\right) \quad \Theta=\left(\begin{array}{lll}
\theta_{11} & \theta_{12} & \theta_{13} \\
\theta_{21} & \theta_{22} & \theta_{23} \\
\theta_{31} & \theta_{32} & \theta_{33}
\end{array}\right) \Lambda=\left(\begin{array}{ccc}
1 & \frac{1-e^{-n_{1} / \lambda}}{n_{1} / \lambda} & \frac{1-e^{-n_{1} / \lambda}}{n_{1} / \lambda}-e^{-n_{1} / \lambda} \\
1 & \frac{1-e^{-n_{2} / \lambda}}{n_{2} / \lambda} & \frac{1-e^{-n_{2} / \lambda}}{n_{2} / \lambda}-e^{-n_{2} / \lambda} \\
\vdots & \vdots & \vdots \\
1 & \frac{1-e^{-n_{N} / \lambda}}{n_{N} / \lambda} & \frac{1-e^{-n_{N} / \lambda}}{n_{N} / \lambda}-e^{-n_{N} / \lambda}
\end{array}\right) \\
\Sigma_{\zeta}=\left(\begin{array}{lll}
\sigma_{\zeta, 11} & \sigma_{\zeta, 12} & \sigma_{\zeta, 13} \\
\sigma_{\zeta, 21} & \sigma_{\zeta, 22} & \sigma_{\zeta, 23} \\
\sigma_{\zeta, 3} & \sigma_{\zeta, 32} & \sigma_{\zeta, 33}
\end{array}\right) \Sigma_{\varepsilon}=\left(\begin{array}{cccc}
\sigma_{\varepsilon, 11} & 0 & \ldots & 0 \\
0 & \sigma_{\varepsilon, 22} & \ldots & 0 \\
\vdots & \vdots & \vdots & \vdots \\
0 & 0 & \ldots & \sigma_{\varepsilon, N N}
\end{array}\right)
\end{gathered}
$$

We stack all the parameters to be estimated from Equation $A .1$ and $(\mathrm{A} .2)$ in a vector $\Omega \in \mathbb{R}^{22+N}$ :

$$
\begin{gathered}
\Omega=\left(\lambda, \mu_{L}, \mu_{S}, \mu_{C}, \theta_{11}, \theta_{12}, \theta_{13}, \theta_{21}, \theta_{22}, \theta_{23}, \theta_{31}, \theta_{32}, \theta_{33}, \ldots\right. \\
\left.\sigma_{\zeta, 11}, \sigma_{\zeta, 12}, \sigma_{\zeta, 13}, \sigma_{\zeta, 21}, \sigma_{\zeta, 22}, \sigma_{\zeta, 23}, \sigma_{\zeta, 31}, \sigma_{\zeta, 32}, \sigma_{\zeta, 33}, \sigma_{\varepsilon, 11}, \ldots, \sigma_{\varepsilon, N N}\right)^{\prime}
\end{gathered}
$$

as $N_{y}=11$ yields in our case, where $\sigma_{\varepsilon, i i}$ is the element found on line $i$ column $i$ in matrix $\Sigma_{\varepsilon}$ from Equation (2) and $\sigma_{\zeta, i j}$ is the element found on line $i$ column $j$ in matrix $\Sigma_{\zeta}$ from Equation (3).

By Bayes rule, the marginal posterior distribution of $\Omega$ conditional on the sequence of observations $\mathcal{Y}_{T}=\left(Y_{1}, \ldots, Y_{T}\right)^{\prime}$ is:

$$
p\left(\Omega \mid \mathcal{Y}_{T}\right)=\frac{p\left(\Omega, \mathcal{Y}_{T}\right)}{p\left(\mathcal{Y}_{T}\right)}
$$

where $p\left(\Omega, \mathcal{Y}_{T}\right)$ is the joint density and $p\left(\mathcal{Y}_{T}\right)$ is the marginal density of the sample.

$$
p\left(\Omega \mid \mathcal{Y}_{T}\right)=\frac{p\left(\mathcal{Y}_{T} \mid \Omega\right) p(\Omega)}{p\left(\mathcal{Y}_{T}\right)}
$$

where $p\left(\mathcal{Y}_{T} \mid \Omega\right)$ is the marginal likelihood and $p(\Omega)$ is the prior density.

We also have that:

$$
p\left(\mathcal{Y}_{T}\right)=\int_{-\infty}^{+\infty} p\left(\mathcal{Y}_{T} \mid \Omega\right) p(\Omega) d \Omega
$$


is a normalization constant that does not depend on the parameters $\Omega$ : it can be left aside. Then,

$$
p\left(\Omega \mid \mathcal{Y}_{T}\right) \propto p\left(\mathcal{Y}_{T} \mid \Omega\right) p(\Omega)
$$

Using the prediction error decomposition, we have that:

$$
p\left(\mathcal{Y}_{T} \mid \Omega\right)=\prod_{t=1}^{T} p\left(Y_{t} \mid \mathcal{Y}_{t-1} ; \Omega\right)
$$

For convenience, we will not work with the marginal posterior distribution $p\left(\Omega \mid \mathcal{Y}_{T}\right)$ but with an energy function $\phi_{T}$ defined as 10

$$
\phi_{T}(\Omega)=-\log \left[p\left(\mathcal{Y}_{T} \mid \Omega\right)\right]-\log [p(\Omega)]
$$

and using Equation (A.9), we have that:

$$
\phi_{t}(\Omega)=\phi_{t-1}(\Omega)-\log \left[p\left(Y_{t} \mid \mathcal{Y}_{t-1} ; \Omega\right)\right]
$$

where $\phi_{0}(\Omega)=-\log [p(\Omega)]$

Then, the maximum a posteriori (MAP) of the parameter vector $\Omega$ is given by:

$$
\hat{\Omega}^{M A P}=\underset{\Omega}{\arg \min }\left[\phi_{T}\right]
$$

Note that it reduces to a Maximum Likelihood (ML) problem if priors are uniform: $p(\Omega) \propto 1$

Besides, under the linear Gaussian assumption, the distribution of $Y_{t}$ conditional on the sequence of observations $\mathcal{Y}_{t-1}=\left(Y_{1}, \ldots, Y_{t-1}\right)^{\prime}$ is multivariate normal such that:

$$
Y_{t} \mid \mathcal{Y}_{t-1} \sim \mathcal{M V N}\left(\Lambda \hat{X}_{t \mid t-1}, F_{t}\right)
$$

where $F_{t}=\Lambda P_{t \mid t-1} \Lambda^{\prime}+\Sigma_{\varepsilon} \Sigma_{\varepsilon}^{\prime}$

with $P_{t \mid t-1}$ is the Mean Squared Error (MSE) matrix:

$$
P_{t \mid t-1}=E_{t-1}\left[\left(X_{t}-\hat{X}_{t \mid t-1}\right)\left(X_{t}-\hat{X}_{t \mid t-1}\right)^{\prime}\right]
$$

In this framework, the conditional density of $Y_{t}$ can be written as:

$$
p\left(Y_{t} \mid \mathcal{Y}_{t-1} ; \Omega\right)=\frac{\exp \left[-\frac{1}{2}\left(Y_{t}-\Lambda \hat{X}_{t \mid t-1}\right)^{\prime} F_{t}^{-1}\left(Y_{t}-\Lambda \hat{X}_{t \mid t-1}\right)\right]}{(2 \pi)^{N / 2}\left|F_{t}\right|^{1 / 2}}
$$

Plugging Equation A.15 into A.11, we finally obtain:

$$
\phi_{t}(\Omega)=\phi_{t-1}(\Omega)+\frac{N}{2} \ln (2 \pi)+\frac{1}{2} \ln \left|F_{t}\right|+\frac{1}{2}\left(Y_{t}-\Lambda \hat{X}_{t \mid t-1}\right)^{\prime} F_{t}^{-1}\left(Y_{t}-\Lambda \hat{X}_{t \mid t-1}\right)
$$

where $\phi_{0}(\Omega)=-\log [p(\Omega)]$ is the prior.

In order to specify the prior density $p(\Omega)$, we split the parameter vector $\Omega$ in four blocks: $\Omega_{1}, \Omega_{2}$, $\Omega_{3}$ and $\Omega_{4}$. $\Omega_{1}$ and $\Omega_{2}$ respectively contain the autoregressive coefficients and residuals variancecovariance matrix from Sate Equation (3). Similarly, $\Omega_{3}$ and $\Omega_{4}$ contain the autoregressive coefficients and residual variance-covariance matrix from Measurement Equation (2).

$$
\begin{aligned}
& \Omega_{1}=\left(\mu_{L}, \mu_{S}, \mu_{C}, \theta_{11}, \theta_{12}, \theta_{13}, \theta_{21}, \theta_{22}, \theta_{23}, \theta_{31}, \theta_{32}, \theta_{33}\right)^{\prime} \\
& \Omega_{2}=\Sigma_{\zeta}
\end{aligned}
$$

${ }^{10}$ Our energy function is just the mathematical opposite of the penalized log-likelihood. 


$$
\Omega_{3}=\lambda
$$

$$
\Omega_{4}=\Sigma_{\varepsilon}
$$

Assuming independence between these blocks leads to:

$$
p(\Omega)=p\left(\Omega_{1}\right) p\left(\Omega_{2}\right) p\left(\Omega_{3}\right) p\left(\Omega_{4}\right)
$$

Besides, we assume independant Normal-Wishart priors, so that $\Omega_{1}$ follows a normal distribution:

$$
\Omega_{1} \sim \mathcal{M V N N}\left(\omega_{1}, \Sigma_{1}\right)
$$

where $\omega_{1}$ is the vector of likelihood estimates parameters taken from Imakubo et al. (2017) (Table 1 page 14$)$. Besides, we set $\Sigma_{1}=0.8 \times I_{12}$

Then, we assume that $\Omega_{2}$ follows an inverse-Wishart distribution 11

$$
\Omega_{2} \sim \mathcal{W}^{-1}\left(S_{2}, \alpha_{2}\right)
$$

where, $\alpha_{2}=4$ and the scale matrix $S_{2}$ is the variance-covariance matrix from the preliminary OLS regressions.

Similarly, $\Omega_{3}=\lambda$ follows a Normal distribution:

$$
\Omega_{3} \sim \mathcal{N}\left(\omega_{3}, \sigma_{3}\right)
$$

where we set $\omega_{3}=1.36$ (Diebold and Li (2006) value), and $\sigma_{3}=0.8$

Elements of $\Omega_{4}$ follow inverse-Gamma distributions:

$$
\sigma_{\varepsilon, i i} \sim \Gamma^{-1}\left(\alpha_{4}, \beta_{4}\right)
$$

where $\alpha_{4}=2$, and $\beta_{4}$ is the preliminary OLS variance.

Let us now specify the Kalman filter algorithm:

We start at $i=0$, where $i$ is the number of iterations.

\section{Step 0: Setup}

$\Omega=\Omega_{0}$

$i=i+1$

\section{Step 1: Initialization}

Set $\hat{X}_{0 \mid 0}=\hat{X}_{0}$ and $P_{0 \mid 0}=P_{0}$

$t=1$

Step 2: Prediction $\mathbf{1} \leq \mathbf{t} \leq \mathbf{T}$

1) $\hat{X}_{t \mid t-1}=\mu+\Theta \hat{X}_{t-1 \mid t-1}$

2) $P_{t \mid t-1}=\Theta P_{t-1 \mid t-1} \Theta^{\prime}+\Sigma_{\zeta}$

3) $F_{t}=\Lambda P_{t \mid t-1} \Lambda^{\prime}+\Sigma_{\varepsilon}$

\section{Step 3: Updating at $t$}

\footnotetext{
${ }^{11}$ See Kadiyala et al. (1989)
} 
1) $K_{t}=P_{t \mid t-1} \Lambda^{\prime} F_{t}^{-1}$

2) $\hat{X}_{t \mid t}=\hat{X}_{t \mid t-1}+K_{t}\left(Y_{t}-\Lambda \hat{X}_{t \mid t-1}\right)$

3) $P_{t \mid t}=P_{t \mid t-1}-K_{t} F_{t} K_{t}^{\prime}$

Step 4: Compute the energy function

Compute the $\phi_{t}(\Omega)$ using Equation A.16

Step 5: Loop

If $t<T$ then $t=t+1$ and go to Step 2, else go to Step 6

\section{Step 6: Compare the energy function}

If $\left|\phi_{T}(\Omega)-\phi_{T}\left(\Omega_{0}\right)\right| \leq \epsilon$, where $\epsilon=10^{-6}$ is the convergence criterion, then stop.

Else go to Step 0

Starting values $\hat{X}_{0 \mid 0}$ are rough estimates of $\left(L_{t}, S_{t}, C_{t}\right)$ taken from linear combination of yields, as in Diebold et al. (2006). This enables us to conduct OLS regressions to find estimates for $\Omega_{0}$. Besides, we set $P_{0 \mid 0}=I_{3}$

We employ the interior-point optimization algorithm included in the function "fmincon" available in MatLab Optimization Toolbox to minimize the energy function $\phi_{T}(\Omega){ }^{12}$

\section{Proof : Kalman gain $K_{t}$}

First, we compute $P_{t \mid t}$ :

$$
\begin{aligned}
P_{t \mid t} & =E_{t}\left[\left(X_{t}-\hat{X}_{t \mid t}\right)\left(X_{t}-\hat{X}_{t \mid t}\right)^{\prime}\right] \\
& =\operatorname{Cov}\left(X_{t}-\hat{X}_{t \mid t}\right) \\
& =\operatorname{Cov}\left(X_{t}-\hat{X}_{t \mid t-1}-K_{t}\left(Y_{t}-\hat{Y}_{t \mid t-1}\right)\right) \\
& =\operatorname{Cov}\left(X_{t}-\hat{X}_{t \mid t-1}-K_{t}\left(\Lambda X_{t}+\epsilon_{t}-\Lambda \hat{X}_{t \mid t-1}\right)\right) \\
& =\operatorname{Cov}\left[\left(I-K_{t} \Lambda\right)\left(X_{t}-\hat{X}_{t \mid t-1}\right)\right]+\operatorname{Cov}\left(-K_{t} \epsilon_{t}\right) \\
& =\left(I-K_{t} \Lambda\right) \operatorname{cov}\left(X_{t}-\hat{X}_{t \mid t-1}\right)\left(I-K_{t} \Lambda\right)^{\prime}+K_{t} \Sigma_{\epsilon} \Sigma_{\epsilon}^{\prime} K_{t}^{\prime} \\
& =\left(I-K_{t} \Lambda\right) P_{t \mid t-1}\left(I-K_{t} \Lambda\right)^{\prime}+K_{t} \Sigma_{\epsilon} \Sigma_{\epsilon}^{\prime} K_{t}^{\prime} \\
& =P_{t \mid t-1}-P_{t \mid t-1} \Lambda^{\prime} K_{t}^{\prime}-K_{t} \Lambda P_{t \mid t-1}+K_{t} \Lambda P_{t \mid t-1} \Lambda^{\prime} K_{t}^{\prime}+K_{t} \Sigma_{\epsilon} \Sigma_{\epsilon}^{\prime} K_{t}^{\prime} \\
& =P_{t \mid t-1}-P_{t \mid t-1} \Lambda^{\prime} K_{t}^{\prime}-K_{t} \Lambda P_{t \mid t-1}+K_{t}\left(\Lambda P_{t \mid t-1} \Lambda^{\prime}+\Sigma_{\epsilon} \Sigma_{\epsilon}^{\prime}\right) K_{t}^{\prime}
\end{aligned}
$$

Second, as $P_{t \mid t}$ is a MSE matrix, the sum of the diagonal elements is the sum of the mean squared errors for the elements of $X_{t}$. Therefore, we can minimize the MSE by minimizing the trace of $P_{t \mid t}$ :

$$
\operatorname{tr}\left(P_{t \mid t}\right)=\operatorname{tr}\left(P_{t \mid t-1}\right)-2 \operatorname{tr}\left(K_{t} P_{t \mid t-1} \Lambda^{\prime}\right)+\operatorname{tr}\left[K_{t}\left(\Lambda P_{t \mid t-1} \Lambda^{\prime}+\Sigma_{\epsilon} \Sigma_{\epsilon}^{\prime}\right) K_{t}^{\prime}\right]
$$

Third, we differentiate the trace of $P_{t \mid t}$ with respect to $K$ :

$$
\begin{aligned}
\frac{\partial t r\left(P_{t \mid t}\right)}{\partial K}=0 & \Leftrightarrow-2 P_{t \mid t-1} \Lambda^{\prime}+2 K_{t}\left(\Lambda P_{t \mid t-1} \Lambda^{\prime}+\Sigma_{\epsilon} \Sigma_{\epsilon}^{\prime}\right)=0 \\
& \Leftrightarrow \quad K_{t}=P_{t \mid t-1} \Lambda^{\prime}\left(\Lambda P_{t \mid t-1} \Lambda^{\prime}+\Sigma_{\epsilon} \Sigma_{\epsilon}^{\prime}\right)^{-1} \\
& \Leftrightarrow \quad K_{t}=P_{t \mid t-1} \Lambda^{\prime} F_{t}^{-1}
\end{aligned}
$$

\footnotetext{
${ }^{12}$ See Lütkepohl (2005), Section 12 for a discussion concerning the optimization algorithms.
} 


\section{Kalman gain without inversion of $F_{t}$}

So as to avoid round-off errors linked to the inversion of $F_{t}$ and ensure numerical stability in the computation of the Kalman gain, we do not directly compute $F_{t}^{-1}$. Instead, we form the term $\Lambda^{\prime} F_{t}^{-1}$ by solving the following equation:

$$
X\left(U D U^{\prime}\right)=\Lambda^{\prime}
$$

where $X=\Lambda^{\prime} F_{t}^{-1}$ and $F_{t}=U D U^{\prime}$ is a modified Cholesky (UD) decomposition of $F_{t}$, symmetric positive-definite, with $\mathrm{U}$ a unit upper triangular matrix and $\mathrm{D}$ a diagonal matrix.

Solving for $X$ without matrix inversion requires to:

1) solve for $X_{1}$ in $X_{1} U^{\prime}=\Lambda^{\prime}$ by backward substitution,

2) solve for $X_{2}$ in $X_{2} D=X_{1}$ by linear combination,

3) solve for $X$ in $X U=X_{2}$ by forward substitution.

\section{B Kalman Filter - MIDAS-VAR model}

The following presents the Bayesian estimation of the parameters in the MIDAS-VAR model using the Kalman Filter.

We consider the following state-space model:

State Equation:

$$
X_{t}=A X_{t-1}+W_{t} \text { with } W_{t} \sim \mathcal{M V \mathcal { N }}\left(0, \Omega_{1}\right)
$$

Measurement Equation:

$$
Y_{t}=E X_{t}+D X_{t-1}+B Y_{t-1}+U_{t} \text { with } U_{t} \sim \mathcal{M V N}\left(0, \Omega_{2}\right)
$$

where:

$$
\begin{aligned}
& A=\left(\begin{array}{lll}
A_{1} & \mathbf{0}_{3} & \mathbf{0}_{3} \\
\mathbf{0}_{3} & A_{2} & \mathbf{0}_{3} \\
\mathbf{0}_{3} & \mathbf{0}_{3} & A_{3}
\end{array}\right), \quad A_{1}=\left(\begin{array}{ccc}
\beta & \beta & \beta \\
\beta & \beta & \beta \\
\beta & \beta & \beta
\end{array}\right), \quad A_{2}=\left(\begin{array}{lll}
\delta & \delta & \delta \\
\delta & \delta & \delta \\
\delta & \delta & \delta
\end{array}\right), \quad A_{3}=\left(\begin{array}{lll}
\eta & \eta & \eta \\
\eta & \eta & \eta \\
\eta & \eta & \eta
\end{array}\right), \\
& \Omega_{1}=\operatorname{diag}\left(l_{1}^{\star}, l_{2}^{\star}, l_{3}^{\star}, s_{1}^{\star}, s_{2}^{\star}, s_{3}^{\star}, c_{1}^{\star}, c_{2}^{\star}, c_{3}^{\star}\right) \\
& \mathrm{E}=\left(\begin{array}{ccccccccc}
1 & 0 & 0 & 0 & 0 & 0 & 0 & 0 & 0 \\
0 & 1 & 0 & 0 & 0 & 0 & 0 & 0 & 0 \\
0 & 0 & 1 & 0 & 0 & 0 & 0 & 0 & 0 \\
0 & 0 & 0 & 1 & 0 & 0 & 0 & 0 & 0 \\
0 & 0 & 0 & 0 & 1 & 0 & 0 & 0 & 0 \\
0 & 0 & 0 & 0 & 0 & 1 & 0 & 0 & 0 \\
0 & 0 & 0 & 0 & 0 & 0 & 1 & 0 & 0 \\
0 & 0 & 0 & 0 & 0 & 0 & 0 & 1 & 0 \\
0 & 0 & 0 & 0 & 0 & 0 & 0 & 0 & 1 \\
0 & 0 & 0 & 0 & 0 & 0 & 0 & 0 & 0
\end{array}\right), \mathrm{D}=\left(\begin{array}{cccc}
D_{1} & \mathbf{0}_{3} & \mathbf{0}_{3} \\
\mathbf{0}_{3} & D_{2} & \mathbf{0}_{3} \\
\mathbf{0}_{3} & \mathbf{0}_{3} & D_{3} \\
D_{4} & D_{5} & D_{6}
\end{array}\right), \mathrm{D}_{1}=\left(\begin{array}{llll}
-\phi_{L} & -\phi_{L} & -\phi_{L} \\
-\phi_{L} & -\phi_{L} & -\phi_{L} \\
-\phi_{L} & -\phi_{L} & -\phi_{L}
\end{array}\right),
\end{aligned}
$$

\footnotetext{
${ }^{13}$ See Grewal and Andrews $(2008)$, Section 6.4.3.4 page 248
} 


$$
\begin{aligned}
D_{2} & =\left(\begin{array}{ccc}
-\phi_{S} & -\phi_{S} & -\phi_{S} \\
-\phi_{S} & -\phi_{S} & -\phi_{S} \\
-\phi_{S} & -\phi_{S} & -\phi_{S}
\end{array}\right), \quad D_{3}=\left(\begin{array}{ccccc}
-\phi_{C} & -\phi_{C} & -\phi_{C} \\
-\phi_{C} & -\phi_{C} & -\phi_{C} \\
-\phi_{C} & -\phi_{C} & -\phi_{C}
\end{array}\right), \quad D_{4}=\left(\begin{array}{llll}
-\alpha_{L} & -\alpha_{L} & -\alpha_{L}
\end{array}\right), \\
D_{5} & =\left(\begin{array}{lllllllll}
-\gamma_{S} & -\gamma_{S} & -\gamma_{S}
\end{array}\right), \quad D_{6}=\left(\begin{array}{ccccccc}
-\kappa_{S} & -\kappa_{S} & -\kappa_{S}
\end{array}\right), \\
B & =\left(\begin{array}{cccccccccc}
\phi_{L} & \phi_{L} & \phi_{L} & 0 & 0 & 0 & 0 & 0 & 0 & \alpha \\
\phi_{L} & \phi_{L} & \phi_{L} & 0 & 0 & 0 & 0 & 0 & 0 & \alpha \\
\phi_{L} & \phi_{L} & \phi_{L} & 0 & 0 & 0 & 0 & 0 & 0 & \alpha \\
0 & 0 & 0 & \phi_{S} & \phi_{S} & \phi_{S} & 0 & 0 & 0 & \gamma \\
0 & 0 & 0 & \phi_{S} & \phi_{S} & \phi_{S} & 0 & 0 & 0 & \gamma \\
0 & 0 & 0 & \phi_{S} & \phi_{S} & \phi_{S} & 0 & 0 & 0 & \gamma \\
0 & 0 & 0 & 0 & 0 & 0 & \phi_{C} & \phi_{C} & \phi_{C} & \kappa \\
0 & 0 & 0 & 0 & 0 & 0 & \phi_{C} & \phi_{C} & \phi_{C} & \kappa \\
0 & 0 & 0 & 0 & 0 & 0 & \phi_{C} & \phi_{C} & \phi_{C} & \kappa \\
\alpha_{L} & \alpha_{L} & \alpha_{L} & \gamma_{S} & \gamma_{S} & \gamma_{S} & \kappa_{S} & \kappa_{S} & \kappa_{S} & \rho
\end{array}\right), \Omega_{2}=\operatorname{diag}\left(l_{1}, l_{2}, l_{3}, s_{1}, s_{2}, s_{3}, c_{1}, c_{2}, c_{3}, m\right),
\end{aligned}
$$

where zeros in bold either indicate squared sub-matrices of zeros with dimension $k \times k\left(\mathbf{0}_{k}\right)$.

We stack all the parameters to be estimated from Equation $(\overline{B .1})$ and $(\mathrm{B} .2)$ in a vector $\Psi \in \mathbb{R}^{32}$ :

$$
\begin{array}{r}
\Psi=\left(\beta, \delta, \eta, l_{1}^{\star}, l_{2}^{\star}, l_{3}^{\star}, s_{1}^{\star}, s_{2}^{\star}, s_{3}^{\star}, c_{1}^{\star}, c_{2}^{\star}, c_{3}^{\star}, \phi_{L}, \phi_{S}, \phi_{C}, \alpha_{L}, \gamma_{S}, \kappa_{C}, \alpha, \gamma, \kappa, \rho, \ldots\right. \\
\left.l_{1}, l_{2}, l_{3}, s_{1}, s_{2}, s_{3}, c_{1}, c_{2}, c_{3}, m\right)^{\prime}
\end{array}
$$

Under the same Gaussian assumptions presented in Appendix Afor Nelson-Siegel model, we obtain:

$$
\begin{aligned}
& \phi_{t}(\Psi)=\phi_{t-1}(\Psi)+\frac{N}{2} \ln (2 \pi)+\frac{1}{2} \ln \left|F_{t}\right|+\frac{1}{2} R_{t}^{\prime} F_{t}^{-1} R_{t} \\
& R_{t}=Y_{t}-E \hat{X}_{t \mid t-1}-D \hat{X}_{t-1 \mid t-1}-B \hat{Y}_{t-1 \mid t-1} \\
& F_{t}=E P_{t \mid t-1} E^{\prime}+\Omega_{2}+D P_{t-1 \mid t-1} D^{\prime}+E A P_{t-1 \mid t-1} D^{\prime}+D P_{t-1 \mid t-1} A^{\prime} E^{\prime}
\end{aligned}
$$

where $\phi_{0}(\Psi)=-\log [p(\Psi)]$ is the prior.

Again, we split $\Psi$ in 4 blocks to specify the prior densities according to an independant NormalWishart setting:

$$
\Psi_{1}=(\beta, \delta, \eta)^{\prime} \sim \mathcal{M} \mathcal{V N}\left(\psi_{1}, \Sigma_{1}\right)
$$

where $\psi_{1}$ is found in previous OLS estimations on filtered series and we set $\Sigma_{1}=0.005 \times I_{3}$.

$$
\Psi_{2}=\left(\phi_{L}, \phi_{S}, \phi_{C}, \alpha_{L}, \gamma_{S}, \kappa_{C}, \alpha, \gamma, \kappa, \rho\right)^{\prime} \sim \mathcal{M V \mathcal { N }}\left(\psi_{2}, \Sigma_{2}\right)
$$

where $\psi_{2}$ is found in previous OLS estimations on filtered series and we set $\Sigma_{2}=0.005 \times I_{10}$.

Besides, elements of $\Omega_{1}$ and $\Omega_{2}$ contained in $\Psi_{3}$ and $\Psi_{4}$ follow inverse-Gamma distributions:

$$
\left(l_{i}^{\star}, s_{i}^{\star}, c_{i}^{\star}, l_{i}, s_{i}, c_{i}, m\right) \sim \Gamma^{-1}\left(\alpha_{3}, \beta_{3}\right)
$$

where we set $\alpha_{3}=2$, and $\beta_{3}$ is the OLS-variance.

As the Measurement equation contains a lag of the state and of the observed variables, we rely on Qian (2014) for the Kalman filter algorithm. Here, we only present the steps that differ from the ones introduced in Appendix A

Step 2 : Prediction $1 \leq \mathrm{t} \leq \mathbf{T}$

1) $\hat{X}_{t \mid t-1}=A \hat{X}_{t-1 \mid t-1}$ 
2) $P_{t \mid t-1}=A P_{t-1 \mid t-1} A^{\prime}+\Omega_{1}$

3) $F_{t}=E P_{t \mid t-1} E^{\prime}+\Omega_{2}+D P_{t-1 \mid t-1} D^{\prime}+E A P_{t-1 \mid t-1} D^{\prime}+D P_{t-1 \mid t-1} A^{\prime} E^{\prime}$

\section{Step 3: Updating at $\mathbf{t}$}

1) $K_{t}=\left(P_{t \mid t-1} E^{\prime}+A P_{t \mid t-1} D^{\prime}\right) F_{t}^{-1}$

2) $\hat{X}_{t \mid t}=\hat{X}_{t \mid t-1}+K_{t}\left(Y_{t}-B \hat{Y}_{t-1 \mid t-1}-E \hat{X}_{t \mid t-1}-D \hat{X}_{t-1 \mid t-1}\right)$

3) $P_{t \mid t}=P_{t \mid t-1}-K_{t} F_{t} K_{t}^{\prime}$

Starting values $\hat{X}_{0 \mid 0}$ are the HP-filtered trends of $\left(L_{t}, S_{t}, C_{t}\right) . \Psi_{0}$ is initialized with OLS estimates and we set $P_{0 \mid 0}=I_{3}$

We employ the sqp optimization algorithm included in the function "fmincon" available in MatLab Optimization Toolbox to minimize the energy function $\phi_{T}(\Psi)$.

\section{Proof : Kalman gain $K_{t}$}

First, we compute $P_{t \mid t}$ :

$$
\begin{aligned}
& P_{t \mid t}=E_{t}\left[\left(X_{t}-\hat{X}_{t \mid t}\right)\left(X_{t}-\hat{X}_{t \mid t}\right)^{\prime}\right] \\
& =\operatorname{Cov}\left(X_{t}-\hat{X}_{t \mid t}\right) \\
& =\operatorname{Cov}\left(X_{t}-\hat{X}_{t \mid t-1}-K_{t}\left(Y_{t}-\hat{Y}_{t \mid t-1}\right)\right. \\
& =\operatorname{Cov}\left(X_{t}-\hat{X}_{t \mid t-1}-K_{t}\left(E X_{t}+D X_{t-1}+B Y_{t-1}+U_{t}-E \hat{X}_{t \mid t-1}-D \hat{X}_{t-1 \mid t-1}-B Y_{t-1}\right)\right. \\
& =\operatorname{Cov}\left(A X_{t-1}+W_{t}-A \hat{X}_{t-1 \mid t-1}-K_{t}\left(E A X_{t-1}+E W_{t}+D X_{t-1}+U_{t}-E A \hat{X}_{t-1 \mid t-1}-D \hat{X}_{t-1 \mid t-1}\right)\right. \\
& =\operatorname{Cov}\left[\left(\left(I-K_{t} E\right) A-K_{t} D\right)\left(X_{t-1}-\hat{X}_{t-1 \mid t-1}\right)+\left(I-K_{t} E\right) W_{t}-K_{t} U_{t}\right] \\
& =\left(\left(I-K_{t} E\right) A-K_{t} D\right) P_{t-1 \mid t-1}\left(\left(I-K_{t} E\right) A-K_{t} D\right)^{\prime}+\left(I-K_{t} E\right) \Omega_{1}\left(I-K_{t} E\right)^{\prime}+K_{t} \Omega_{2} K_{t}^{\prime} \\
& =A P_{t-1 \mid t-1} A^{\prime}-K_{t} E A P_{t-1 \mid t-1} A^{\prime}-K_{t} D P_{t-1 \mid t-1} A^{\prime}-A P_{t-1 \mid t-1} A^{\prime} E^{\prime} K_{t}^{\prime} \cdots \\
& +K_{t} E A P_{t-1 \mid t-1} A^{\prime} E^{\prime} K_{t}^{\prime}+K_{t} D P_{t-1 \mid t-1} A^{\prime} E^{\prime} K_{t}^{\prime}-A P_{t-1 \mid t-1} D^{\prime} K_{t}^{\prime} \cdots \\
& +K_{t} E A P_{t-1 \mid t-1} D^{\prime} K_{t}^{\prime}+K_{t} D P_{t-1 \mid t-1} D^{\prime} K_{t}^{\prime}+\left(I-K_{t} E\right) \Omega_{1}\left(I-K_{t} E\right)^{\prime}+K_{t} \Omega_{2} K_{t}^{\prime} \\
& =A P_{t-1 \mid t-1} A^{\prime}-K_{t} E A P_{t-1 \mid t-1} A^{\prime}-K_{t} D P_{t-1 \mid t-1} A^{\prime}-A P_{t-1 \mid t-1} A^{\prime} E^{\prime} K_{t}^{\prime}-A P_{t-1 \mid t-1} D^{\prime} K_{t}^{\prime} \cdots \\
& +\left(I-K_{t} E\right) \Omega_{1}\left(I-K_{t} E\right)^{\prime} \ldots \\
& +K_{t}\left(E A P_{t-1 \mid t-1} A^{\prime} E^{\prime}+D P_{t-1 \mid t-1} A^{\prime} E^{\prime}+E A P_{t-1 \mid t-1} D^{\prime}+D P_{t-1 \mid t-1} D^{\prime}+\Omega_{2}\right) K_{t}^{\prime} \\
& =A P_{t-1 \mid t-1} A^{\prime}-K_{t} E A P_{t-1 \mid t-1} A^{\prime}-K_{t} D P_{t-1 \mid t-1} A^{\prime}-A P_{t-1 \mid t-1} A^{\prime} E^{\prime} K_{t}^{\prime}-A P_{t-1 \mid t-1} D^{\prime} K_{t}^{\prime} \cdots \\
& +\left(I-K_{t} E\right) \Omega_{1}\left(I-K_{t} E\right)^{\prime} \ldots \\
& +K_{t}\left(E\left(P_{t \mid t-1}-\Omega_{1}\right) E^{\prime}+D P_{t-1 \mid t-1} A^{\prime} E^{\prime}+E A P_{t-1 \mid t-1} D^{\prime}+D P_{t-1 \mid t-1} D^{\prime}+\Omega_{2}\right) K_{t}^{\prime} \\
& =A P_{t-1 \mid t-1} A^{\prime}-K_{t} E\left(A P_{t-1 \mid t-1} A^{\prime}+\Omega_{1}\right)-\left(A P_{t-1 \mid t-1} A^{\prime}+\Omega_{1}\right) E^{\prime} K_{t}^{\prime} \cdots \\
& -K_{t} D P_{t-1 \mid t-1} A^{\prime}-A P_{t-1 \mid t-1} D^{\prime} K_{t}^{\prime}+\Omega_{1}+K_{t} F_{t} K_{t}^{\prime} \\
& =A P_{t-1 \mid t-1} A^{\prime}-K_{t} E P_{t \mid t-1}-P_{t \mid t-1} E^{\prime} K_{t}^{\prime}+\Omega_{1}-K_{t} D P_{t-1 \mid t-1} A^{\prime}-A P_{t-1 \mid t-1} D^{\prime} K_{t}^{\prime}+K_{t} F_{t} K_{t}^{\prime}
\end{aligned}
$$

Second, as $P_{t \mid t}$ is a MSE matrix, the sum of the diagonal elements is the sum of the mean squared errors for the elements of $X_{t}$. Therefore, we can minimize the MSE by minimizing the trace of $P_{t \mid t}$ :

$$
\operatorname{tr}\left(P_{t \mid t}\right)=\operatorname{tr}\left(A P_{t-1 \mid t-1} A^{\prime}+\Omega_{1}\right)-2 \operatorname{tr}\left(P_{t \mid t-1} E^{\prime} K_{t}^{\prime}\right)-2 \operatorname{tr}\left(A P_{t-1 \mid t-1} D^{\prime} K_{t}^{\prime}\right)+\operatorname{tr}\left(K_{t} F_{t} K_{t}^{\prime}\right)
$$


Third, we differentiate the trace of $P_{t \mid t}$ with respect to $K$ :

$$
\begin{aligned}
\frac{\partial \operatorname{tr}\left(P_{t \mid t}\right)}{\partial K}=0 & \Leftrightarrow-2 P_{t \mid t-1} E^{\prime}-2 A P_{t-1 \mid t-1} D^{\prime}+2 K_{t} F_{t}=0 \\
& \Leftrightarrow K_{t} F_{t}=P_{t \mid t-1} E^{\prime}+A P_{t-1 \mid t-1} D^{\prime} \\
& \Leftrightarrow K_{t}=\left(P_{t \mid t-1} E^{\prime}+A P_{t-1 \mid t-1} D^{\prime}\right) F_{t}^{-1}
\end{aligned}
$$

\section{Kalman gain without inversion of $F_{t}$}

The procedure is similar to the one described in the previous section. One only needs to replace $\Lambda^{\prime}$ by $\left(P_{t \mid t-1} E^{\prime}+A P_{t-1 \mid t-1} D^{\prime}\right)$

\section{Kalman Filter - MIDAS model}

The following presents the Bayesian estimation of the parameters in the MIDAS model using the Kalman Filter.

We consider the following state-space model:

State Equation:

$$
X_{t}=\alpha+A X_{t-1}+W_{t} \text { with } W_{t} \sim \mathcal{M V N N}\left(0, \Omega_{3}\right)
$$

Measurement Equation:

$$
Y_{t}=\beta+E X_{t}+D X_{t-1}+B Z_{t-1}+U_{t} \text { with } U_{t} \sim \mathcal{M V N}\left(0, \Omega_{4}\right)
$$

where:

$\alpha^{\prime}=\left(0, \phi_{g_{0}}, \chi_{0}\right), \quad A=\left(\begin{array}{ccc}1 & 1 & 0 \\ 0 & \phi_{g_{1}} & 0 \\ 0 & 0 & \chi_{1}\end{array}\right), \quad \Omega_{3}=\operatorname{diag}\left(\sigma_{y^{\star}}^{2}, \sigma_{g}^{2}, \sigma_{c a p^{\star}}^{2}\right), \quad \beta^{\prime}=\left(0, \theta_{0}, 0\right)$,

$$
E=\left(\begin{array}{ccc}
0 & 0 & 0 \\
0 & 0 & 1 \\
1 & 0 & 0
\end{array}\right), \quad D=\left(\begin{array}{ccc}
0 & 0 & -\eta_{1} \\
-\theta_{2} & 0 & -\theta_{1} \\
-\phi_{1} & 0 & 0
\end{array}\right)
$$

$B^{\prime}=\left(\begin{array}{ccc}d_{\pi} & 0 & -\mu \\ \eta_{2} & 0 & 0 \\ \eta_{3} & 0 & 0 \\ \eta_{4} & 0 & 0 \\ \eta_{5} & 0 & 0 \\ 0 & \theta_{2} & \phi_{1} \\ \eta_{1} & \theta_{1} & 0 \\ 0 & 0 & \eta_{o b} \\ 0 & 0 & \mu_{L} \times \mathrm{b}_{L}\left(1, \theta_{1}^{L}, \theta_{2}^{L}\right) \\ \vdots & \vdots & \vdots \\ 0 & 0 & \mu_{L} \times \mathrm{b}_{L}\left(j_{\max }, \theta_{1}^{L}, \theta_{2}^{L}\right) \\ 0 & 0 & \mu_{S} \times \mathrm{b}_{S}\left(1, \theta_{1}^{S}, \theta_{2}^{S}\right) \\ \vdots & \vdots & \vdots \\ 0 & 0 & \mu_{S} \times \mathrm{b}_{S}\left(j_{\max }, \theta_{1}^{S}, \theta_{2}^{S}\right) \\ 0 & 0 & \mu_{C} \times \mathrm{b}_{C}\left(1, \theta_{1}^{C}, \theta_{2}^{C}\right) \\ \vdots & \vdots & \vdots \\ 0 & 0 & \mu_{C} \times \mathrm{b}_{C}\left(j_{\max }, \theta_{1}^{C}, \theta_{2}^{C}\right)\end{array}\right), \Omega_{4}=\operatorname{diag}\left(\sigma_{\pi}^{2}, \sigma_{c a p}^{2}, \sigma_{y}^{2}\right)$ 
We stack all the parameters to be estimated from Equation $(\mathrm{C} .1)$ and $\overline{C .2}$ in a vector $\Gamma \in \mathbb{R}^{28}$ :

$$
\begin{array}{r}
\Gamma=\left(\phi_{g_{0}}, \chi_{0}, \phi_{g_{1}}, \chi_{1}, \sigma_{y^{\star}}^{2}, \sigma_{g}^{2}, \sigma_{c a p^{\star}}^{2}, \theta_{0}, \theta_{1}, \theta_{2}, \phi_{1}, d_{\pi}, \eta_{o b s}, \eta_{1}, \eta_{2}, \eta_{3}, \eta_{4}, \eta_{5}, \mu, \ldots\right. \\
\left.\theta_{1}^{L}, \theta_{2}^{L}, \theta_{1}^{S}, \theta_{2}^{S}, \theta_{1}^{C}, \theta_{2}^{C}, \sigma_{\pi}^{2}, \sigma_{c a p}^{2}, \sigma_{y}^{2}\right)^{\prime}
\end{array}
$$

Under the same Gaussian assumptions presented in Appendix $\mathrm{A}$ and $\mathrm{B}$, we obtain:

$$
\begin{aligned}
& \phi_{t}(\Gamma)=\phi_{t-1}(\Gamma)+\frac{N}{2} \ln (2 \pi)+\frac{1}{2} \ln \left|F_{t}\right|+\frac{1}{2} R_{t}^{\prime} F_{t}^{-1} R_{t}, \\
& R_{t}=Y_{t}-\beta-E \hat{X}_{t \mid t-1}-D \hat{X}_{t-1 \mid t-1}-B \hat{Z}_{t-1 \mid t-1}, \\
& F_{t}=E P_{t \mid t-1} E^{\prime}+\Omega_{4}+D P_{t-1 \mid t-1} D^{\prime}+E A P_{t-1 \mid t-1} D^{\prime}+D P_{t-1 \mid t-1} A^{\prime} E^{\prime},
\end{aligned}
$$

where $\phi_{0}(\Gamma)=-\log [p(\Gamma)]$ is the prior.

Again, we split $\Gamma$ in 4 blocks to specify the prior densities according to an independant NormalWishart setting :

$$
\Gamma_{1}=\left(\phi_{g_{0}}, \phi_{g_{1}}, \chi_{0}, \chi_{1}\right)^{\prime} \sim \mathcal{M V N}\left(\tau_{1}, \Sigma_{1}\right)
$$

where $\tau_{1}$ is found in previous OLS estimations on filtered series and we set $\Sigma_{1}=0.005 \times I_{3}$.

$$
\Gamma_{2}=\left(\theta_{0}, \theta_{1}, \theta_{2}, \phi_{1}, d_{\pi}, \eta_{o b s}, \eta_{1}, \eta_{2}, \eta_{3}, \eta_{4}, \eta_{5}, \mu, \theta_{1}^{L}, \theta_{2}^{L}, \theta_{1}^{S}, \theta_{2}^{S}, \theta_{1}^{C}, \theta_{2}^{C}\right)^{\prime} \sim \mathcal{M V N}\left(\tau_{2}, \Sigma_{2}\right)
$$

where $\tau_{2}$ is found in previous OLS estimations on filtered series and we set $\Sigma_{2}=0.005 \times I_{18}$.

Besides, elements of $\Omega_{3}$ and $\Omega_{4}$ contained in $\Gamma_{3}$ and $\Gamma_{4}$ follow inverse-Gamma distributions:

$$
\left(\sigma_{y^{\star}}^{2}, \sigma_{g}^{2}, \sigma_{c a p^{\star}}^{2}, \sigma_{\pi}^{2}, \sigma_{c a p}^{2}, \sigma_{y}^{2}\right) \sim \Gamma^{-1}\left(\alpha_{4}, \beta_{4}\right),
$$

where we set $\alpha_{4}=1$, and $\beta_{4}=0.02$.

The Kalman Filter algorithm does not differ from the one described in Appendix B

Starting values $\hat{X}_{0 \mid 0}$ are the HP-filtered trends of $\left(y_{t}, y_{t}-y_{t-1}, c a p_{t}\right) . \Gamma_{0}$ is initialized with OLS estimates and we set $P_{0 \mid 0}=I_{3}$ 


\section{Data}

\begin{tabular}{|c|c|c|}
\hline Variable name & Data & Source \\
\hline $\mathrm{y}^{(n)}$ & nominal yields & Ministry of Finance \\
\hline$R E E R$ & $\begin{array}{l}\text { Real Effective Exchange } \\
\text { Rate }\end{array}$ & Bank of Japan*** \\
\hline Policy & $\begin{array}{l}\text { Call Rate, Uncollateral- } \\
\text { ized Overnight/Average } \\
(\% \text { per annum) }\end{array}$ & Bank of Japan \\
\hline BOJbase & M3 growth & FRED database \\
\hline$\pi$ & Consumer Price & OECD \\
\hline$\pi^{\text {energy }}$ & Energy Price & OECD \\
\hline$\pi^{U S, P P I}$ & $\begin{array}{l}\text { Producer Price Index (To- } \\
\text { tal, US) }\end{array}$ & OECD \\
\hline$c a p$ & $\begin{array}{l}\text { Rate of Capacity Utili- } \\
\text { sation, EC and National } \\
\text { Indicators, Manufacturing } \\
\text { SA }\end{array}$ & OECD/Datastream*** \\
\hline y (real GDP per capita) & $\begin{array}{l}\text { Quarterly nominal GDP } \\
(\mathrm{AR}, \mathrm{SA}) \text {, level }\end{array}$ & $\begin{array}{ll}\text { Cabinet } & \text { Of- } \\
\text { fice/Datastream }\end{array}$ \\
\hline y (real GDP per capita) & GDP Deflator & OECD/Datastream \\
\hline y (real GDP per capita) & Yearly population level & World Bank* \\
\hline financial & $\begin{array}{l}\text { Residential property } \\
\text { prices: all houses (Tokyo) } \\
\text { - pure price }\end{array}$ & BIS/Datastream \\
\hline financial & Share prices index & $\begin{array}{l}\text { Oxford Eco- } \\
\text { nomics/Datastream }\end{array}$ \\
\hline financial & $\begin{array}{l}\text { Credit to Private Non- } \\
\text { Financial Sector, Pro- } \\
\text { vided by Domestic Banks, } \\
\text { Adjusted For Breaks, } \\
\text { Market Value }\end{array}$ & BIS/Datastream*** \\
\hline$\pi^{\text {wages }}$ & $\begin{array}{l}\text { Labour Market wage rate } \\
\text { index }\end{array}$ & IMF/Datastream \\
\hline TOT $T^{\text {emerg }}$ & $\begin{array}{l}\text { Terms of trade emerging } \\
\text { and developing countries } \\
\text { (goods and services) }\end{array}$ & IMF/Datastream** \\
\hline$o b$ & $\begin{array}{l}\text { Government Balance (\% } \\
\text { GDP) }\end{array}$ & $\begin{array}{l}\text { Oxford Eco- } \\
\text { nomics/Datastream }\end{array}$ \\
\hline
\end{tabular}

Table 7: * Interpolated from yearly to quarterly data using a Quadratic Match average method Population for 2017 is assumed to be as in 2016:Q4

** Interpolated from yearly to quarterly data using a Quadratic Match average method *** Data are divided by their standard deviation for homogeneity with other series 


\section{E Results for NS model}

\begin{tabular}{|c|c|c|c|c|c|}
\hline Nelson-Siegel & Initial values (Kalman) & \multicolumn{3}{|c|}{ Posterior (Results) } & \\
\hline RMSE & 0.228 & 0.165 & & & \\
\hline Log-Likelihood & 717 & 4526 & Standard errors & Z-ratio & P-values \\
\hline$\mu_{L}^{\prime}$ & 0.005 & 0.062 & 0.031 & 2.017 & 0.0437 \\
\hline$\mu_{S}^{\prime}$ & 0.030 & -0.034 & 0.033 & -1.047 & 0.2950 \\
\hline$\mu_{C}^{\prime}$ & -0.021 & -0.129 & 0.066 & -1.947 & 0.0515 \\
\hline$\theta_{11}^{\prime}$ & 0.998 & 0.997 & 0.007 & 148.072 & 0.0000 \\
\hline$\theta_{12}^{\prime}$ & -0.014 & -0.006 & 0.007 & -0.829 & 0.4072 \\
\hline$\theta_{13}^{\prime}$ & -0.044 & 0.005 & 0.015 & 0.308 & 0.7580 \\
\hline$\theta_{21}^{\prime}$ & -0.002 & 0.005 & 0.012 & 0.438 & 0.6612 \\
\hline$\theta_{22}^{\prime}$ & 0.973 & 0.998 & 0.013 & 78.980 & 0.0000 \\
\hline$\theta_{23}^{\prime}$ & 0.057 & 0.054 & 0.026 & 2.066 & 0.0389 \\
\hline$\theta_{31}^{\prime}$ & 0.007 & 0.025 & 0.012 & 2.117 & 0.0342 \\
\hline$\theta_{32}^{\prime}$ & 0.009 & -0.023 & 0.013 & -1.784 & 0.0744 \\
\hline$\theta_{33}^{\prime}$ & 0.937 & 0.897 & 0.026 & 34.162 & 0.0000 \\
\hline$\sigma_{\zeta_{11}}^{\prime}$ & 0.020 & 0.055 & 0.006 & 9.657 & 0.0000 \\
\hline$\sigma_{\zeta_{12}}^{\prime 11}$ & 0.002 & -0.048 & 0.005 & -8.980 & 0.0000 \\
\hline$\sigma_{\zeta_{13}}^{\prime 12}$ & 0.006 & -0.068 & 0.010 & -6.602 & 0.0000 \\
\hline & 0.013 & 0.062 & 0.006 & 10.280 & 0.0000 \\
\hline$\sigma_{\zeta_{23}}^{\prime 22}$ & 0.003 & 0.070 & 0.011 & 6.414 & 0.0000 \\
\hline$\sigma_{\zeta_{33}}^{\prime 233}$ & 0.010 & 0.257 & 0.027 & 9.698 & 0.0000 \\
\hline$\sigma_{\epsilon}^{\prime}$ & 0.934 & 0.000 & 0.000 & 0.000 & 1.0000 \\
\hline$\sigma_{\epsilon_{22}}^{\prime 11}$ & 0.519 & 0.002 & 0.000 & 7.257 & 0.0000 \\
\hline$\sigma_{\epsilon_{33}}^{\prime 22}$ & 0.267 & 0.001 & 0.000 & 8.058 & 0.0000 \\
\hline$\sigma_{\epsilon_{44}}^{\prime}$ & 0.106 & 0.000 & 0.000 & 2.564 & 0.0103 \\
\hline$\sigma_{\epsilon_{55}}^{\prime t_{4}}$ & 0.032 & 0.002 & 0.000 & 10.272 & 0.0000 \\
\hline$\sigma_{\epsilon_{66}}^{\prime}$ & 0.006 & 0.005 & 0.000 & 11.928 & 0.0000 \\
\hline$\sigma_{\epsilon_{77}}^{\prime}$ & 0.008 & 0.003 & 0.000 & 11.366 & 0.0000 \\
\hline$\sigma_{\epsilon_{88}^{\prime}}^{\prime}$ & 0.019 & 0.000 & 0.000 & 2.481 & 0.0131 \\
\hline $\begin{array}{l}\epsilon_{88} \\
\sigma_{\epsilon}^{\prime}\end{array}$ & 0.035 & 0.004 & 0.000 & 10.924 & 0.0000 \\
\hline$\sigma_{\epsilon_{1010}^{\prime}}^{\prime 99}$ & 0.050 & 0.014 & 0.001 & 11.827 & 0.0000 \\
\hline$\lambda$ & 1.368 & 2.409 & 0.063 & 38.210 & 0.0000 \\
\hline
\end{tabular}

Table 8: Parameters of NS model

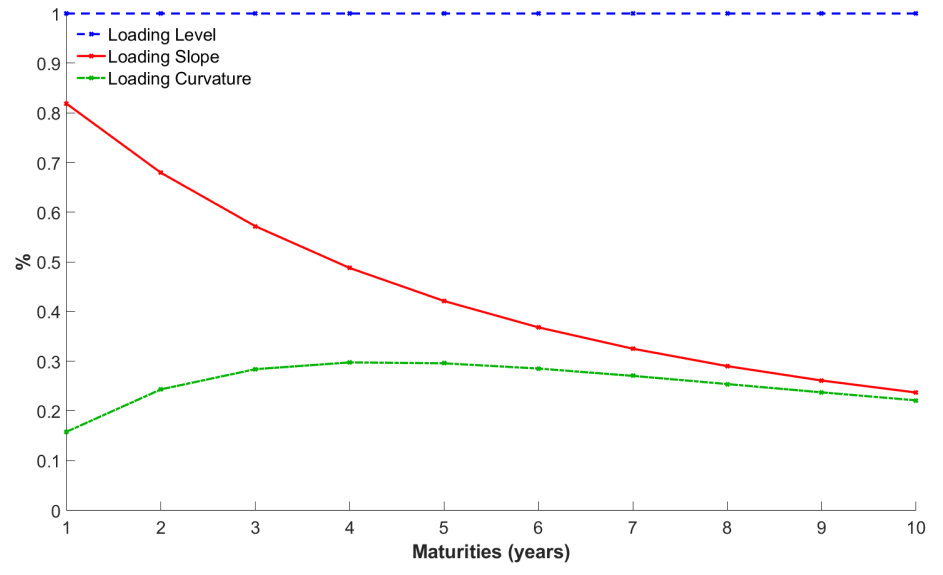

Figure 10: Loadings of the yield curve 


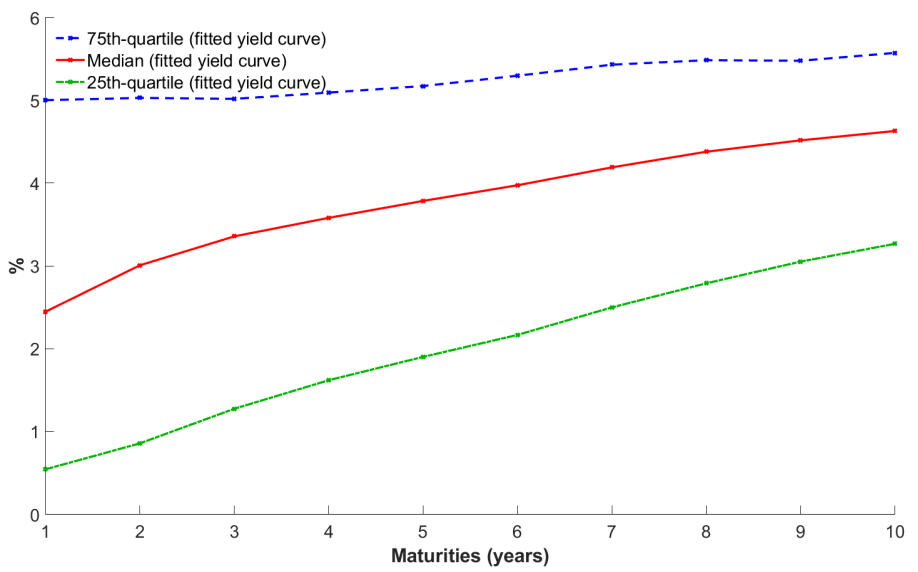

Figure 11: Yield curve during the pre-regime period

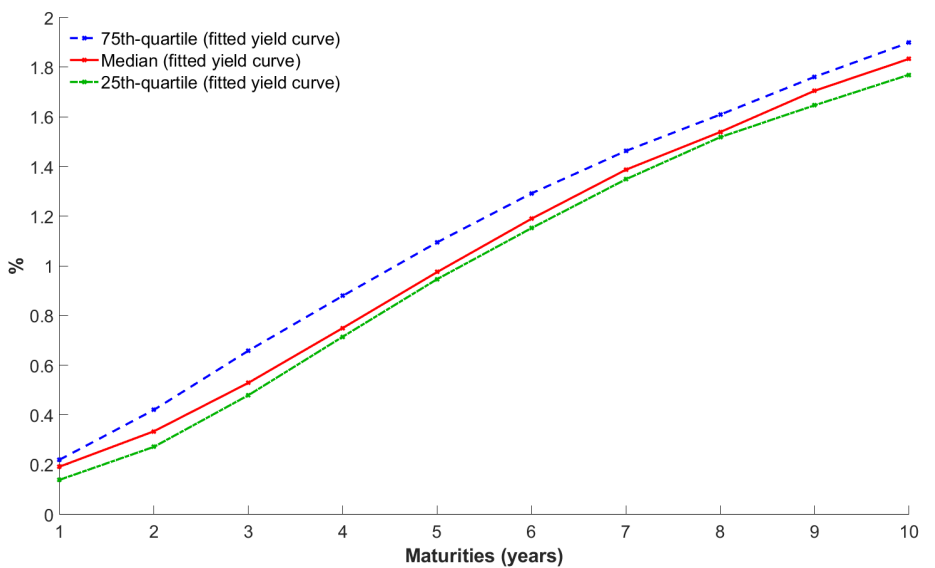

Figure 12: Yield curve during the ZIRP regime period

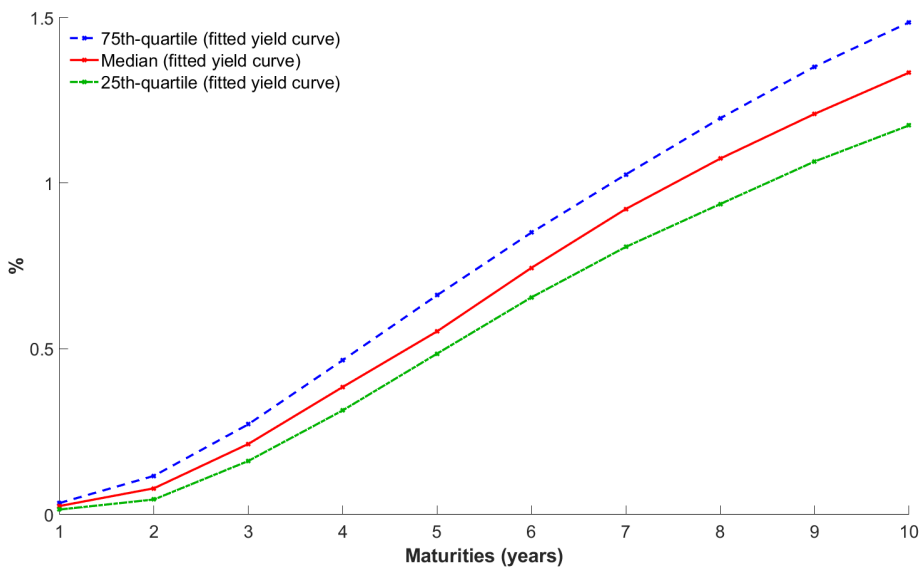

Figure 13: Yield curve during the QE regime period 


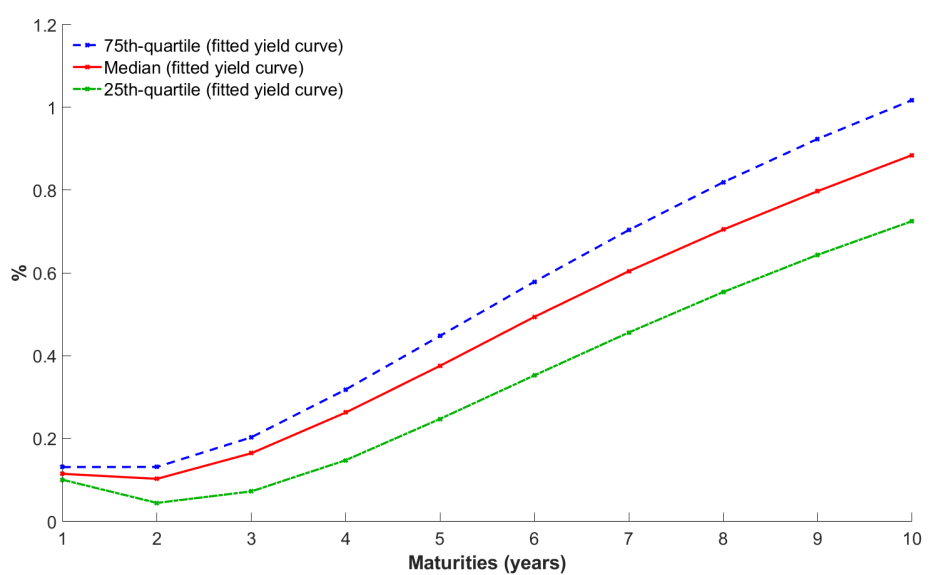

Figure 14: Yield curve during the CME regime period

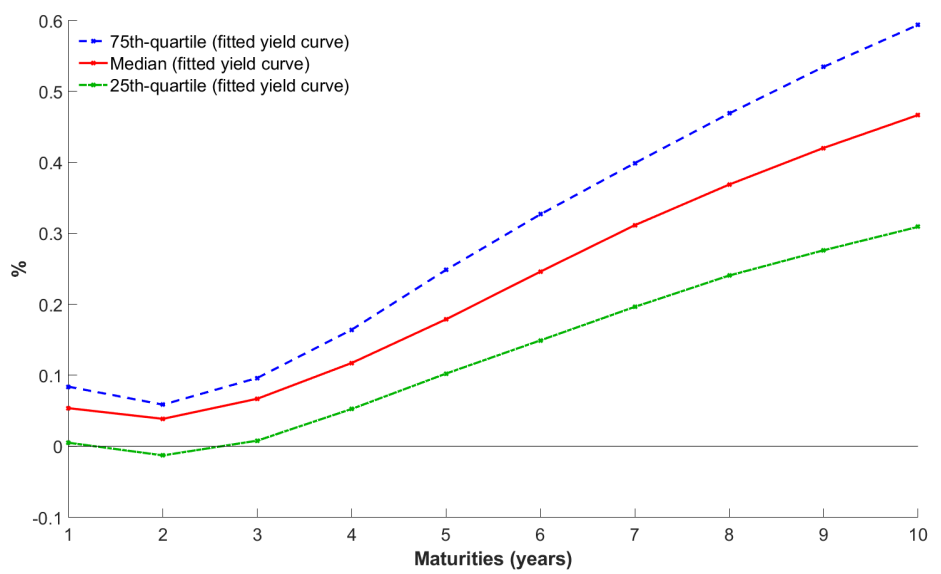

Figure 15: Yield curve during the QQE regime period

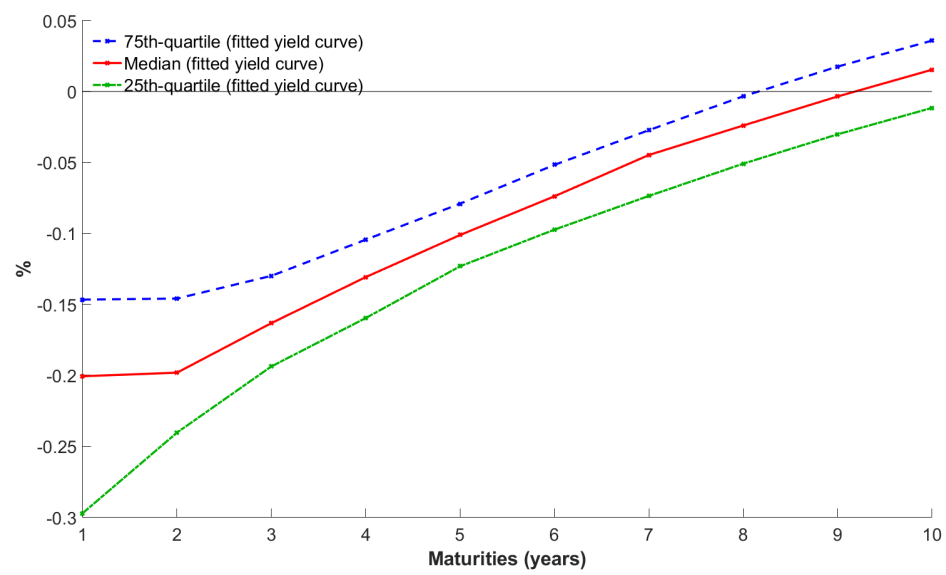

Figure 16: Yield curve during the QQE with yield curve control regime period 


\section{F Results for MIDAS-VAR model}

\begin{tabular}{|c|c|c|c|c|c|}
\hline MIDAS-VAR & Initial values (Kalman) & \multicolumn{3}{|c|}{ Posterior (Results) } & \\
\hline RMSE & 0.607 & 0.547 & & & \\
\hline Log-Likelihood & -1284 & -920 & Standard errors & Z-ratio & P-values \\
\hline$\beta$ & 0.330 & 0.328 & 0.001 & 220.66 & 0.00 \\
\hline$\delta$ & 0.333 & 0.331 & 0.002 & 136.43 & 0.00 \\
\hline$\eta$ & 0.333 & 0.331 & 0.004 & 91.41 & 0.00 \\
\hline$\phi_{L}$ & 0.170 & 0.224 & 0.025 & 8.91 & 0.00 \\
\hline$\phi_{S}$ & 0.192 & 0.146 & 0.025 & 5.76 & 0.00 \\
\hline$\phi_{C}$ & 0.156 & 0.176 & 0.021 & 8.21 & 0.00 \\
\hline$\alpha_{L_{1}}$ & 0.027 & -0.002 & 0.020 & -0.09 & 0.93 \\
\hline$\alpha_{L_{2}}$ & -0.143 & -0.108 & 0.027 & -3.92 & 0.00 \\
\hline$\alpha_{L_{3}}$ & -0.123 & -0.099 & 0.041 & -2.40 & 0.02 \\
\hline$\alpha_{L_{4}}$ & -0.394 & -0.475 & 0.053 & -8.95 & 0.00 \\
\hline$\alpha_{L_{5}}$ & 0.025 & 0.028 & 0.025 & 1.13 & 0.26 \\
\hline$\alpha_{L_{6}}$ & 0.059 & 0.043 & 0.039 & 1.09 & 0.28 \\
\hline$\gamma_{S_{1}}$ & -0.014 & -0.146 & 0.024 & -5.95 & 0.00 \\
\hline$\gamma_{S_{2}}$ & -0.088 & -0.041 & 0.019 & -2.22 & 0.03 \\
\hline$\gamma_{S_{3}}$ & 0.007 & -0.015 & 0.025 & -0.60 & 0.55 \\
\hline$\gamma_{S_{4}}$ & -0.216 & -0.149 & 0.057 & -2.62 & 0.01 \\
\hline$\gamma_{S_{5}}$ & 0.021 & 0.016 & 0.014 & 1.11 & 0.27 \\
\hline$\gamma_{S_{6}}$ & -0.008 & 0.069 & 0.027 & 2.52 & 0.01 \\
\hline$\kappa_{C_{1}}$ & 0.001 & 0.007 & 0.009 & 0.77 & 0.44 \\
\hline$\kappa_{C_{2}}$ & -0.012 & -0.017 & 0.013 & -1.24 & 0.21 \\
\hline$\kappa_{C_{3}}$ & -0.034 & -0.018 & 0.023 & -0.78 & 0.44 \\
\hline$\kappa_{C_{4}}$ & -0.075 & -0.114 & 0.027 & -4.18 & 0.00 \\
\hline$\kappa_{C_{5}}$ & -0.008 & -0.006 & 0.013 & -0.47 & 0.64 \\
\hline$\kappa_{C_{6}}$ & 0.003 & -0.030 & 0.025 & -1.21 & 0.22 \\
\hline$\alpha_{11}$ & 0.002 & -0.021 & 0.016 & -1.30 & 0.19 \\
\hline$\alpha_{12}$ & 0.010 & 0.022 & 0.031 & 0.69 & 0.49 \\
\hline$\alpha_{13}$ & 0.055 & 0.054 & 0.025 & 2.21 & 0.03 \\
\hline$\alpha_{14}$ & 0.038 & 0.057 & 0.014 & 4.13 & 0.00 \\
\hline$\alpha_{15}$ & 0.001 & 0.036 & 0.015 & 2.39 & 0.02 \\
\hline$\alpha_{16}$ & 0.027 & 0.018 & 0.030 & 0.61 & 0.54 \\
\hline$\gamma_{11}$ & 0.014 & 0.185 & 0.045 & 4.13 & 0.00 \\
\hline$\gamma_{12}$ & 0.053 & -0.020 & 0.038 & -0.53 & 0.59 \\
\hline$\gamma_{13}$ & -0.052 & -0.050 & 0.025 & -1.98 & 0.05 \\
\hline$\gamma_{14}$ & 0.007 & 0.021 & 0.017 & 1.23 & 0.22 \\
\hline$\gamma_{15}$ & -0.008 & -0.047 & 0.029 & -1.62 & 0.10 \\
\hline$\gamma_{16}$ & -0.057 & -0.047 & 0.027 & -1.71 & 0.09 \\
\hline$\kappa_{11}$ & -0.035 & -0.038 & 0.042 & -0.89 & 0.38 \\
\hline$\kappa_{12}$ & 0.071 & 0.058 & 0.057 & 1.01 & 0.31 \\
\hline$\kappa_{13}$ & -0.009 & -0.050 & 0.046 & -1.10 & 0.27 \\
\hline$\kappa_{14}$ & 0.027 & 0.047 & 0.027 & 1.76 & 0.08 \\
\hline$\kappa_{15}$ & -0.003 & -0.052 & 0.045 & -1.15 & 0.25 \\
\hline$\kappa_{16}$ & 0.002 & 0.015 & 0.051 & 0.30 & 0.76 \\
\hline
\end{tabular}

Table 9: Parameters of the MIDAS-VAR model 


\begin{tabular}{|c|c|c|c|c|c|}
\hline MIDAS-VAR & Initial values (Kalman) & \multicolumn{3}{|c|}{ Posterior } & \\
\hline RMSE & 0.607 & 0.547 & & & \\
\hline Log-Likelihood & -1284 & -920 & Standard errors & Z-ratio & P-values \\
\hline$\rho_{11}$ & 0.960 & 1.099 & 0.032 & 34.26 & 0.00 \\
\hline$\rho_{12}$ & 0.251 & 0.143 & 0.035 & 4.12 & 0.00 \\
\hline$\rho_{13}$ & 0.044 & 0.020 & 0.019 & 1.06 & 0.29 \\
\hline$\rho_{14}$ & 0.029 & 0.034 & 0.012 & 2.90 & 0.00 \\
\hline$\rho_{15}$ & -0.024 & -0.049 & 0.021 & -2.29 & 0.02 \\
\hline$\rho_{16}$ & 0.022 & 0.031 & 0.022 & 1.41 & 0.16 \\
\hline$\rho_{22}$ & 0.785 & 0.773 & 0.041 & 18.69 & 0.00 \\
\hline$\rho_{23}$ & -0.024 & -0.019 & 0.032 & -0.59 & 0.56 \\
\hline$\rho_{24}$ & 0.009 & 0.012 & 0.018 & 0.66 & 0.51 \\
\hline$\rho_{25}$ & 0.017 & 0.041 & 0.016 & 2.56 & 0.01 \\
\hline$\rho_{26}$ & 0.056 & 0.067 & 0.039 & 1.73 & 0.08 \\
\hline$\rho_{33}$ & 0.658 & 0.662 & 0.049 & 13.60 & 0.00 \\
\hline$\rho_{34}$ & 0.072 & 0.071 & 0.028 & 2.53 & 0.01 \\
\hline$\rho_{35}$ & -0.001 & 0.020 & 0.018 & 1.10 & 0.27 \\
\hline$\rho_{36}$ & -0.188 & -0.187 & 0.055 & -3.41 & 0.00 \\
\hline$\rho_{44}$ & 0.974 & 1.010 & 0.036 & 27.74 & 0.00 \\
\hline$\rho_{45}$ & 0.007 & 0.095 & 0.053 & 1.78 & 0.08 \\
\hline$\rho_{46}$ & -0.046 & -0.019 & 0.051 & -0.38 & 0.70 \\
\hline$\rho_{55}$ & 0.995 & 0.986 & 0.010 & 94.47 & 0.00 \\
\hline$\rho_{56}$ & 0.071 & 0.061 & 0.039 & 1.56 & 0.12 \\
\hline$\rho_{66}$ & -0.068 & -0.113 & 0.057 & -2.00 & 0.05 \\
\hline $\mathrm{L}_{11}^{\star}$ & 0.013 & 0.159 & 0.031 & 5.14 & 0.00 \\
\hline $\mathrm{L}_{22}^{\star}$ & 0.008 & 0.100 & 0.029 & 3.49 & 0.00 \\
\hline $\mathrm{L}_{33}^{\star}$ & 0.003 & 0.001 & 0.001 & 1.33 & 0.18 \\
\hline $\mathrm{S}_{11}^{\star}$ & 0.029 & 0.186 & 0.030 & 6.21 & 0.00 \\
\hline $\mathrm{S}_{22}^{\star}$ & 0.016 & 0.111 & 0.024 & 4.65 & 0.00 \\
\hline $\mathrm{S}_{33}^{\star}$ & 0.007 & 0.054 & 0.016 & 3.40 & 0.00 \\
\hline $\mathrm{C}_{11}^{\star}$ & 0.022 & 0.688 & 0.168 & 4.09 & 0.00 \\
\hline $\mathrm{C}_{22}^{\star}$ & 0.012 & 0.004 & 0.003 & 1.53 & 0.13 \\
\hline $\mathrm{C}_{33}^{\star}$ & 0.005 & 0.002 & 0.001 & 1.51 & 0.13 \\
\hline $\mathrm{L}_{11}$ & 0.148 & 0.051 & 0.021 & 2.38 & 0.02 \\
\hline $\mathrm{L}_{22}$ & 0.128 & 0.057 & 0.024 & 2.39 & 0.02 \\
\hline $\mathrm{L}_{33}$ & 0.091 & 0.099 & 0.013 & 7.43 & 0.00 \\
\hline $\mathrm{S}_{11}$ & 0.164 & 0.040 & 0.015 & 2.62 & 0.01 \\
\hline $\mathrm{S}_{22}$ & 0.144 & 0.060 & 0.020 & 2.95 & 0.00 \\
\hline $\mathrm{S}_{33}$ & 0.090 & 0.037 & 0.014 & 2.68 & 0.01 \\
\hline $\mathrm{C}_{11}$ & 0.770 & 0.348 & 0.131 & 2.66 & 0.01 \\
\hline $\mathrm{C}_{22}$ & 0.629 & 0.664 & 0.089 & 7.45 & 0.00 \\
\hline $\mathrm{C}_{33}$ & 0.412 & 0.417 & 0.056 & 7.44 & 0.00 \\
\hline $\mathrm{m}_{11}$ & 0.033 & 0.018 & 0.003 & 5.24 & 0.00 \\
\hline $\mathrm{m}_{22}$ & 0.079 & 0.077 & 0.010 & 7.59 & 0.00 \\
\hline $\mathrm{m}_{33}$ & 0.289 & 0.281 & 0.036 & 7.73 & 0.00 \\
\hline $\mathrm{m}_{44}$ & 0.383 & 0.166 & 0.033 & 5.02 & 0.00 \\
\hline $\mathrm{m}_{55}$ & 0.088 & 0.084 & 0.011 & 7.72 & 0.00 \\
\hline $\mathrm{m}_{66}$ & 0.363 & 0.327 & 0.043 & 7.58 & 0.00 \\
\hline
\end{tabular}

Table 10: Parameters of the MIDAS-VAR model

Figures 17, 18, $19,20,21$ and 22 show the yield curve gap across different monetary policy regimes in Japan. 


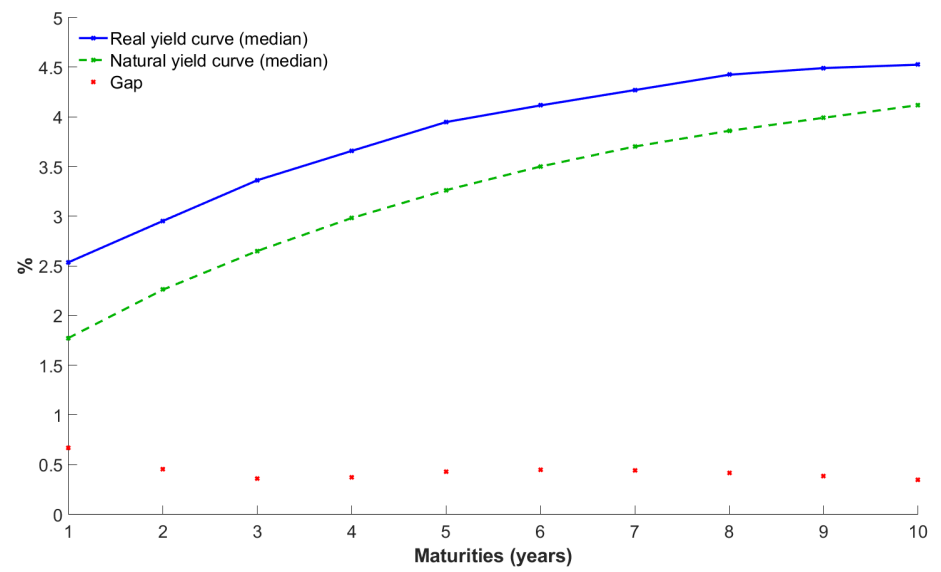

Figure 17: Yield curve gap during the pre-regimes period

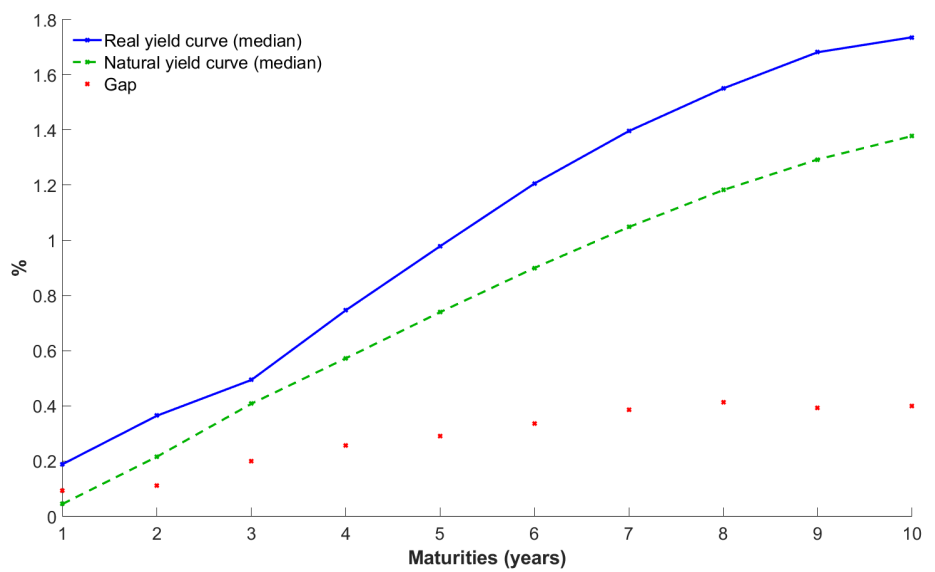

Figure 18: Yield curve gap during the ZIRP regime period

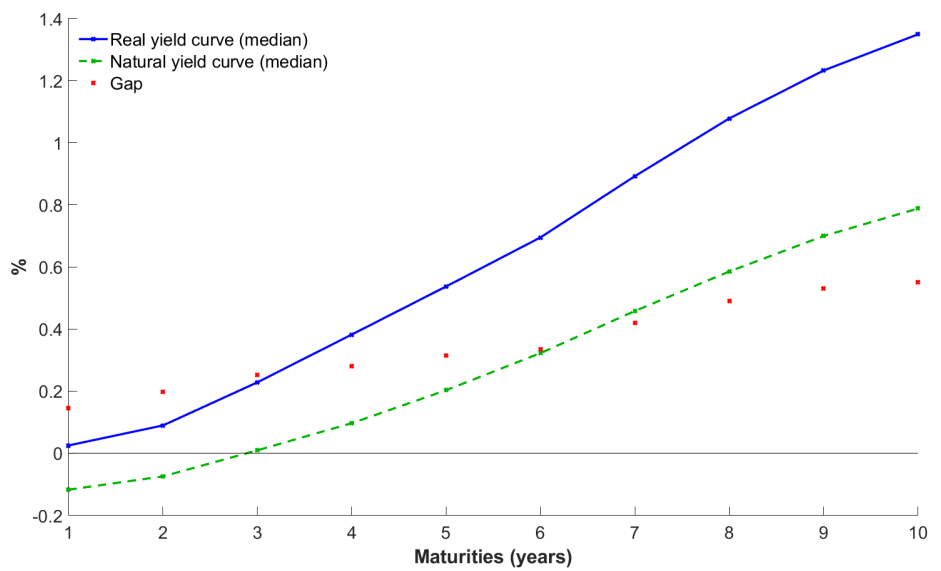

Figure 19: Yield curve gap during the QE regime period 


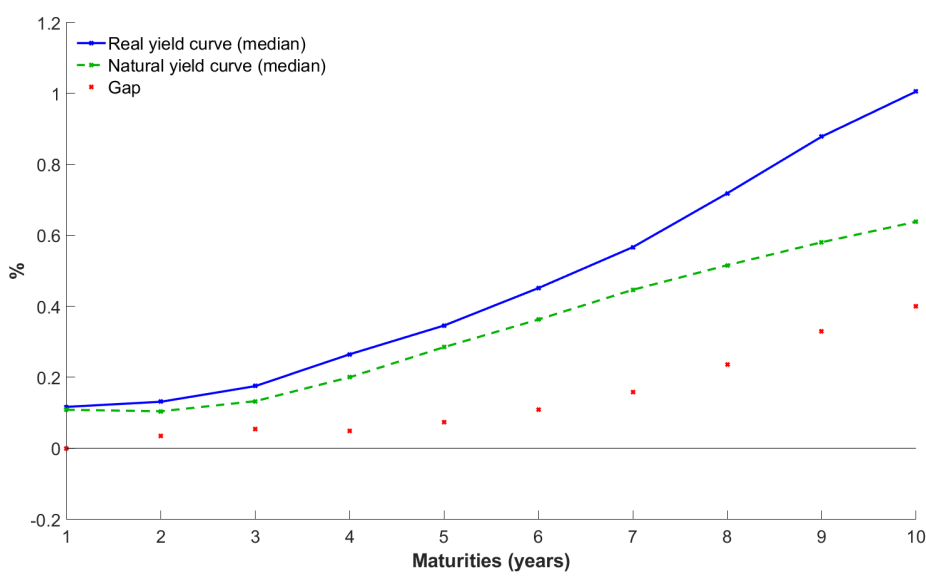

Figure 20: Yield curve gap during the CME regime period

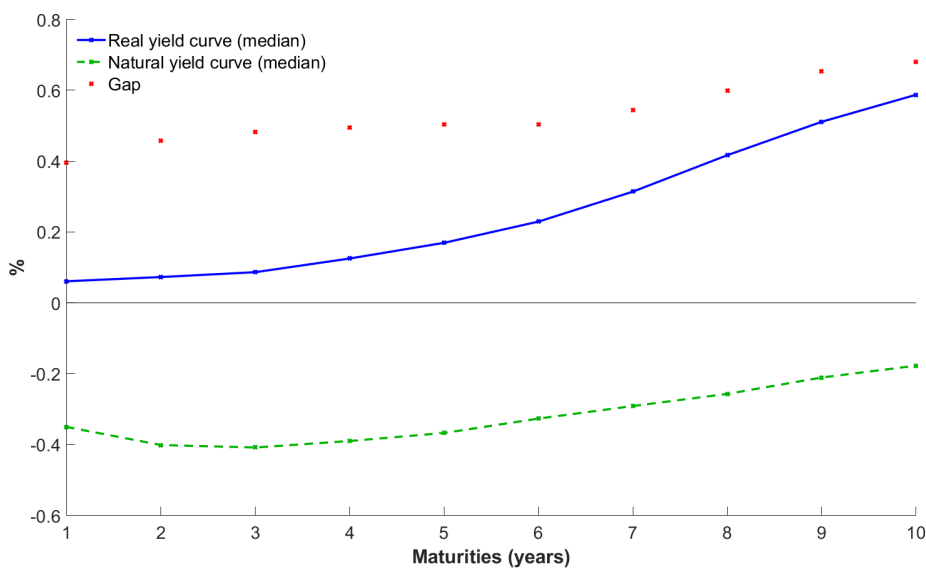

Figure 21: Yield curve gap during the QQE regime period

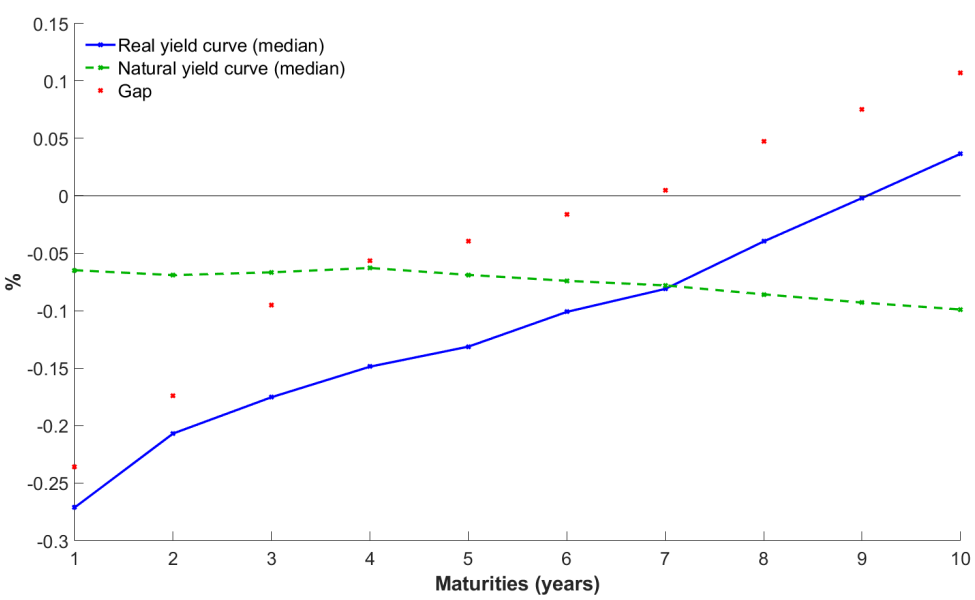

Figure 22: Yield curve gap during the QQE with yield curve control regime period

Figures 23 24 and 25 show the level gap, slope gap and the curvature gap across different monetary 
policy regimes in Japan.

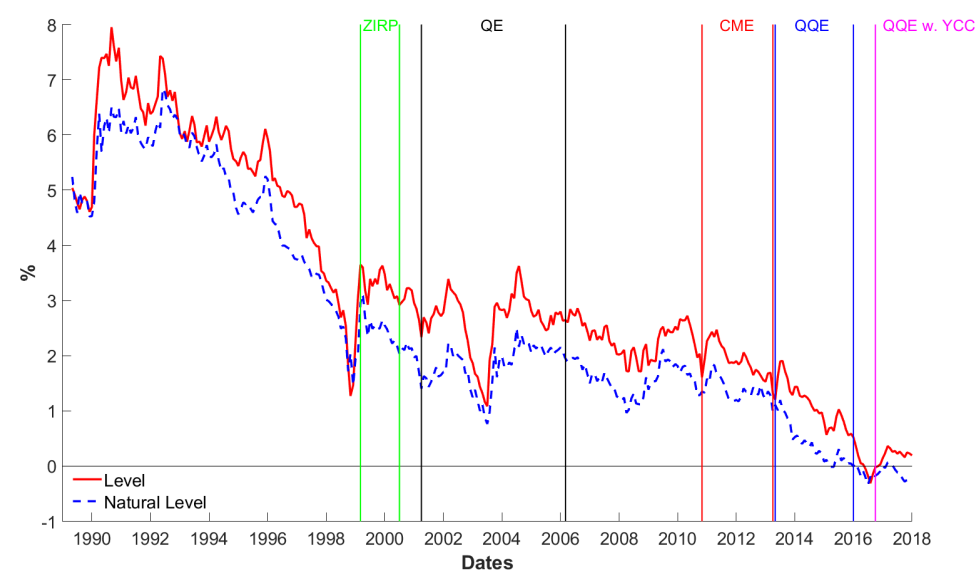

Figure 23: Level gap under different monetary policy regimes

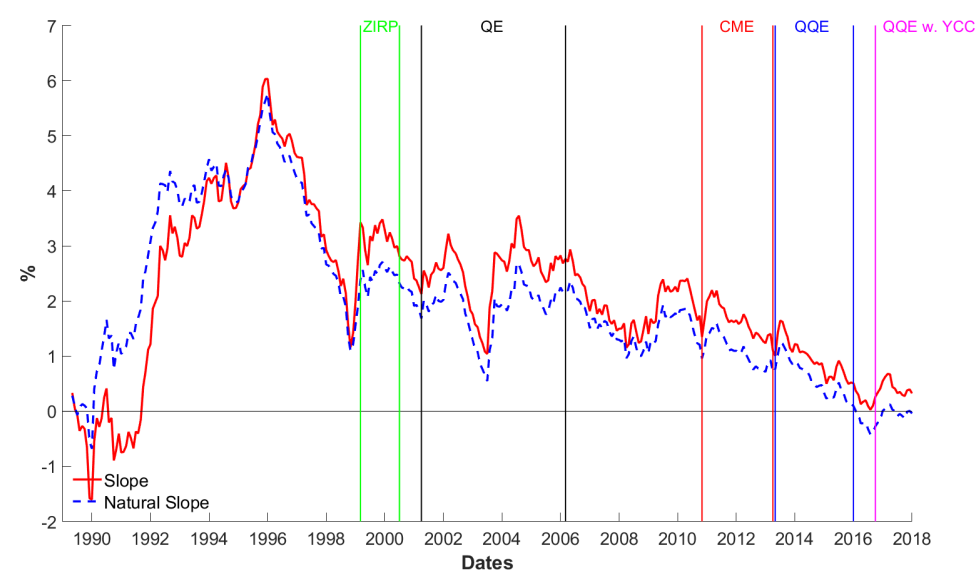

Figure 24: Slope gap under different monetary policy regimes

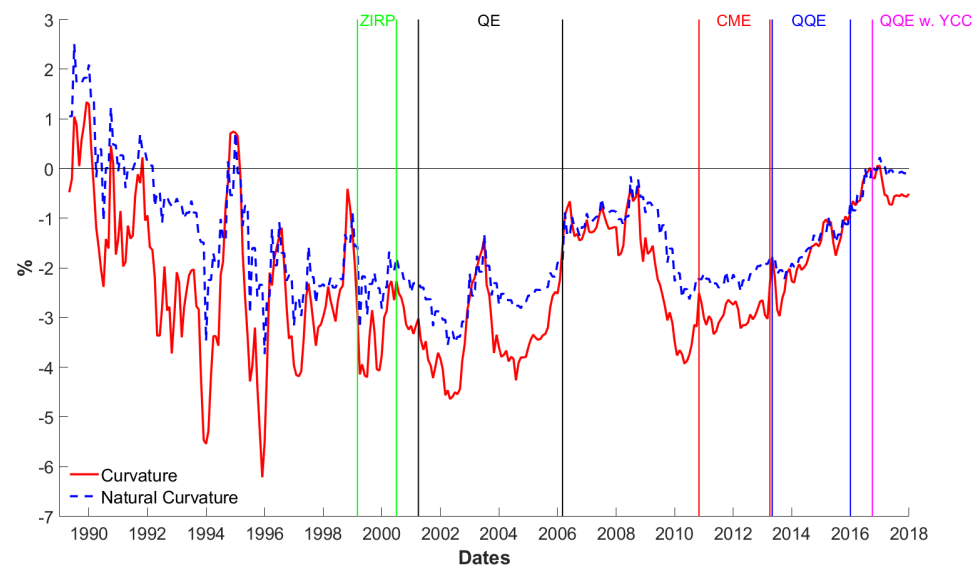

Figure 25: Curvature gap under different monetary policy regimes 


\section{G Results for MIDAS model}

\begin{tabular}{|c|c|c|c|c|c|}
\hline MIDAS & Initial values (Kalman) & \multicolumn{3}{|c|}{ Posterior } & \\
\hline RMSE & $\mathbf{0 . 3 9 8}$ & 0.370 & & & \\
\hline Log-Likelihood & $\mathbf{- 1 6 3}$ & -133 & Standard errors & Z-ratio & P-values \\
\hline$\chi_{0}$ & -0.041 & -0.022 & 0.021 & -1.08 & 0.281683539 \\
$\phi_{g_{0}}$ & 0.000 & 0.070 & 0.040 & 1.75 & 0.079538818 \\
$\phi_{g_{1}}$ & 0.976 & 0.246 & 0.089 & 2.77 & 0.00567438 \\
$\chi_{1}$ & 0.966 & 0.965 & 0.014 & 70.20 & 0 \\
$\sigma_{y^{\star}}^{2}$ & 0.000 & 0.002 & 0.001 & 1.95 & 0.051350525 \\
$\sigma_{g}^{2}$ & 0.000 & 0.170 & 0.023 & 7.29 & $3.1132 \mathrm{E}-13$ \\
$\sigma_{c a p^{\star}}^{2}$ & 0.005 & 0.002 & 0.001 & 1.78 & 0.075015937 \\
$\theta_{0}$ & 0.007 & 0.531 & 0.209 & 2.54 & 0.011179914 \\
$\eta_{1}$ & 0.259 & 0.210 & 0.046 & 4.56 & $5.08832 \mathrm{E}-06$ \\
$\theta_{2}$ & -0.140 & 1.027 & 0.199 & 5.17 & $2.35155 \mathrm{E}-07$ \\
$\theta_{1}$ & 0.996 & 0.746 & 0.096 & 7.77 & $7.60324 \mathrm{E}-15$ \\
$\phi_{1}$ & 0.778 & 0.924 & 0.034 & 27.56 & $3.0857 \mathrm{E}-167$ \\
$\mathrm{~d}_{\pi}$ & 0.019 & -0.078 & 0.083 & -0.94 & 0.347271653 \\
$\eta_{2}$ & -0.224 & -0.344 & 0.061 & -5.64 & $1.71773 \mathrm{E}-08$ \\
$\eta_{3}$ & 0.027 & 0.019 & 0.029 & 0.65 & 0.515224315 \\
$\eta_{4}$ & -0.033 & -0.028 & 0.012 & -2.26 & 0.023672322 \\
$\eta_{5}$ & 0.126 & 0.123 & 0.018 & 6.75 & $1.52503 \mathrm{E}-11$ \\
$\eta_{o b}$ & 0.076 & 0.047 & 0.021 & 2.24 & 0.024925381 \\
$\mu_{1}^{L}$ & 0.000 & -0.076 & 0.021 & -3.66 & 0.000250085 \\
$\theta_{1}^{L}$ & 0.020 & 0.032 & 0.314 & 0.10 & 0.918355008 \\
$\theta_{2}^{L}$ & 0.020 & 0.048 & 0.101 & 0.47 & 0.63482697 \\
$\theta_{1}^{S}$ & 0.020 & 0.029 & 0.316 & 0.09 & 0.927465717 \\
$\theta_{2}^{S}$ & -0.201 & -0.169 & 0.335 & -0.50 & 0.614356266 \\
$\theta_{1}^{C}$ & -0.200 & -0.174 & 0.314 & -0.55 & 0.579490017 \\
$\theta_{2}^{C}$ & -0.200 & -0.139 & 0.242 & -0.57 & 0.567447228 \\
$\sigma_{\pi}^{2}$ & 0.215 & 0.131 & 0.017 & 7.68 & $1.62663 \mathrm{E}-14$ \\
$\sigma_{c a p}^{2}$ & 0.063 & 0.021 & 0.007 & 3.05 & 0.002277343 \\
$\sigma_{y}^{2}$ & 0.138 & 0.009 & 0.004 & 2.18 & 0.029582637 \\
\hline
\end{tabular}

Table 11: Parameters of the MIDAS model

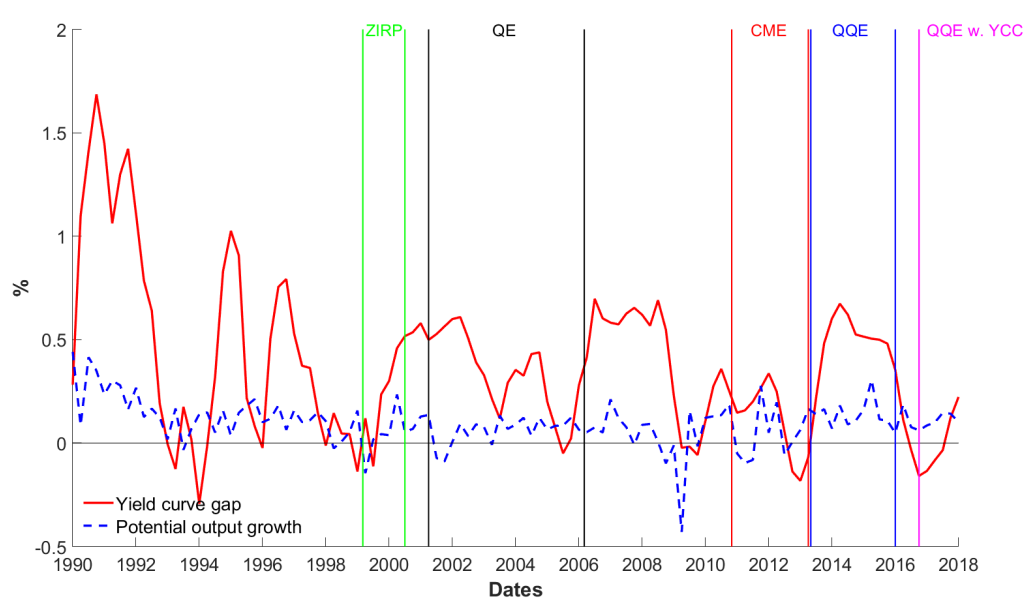

Figure 26: Potential output growth and yield curve gap 


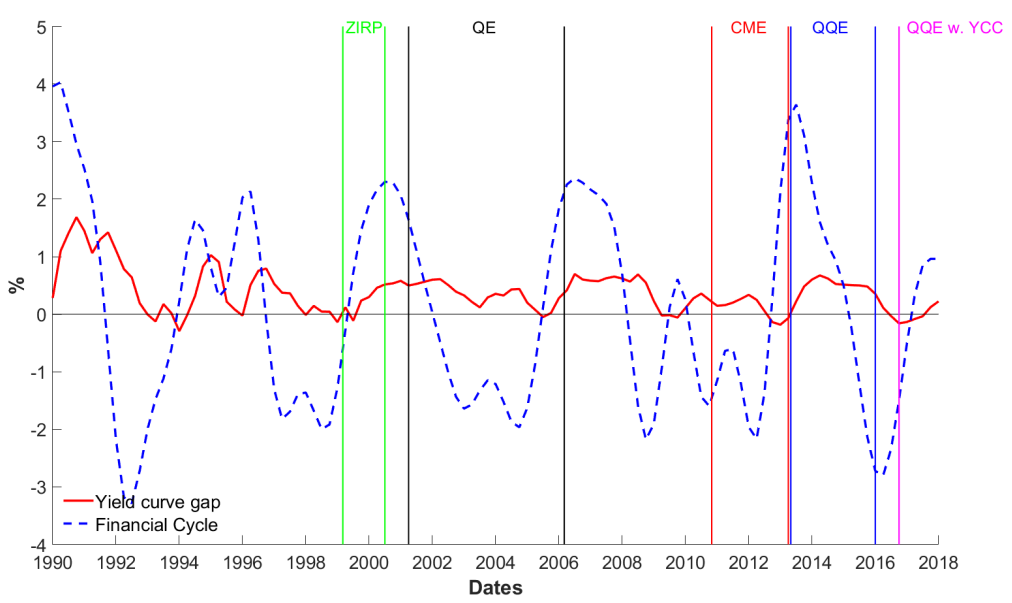

Figure 27: Financial cycle and yield curve gap

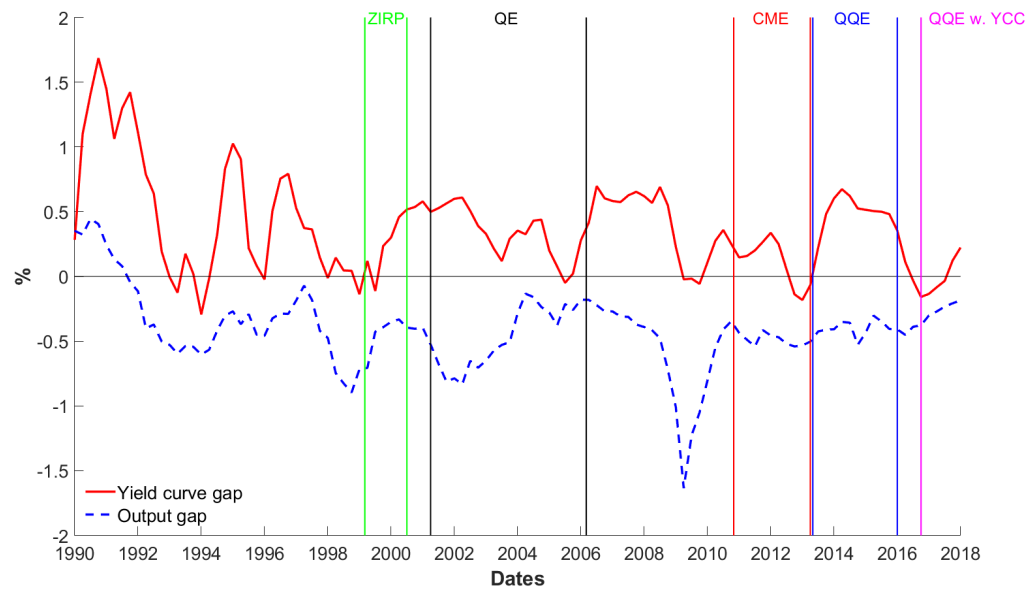

Figure 28: Output gap and yield curve gap 